\title{
Characterization of the Brain Functional Architecture of Psychostimulant Withdrawal Using Single-Cell Whole-Brain Imaging
}

\author{
(DAdam Kimbrough,, ${ }^{1,2,3}$ Marsida Kallupi, ${ }^{1,3}$ Lauren C. Smith, ${ }^{1,3}$ Sierra Simpson, ${ }^{1,3}$ Andres Collazo, ${ }^{4}$ and \\ (1) Olivier George ${ }^{1,3}$
}

https://doi.org/10.1523/ENEURO.0208-19.2021

${ }^{1}$ School of Medicine, Department of Psychiatry, University of California San Diego, La Jolla, CA 92093, ${ }^{2}$ College of Veterinary Medicine, Department of Basic Medical Sciences, Purdue University, West Lafayette, IN 47907,

${ }^{3}$ Department of Neuroscience, The Scripps Research Institute, La Jolla, CA 92037, and ${ }^{4}$ Beckman Institute, Cal-Tech, Pasadena, CA 91125

\begin{abstract}
Numerous brain regions have been identified as contributing to withdrawal behaviors, but it is unclear the way in which these brain regions as a whole lead to withdrawal. The search for a final common brain pathway that is involved in withdrawal remains elusive. To address this question, we implanted osmotic minipumps containing either saline, nicotine $(24 \mathrm{mg} / \mathrm{kg} / \mathrm{d})$, cocaine $(60 \mathrm{mg} / \mathrm{kg} / \mathrm{d})$, or methamphetamine $(4 \mathrm{mg} / \mathrm{kg} / \mathrm{d})$ for one week in male C57BL/6J mice. After one week, the minipumps were removed and brains collected $8 \mathrm{~h}$ (saline, nicotine, and cocaine) or $12 \mathrm{~h}$ (methamphetamine) after removal. We then performed single-cell whole-brain imaging of neural activity during the withdrawal period when brains were collected. We used hierarchical clustering and graph theory to identify similarities and differences in brain functional architecture. Although methamphetamine and cocaine shared some network similarities, the main common neuroadaptation between these psychostimulant drugs was a dramatic decrease in modularity, with a shift from a cortical-driven to subcortical-driven network, including a decrease in total hub brain regions. These results demonstrate that psychostimulant withdrawal produces the drug-dependent remodeling of functional architecture of the brain and suggest that the decreased modularity of brain functional networks and not a specific set of brain regions may represent the final common pathway associated with withdrawal.
\end{abstract}

Key words: addiction; functional connectivity; graph theory; iDISCO; neural activity; withdrawal

\section{Significance Statement}

A key aspect of treating drug abuse is understanding similarities and differences of how drugs of abuse affect the brain. In the present study, we examined how the brain is altered during withdrawal from psychostimulants. We found that each drug produced a unique pattern of activity in the brain, but that brains in withdrawal from cocaine and methamphetamine shared similar features. Interestingly, we found the major common link between withdrawal from all psychostimulants, when compared with controls, was a shift in the broad organization of the brain in the form of reduced modularity. Reduced modularity has been shown in several brain disorders, including traumatic brain injury, and dementia, and may be the common link between drugs of abuse.

Received May 31, 2019; accepted August 9, 2021; First published September 17, 2021.

The authors declare no competing financial interests.
Author contributions: A.K. and O.G. designed research; A.K., M.K., L.C.S., and A.C. performed research; A.K., L.C.S., and S.S. analyzed data; A.K. and O.G. wrote the paper. 


\section{Introduction}

Psychostimulants are a class of highly addictive and commonly abused drugs that includes cocaine, nicotine, and methamphetamine (Balfour, 2008; Phillips et al., 2014). A large number of brain regions have been implicated in withdrawal associated with psychostimulant use (Kalivas and McFarland, 2003; Robinson and Kolb, 2004; Kalivas, 2007; Everitt et al., 2008; Jedynak et al., 2012; Koob and Volkow, 2016; Bobadilla et al., 2017). However, the complete neural network that is associated with psychostimulant withdrawal remains understudied, and the search for a common brain pathway that is responsible for psychostimulant withdrawal remains elusive. Common features of withdrawal may not be found at the brain region level but rather at the network level.

The identification of changes in neural network structure that are caused by psychostimulant withdrawal may be critical to understanding the ways in which these drugs affect the brain. Previous studies identified changes in network function after psychostimulant use (Tomasi et al., 2010; Konova et al., 2013, 2015; Ma et al., 2015), but these analyses focused on macroscale changes and not the mesoscale level, or they focused on preselected regions of interest.

The present study sought to identify the ways in which withdrawal from different commonly abused psychostimulants alters functional architecture of the brain. We hypothesized that withdrawal from psychostimulants would result in changes in functional neural networks and decrease modular structuring of the brain. We further hypothesized that each psychostimulant that was examined herein (i.e., methamphetamine, nicotine, and cocaine) would have a unique neural network that is associated with withdrawal. We measured single-cell whole-brain activity using Fos as a marker for neuronal activation in mice that underwent withdrawal from chronic psychostimulant (cocaine, methamphetamine, and nicotine) administration. To accomplish this, mice were implanted with osmotic minipumps for one week to induce dependence to each drug. Following one-week minipumps were removed and brains were collected from mice during acute withdrawal. This method of acute withdrawal was chosen to control the amount of drug each animal received and create strong dependence in a short period of time. The psychostimulant doses were chosen based on previous studies that reported rewarding effects during use and observed withdrawal-like symptoms after the cessation of chronic exposure for each drug (Johnson et al., 2008; Fish et al., 2010; Eisener-Dorman et al., 2011;

This work was supported by National Institutes of Health Grants DA044451, DA043799, DA047113, AA006420, AA020608, AA022977, AA027301, and AA007456; the Tobacco-Related Disease Research Program Grant 27IR0047; Tobacco-Related Disease Research Program (grant no. T31KT1859); the 2021 Psychiatry Department Chair's Excellence Fund to M.K.; the Pearson Center for Alcoholism and Addiction Research and the Preclinical Addiction Research Consortium at UCSD.

Correspondence should be addressed to Olivier George at olgeorge@ucsd.edu.

https://doi.org/10.1523/ENEURO.0208-19.2021

Copyright $(\subseteq) 2021$ Kimbrough et al.

This is an open-access article distributed under the terms of the Creative Commons Attribution 4.0 International license, which permits unrestricted use, distribution and reproduction in any medium provided that the original work is properly attributed.
Stoker and Markou, 2011; Stoker et al., 2012; Tracy et al., 2016; Zhu et al., 2017). We then used single-cell wholebrain activity to identify coactivation patterns of brain regions in the network that was associated with each treatment using hierarchical clustering. The functional connectivity measures were used to determine the modular structuring of each network. Graph theory was then used to further characterize each network to determine the brain regions that are most heavily involved in intramodular and intermodular connectivity of the functional network.

\section{Materials and Methods}

\section{Animals}

Male C57BL/6J mice were bred at The Scripps Research Institute. They were 20-30 g and $60 \mathrm{~d}$ old at the start of the experiment. The mice were maintained on a 12/12 h light/ dark cycle with ad libitum access to food and water. All of the procedures were conducted in strict adherence to the National Institutes of Health Guide for the Care and Use of Laboratory Animals and approved by The Scripps Research Institute Institutional Animal Care and Use Committee and by the Institutional Animal Care and Use Committee of the University of California.

\section{Drugs}

The doses were $4 \mathrm{mg} / \mathrm{kg} / \mathrm{d}$ for methamphetamine, $24 \mathrm{mg} / \mathrm{kg} / \mathrm{d}$ for nicotine, and $60 \mathrm{mg} / \mathrm{kg} / \mathrm{d}$ for cocaine. These doses were chosen based on previous studies that indicated rewarding effects during use, resulting in withdrawal-like symptoms after the cessation of chronic use (Johnson et al., 2008; Fish et al., 2010; Eisener-Dorman et al., 2011; Stoker and Markou, 2011; Stoker et al., 2012; Tracy et al., 2016; Zhu et al., 2017). Each drug was dissolved in saline, and the $\mathrm{pH}$ was adjusted to 7.4. The drugs were loaded into osmotic minipumps (Alzet; model 1002). The minipumps sat overnight in saline before insertion to ensure that drug delivery would begin immediately.

\section{Minipump implantation and removal}

The mice were split into four groups for the experiment: methamphetamine withdrawal group $(n=5)$, nicotine withdrawal group $(n=5)$, cocaine withdrawal group $(n=5)$, and saline control group $(n=4)$. Each mouse was surgically implanted with an osmotic minipump for methamphetamine, nicotine, cocaine, and saline based on group assignment. The minipumps were implanted in the lower back of each mouse under anesthesia. After brief recovery, the mice were returned to their home cages. The mice remained in their home cages for one week to allow for chronic infusion of the drug.

After one week, the minipumps were surgically removed under anesthesia to allow for drug washout and withdrawal to begin. Mice in the nicotine, cocaine, and saline groups were perfused $8 \mathrm{~h}$ after removal of the minipumps. Mice in the methamphetamine group were perfused $12 \mathrm{~h}$ after removal of the minipumps. These time points were chosen to represent an acute withdrawal period from each drug (e.g., a minimum of $4 \mathrm{~h}$ without the drug present) and based on the half-life of each drug in mice 
(Benuck et al., 1987; Cho et al., 2001; Norman et al., 2007; Siu and Tyndale, 2007; Shabani et al., 2012).

\section{Tissue collection}

The mice were deeply anesthetized and perfused with $15 \mathrm{ml}$ of PBS followed by $50 \mathrm{ml}$ of $4 \%$ formaldehyde. The brains were postfixed in formaldehyde overnight. The next day, the brains were washed for 30 min three times with PBS and transferred to a PBS $/ 0.1 \%$ azide solution at $4^{\circ} \mathrm{C}$ for $2-3 \mathrm{~d}$ before processing via iDISCO + .

\section{iDISCO+}

The iDISCO+ procedure was performed as reported previously (Renier et al., 2014, 2016). The associated immunostaining, sample clearing, and image collection for iDISCO + are detailed below. For an experimental design overview see Figure 1.

\section{Immunostaining}

Fixed samples were washed in $20 \%$ methanol (in double-distilled $\mathrm{H}_{2} \mathrm{O}$ ) for $1 \mathrm{~h}, 40 \%$ methanol for $1 \mathrm{~h}, 60 \%$ methanol for $1 \mathrm{~h}, 80 \%$ methanol for $1 \mathrm{~h}$, and $100 \%$ methanol for $1 \mathrm{~h}$ twice. The samples were then precleared with overnight incubation in 33\% methanol and 66\% dichloromethane (DCM; Sigma, catalog \#270997-12X100ML). The next day, the samples were bleached with $5 \% \mathrm{H}_{2} \mathrm{O}_{2}$ (1 volume of $30 \% \mathrm{H}_{2} \mathrm{O}_{2}$ for 5 volumes of methanol, ice cold) at $4^{\circ} \mathrm{C}$ overnight. After bleaching, the samples were slowly re-equilibrated at room temperature and rehydrated in $80 \%$ methanol in double-distilled $\mathrm{H}_{2} \mathrm{O}$ for $1 \mathrm{~h}$, $60 \%$ methanol for $1 \mathrm{~h}, 40 \%$ methanol for $1 \mathrm{~h}, 20 \%$ methanol for $1 \mathrm{~h}$, PBS for $1 \mathrm{~h}$, and PBS and $0.2 \%$ Triton X-100 for $1 \mathrm{~h}$ twice. The samples were then incubated in PBS, $0.2 \%$ Triton X-100, 20\% dimethylsulfoxide (DMSO), $0.3 \mathrm{M}$ glycine at $37^{\circ} \mathrm{C}$ for $2 \mathrm{~d}$ and then blocked in PBS, $0.2 \%$ Triton $\mathrm{X}-100,10 \% \mathrm{DMSO}$, and $6 \%$ donkey serum at $37^{\circ} \mathrm{C}$ for $2 \mathrm{~d}$. The samples were then incubated in rabbit anti c-fos (1:2000; Synaptic Systems catalog \#226003) in PBS-0.2\% Tween with $10 \mu \mathrm{g}, \mathrm{ml}$ heparin $(\mathrm{PTwH})$, and 5\% DMSO/3\% donkey serum at $37^{\circ} \mathrm{C}$ for $7 \mathrm{~d}$. The samples were then washed in $\mathrm{PTwH}$ for $24 \mathrm{~h}$ (five changes of the PTwH solution over that time) and incubated in donkey anti-rabbit Alexa Fluor 647 (1:500; Invitrogen, catalog \#A31573) in PTwH/3\% donkey serum at $37^{\circ} \mathrm{C}$ for $7 \mathrm{~d}$. The samples were finally washed in $\mathrm{PTwH}$ for $1 \mathrm{~d}$ before clearing and imaging.

\section{Sample clearing}

Immunolabeled brains were cleared using the procedure of Renier et al. (2016). The samples were dehydrated in $20 \%$ methanol in double-distilled $\mathrm{H}_{2} \mathrm{O}$ for $1 \mathrm{~h}, 40 \%$ methanol for $1 \mathrm{~h}, 60 \%$ methanol for $1 \mathrm{~h}, 80 \%$ methanol for $1 \mathrm{~h}, 100 \%$ methanol for $1 \mathrm{~h}$, and $100 \%$ methanol again overnight. The next day, the samples were incubated for 3 $\mathrm{h}$ in $33 \%$ methanol/66\% DCM until they sank to the bottom of the incubation tube. The methanol was then washed for 20 min twice in 100\% DCM. Finally, the samples were incubated in dibenzyl ether (DBE; Sigma, catalog \#108014-1KG) until clear and then stored in DBE at room temperature until imaged.

\section{Image acquisition}

Left hemispheres of cleared samples were imaged in the sagittal orientation (right lateral side up). A single hemisphere was imaged as done in previous studies to avoid the need to stitch images or analyze separate image stacks for the same sample (Renier et al., 2014, 2016). Future studies examining both hemispheres would provide interesting additional results. Samples were imaged on a light-sheet microscope (Ultramicroscope II, LaVision Biotec) equipped with an sCMOS camera (Andor Neo) and $2 \times / 0.5$ objective lens (MVPAPO $2 \times$ ) equipped with a $6-\mathrm{mm}$ working distance dipping cap. Imspector Microscope controller v144 software was used. The microscope was equipped with an NKT Photonics SuperK EXTREME EXW-12 white light laser with three fixed light sheet generating lenses on each side. Scans were made at $0.8 \times$ magnification (1.6× effective magnification) with a light sheet numerical aperture of 0.148 . Excitation filters of $480 / 30,560 / 40$, and 630/30 nm were used. Emission filters of $525 / 50,595 / 40$, and $680 / 30 \mathrm{~nm}$ were used. The samples were scanned with a step size of $3 \mu \mathrm{m}$ using dynamic horizontal scanning from one side (the right) for the 560 - and $630-\mathrm{nm}$ channels (20 acquisitions per plane with 240-ms exposure, combined into one image using the horizontal adaptive algorithm) and without horizontal scanning for the 480-nm channel using two-sided illumination (100-ms exposure for each side, combined into one image using the blending algorithm). To accelerate acquisition, both channels where acquired in two separate scans. The imaging resolution $(x=4 \mu \mathrm{m}, y=4 \mu \mathrm{m}$, $z=3 \mu \mathrm{m}$ ) was selected to minimize imaging time without loss in terms of sensitivity or selectivity of the cell detection process or brain segmentation. The approach of clearing, alignment, cell detection, and registration has been validated in great detail in the original Renier et al. (2016) paper and shows that cell count obtained using ClearMap is $99 \%$ similar to manual detection by a trained user (Renier et al., 2016) when using a conservative cell voxel size threshold of 20 pixel (as in our study). The cell segmentation parameters and intensity threshold used to identify Fos-positive cells in this study are the default settings included in the ClearMap package (Renier et al., 2016) without further validation, but visual confirmation was made manually on every brain to verify appropriate alignment to the reference atlas and to verify that thresholding and pixel detection were set to maximize the number of cells detected while ensuring that cells were not double counted. To account for micro-movements of the samples that may occur between scans, three-dimensional image affine registration was performed to align both channels using ClearMap (Renier et al., 2016). Representative images of Fos collected can be seen in Figure 2.

\section{Data analysis}

\section{Identification of activated brain regions}

Images that were acquired from the light-sheet microscope were analyzed from the end of the olfactory bulbs (the olfactory bulbs were not included in the analysis) to the beginning of the hindbrain and cerebellum. Counts of Fos-positive nuclei from each sample were identified for 
each brain region using ClearMap (Renier et al., 2016). ClearMap uses autofluorescence that is acquired in the 488-nm channel to align the brain to the Allen Mouse Brain Atlas (Allen Institute for Brain Science, 2004) and then registers Fos counts to regions that are annotated by the atlas. ClearMap has been validated and used now in several recent studies to identify labeled neurons and quantify the number labeled in a given brain region (Liebmann et al., 2016; Renier et al., 2016; Kimbrough et al., 2020; Kirst et al., 2020; Qian et al., 2021). For raw Fos counts and information on brain regions showing significant differences between saline and treatment Fos levels assessed by traditional comparison see the Extended Data Figures 2-1 and 2-2. A potential confound of the present approach is that possible errors in atlas registration, although unlikely, are would impact data from smaller brain regions more than larger brain regions. The data were normalized to a $\log _{10}$ value to reduce variability and bring brain regions with high numbers (e.g., thousands) and low numbers (e.g., tens to hundreds) of Fos counts to a similar scale.

\section{Identification of functional connectivity within individual networks}

Separate interregional Pearson correlations were then calculated using Statistica software (Tibco) across animals in the saline, cocaine, methamphetamine, and nicotine groups to compare the $\log _{10}$ Fos data from each brain region to each of the other brain regions. See Table 1 for a list of brain regions, their abbreviations, and their Allen atlas grouping. It should be noted that connectivity throughout refers to functional connectivity of brain regions and not structural connectivity.

\section{Hierarchical clustering}

Previous rat and mouse studies that examined functional connectivity used five to eight animals (Wheeler et al., 2013; Orsini et al., 2018). The number of samples that are examined in functional connectivity studies is the number of potential functional connections (i.e., 178 total brain regions all connecting with each other for each treatment). Furthermore, hierarchical clustering organizes brain regions into modules by grouping regions that show a similar functional connectivity profile across all other brain regions. Thus, more total functional connections minimize the effect that an inaccurate brain region-to-brain region functional connection has on network organization and overall network structure.

Interregional Pearson correlations were then used to calculate complete Euclidean distances between each pair of brain regions in each group of mice. The distance matrices were then hierarchically clustered using $\mathrm{R}$ Studio software by both row and column using the complete method to identify modules of functional connectivity within each treatment group. The hierarchical cluster dendrograms were trimmed at half the height of each given tree to split the dendrogram into specific modules. The result of a decrease in modularity that is attributable to psychostimulant use was consistent across multiple tree-cutting thresholds (Fig. 3E).

\section{Graph theory identification of functional networks}

We used a graph theory-based approach to identify the functional neural networks that were associated with each treatment condition. Graph theory is a branch of mathematics that is used to analyze complex networks, such as social, financial, protein, and neural networks (Jeong et al., 2001; Barabasi, 2009; Chiang et al., 2011; Varshney et al., 2011; Babu et al., 2012; Jarrell et al., 2012; Bargmann and Marder, 2013; Wheeler et al., 2013; Oh et al., 2014; Markov et al., 2014; Cohen and D'Esposito, 2016; Vetere et al., 2017). Using graph theory, functional networks can be delineated, and key brain regions of the network can be identified (Sporns et al., 2007; Rubinov and Sporns, 2010; Wheeler et al., 2013; Vetere et al., 2017).

Previous studies of regional functional connectivity profiles using Fos have focused on global measures of connectivity (e.g., degree; Wheeler et al., 2013). However, in correlation-based networks, these measures can be strongly influenced by the size of the subnetwork (module) in which a node participates (Power et al., 2013). For the graph theory analyses, we were interested in regional properties and not module size per se. Thus, module structure needs to be considered when examining the role that each region plays in the network. To accomplish this, we used two widely used centrality metrics that were designed for application to modular systems. The Z-scored version of within-module degree (WMDz) indexes the relative importance of a region within its own module (e.g., intramodule connectivity), and the participation coefficient (PC) indexes the extent to which a region connects diversely to multiple modules (e.g., intermodule connectivity; Guimera and Nunes Amaral, 2005).

We used the Pearson correlation values that were calculated for the brain regions from each treatment. Before plotting and calculating regional connectivity metrics, the network was thresholded to remove any edges that were weaker than $R=0.75$. As such, visualization and graph theory analyses were performed using only edges with positive weights. Regional connectivity metrics (PC and WMDz) were calculated as originally defined by Guimera and Nunes Amaral (2005), modified for application to networks with weighted edges. PC and WMDz were calculated using a customized version of the bctpy Python package (https://github.com/aestrivex/bctpy), which is derived from the MATLAB implementation of Brain Connectivity Toolbox (Rubinov and Sporns, 2010).

For WMDz, let $k_{i}$ (within-module degree) be the summed weight of all edges between region $i$ and other regions in module $s_{i}$. Then, $\bar{k}_{s_{i}}$ is the average within-module degree of all regions in module $s_{i}$, and $\sigma_{k_{s_{i}}}$ is the standard deviation of those values. The WMDz is then defined as:

$$
W M D z=\frac{k_{i}-\bar{k}_{s_{i}}}{\sigma_{k_{s_{i}}}} .
$$

This provides a measure of the extent to which each region is connected to other regions in the same module.

For PC, let $k_{\text {is }}$ (between-module degree) be the summed weight of all edges between region $i$ and regions in module $s$, and let $k_{i}$ (total degree) be the summed weight of all edges between region $i$ and all other regions in the network. The PC of each region is then defined as: 
Table 1: Continued

\begin{tabular}{|c|c|c|}
\hline Brain region & Abbreviation & Allen Group name \\
\hline Anterior amygdalar area & AAA & Striatum \\
\hline Bed nucleus of the accessory olfactory tract & BA & Striatum \\
\hline Caudoputamen & $\mathrm{CP}$ & Striatum \\
\hline Central amygdalar nucleus & CEA & Striatum \\
\hline Fundus of striatum & FS & Striatum \\
\hline Intercalated amygdalar nucleus & IA & Striatum \\
\hline Lateral septal complex & LSX & Striatum \\
\hline Medial amygdalar nucleus & MEA & Striatum \\
\hline Nucleus accumbens & ACB & Striatum \\
\hline Olfactory tubercle & OT & Striatum \\
\hline Septofimbrial nucleus & SF & Striatum \\
\hline Bed nuclei of the stria terminalis & BST & Pallidum \\
\hline Diagonal band nucleus & NDB & Pallidum \\
\hline Globus pallidus external segment & $\mathrm{GPe}$ & Pallidum \\
\hline Globus pallidus internal segment & GPi & Pallidum \\
\hline Magnocellular nucleus & MA & Pallidum \\
\hline Medial septal nucleus & MS & Pallidum \\
\hline Substantia innominata & $\mathrm{SI}$ & Pallidum \\
\hline Triangular nucleus of septum & TRS & Pallidum \\
\hline Anterior group of the dorsal thalamus & ATN & Thalamus \\
\hline Anterodorsal nucleus & $A D$ & Thalamus \\
\hline Anteroventral nucleus of thalamus & AV & Thalamus \\
\hline Central lateral nucleus of the thalamus & $\mathrm{CL}$ & Thalamus \\
\hline Central medial nucleus of the thalamus & $\mathrm{CM}$ & Thalamus \\
\hline Dorsal part of the lateral geniculate complex & LGd & Thalamus \\
\hline Interanterodorsal nucleus of the thalamus & IAD & Thalamus \\
\hline Interanteromedial nucleus of the thalamus & IAM & Thalamus \\
\hline Intergeniculate leaflet of the lateral geniculate complex & IGL & Thalamus \\
\hline Intermediodorsal nucleus of the thalamus & IMD & Thalamus \\
\hline Lateral dorsal nucleus of thalamus & LD & Thalamus \\
\hline Lateral habenula & $\mathrm{LH}$ & Thalamus \\
\hline Lateral posterior nucleus of the thalamus & LP & Thalamus \\
\hline Medial geniculate complex & MG & Thalamus \\
\hline Medial habenula & $\mathrm{MH}$ & Thalamus \\
\hline Mediodorsal nucleus of thalamus & MD & Thalamus \\
\hline Nucleus of reuniens & $\mathrm{RE}$ & Thalamus \\
\hline Paracentral nucleus & PCN & Thalamus \\
\hline Parafascicular nucleus & PF & Thalamus \\
\hline Parataenial nucleus & PT & Thalamus \\
\hline Paraventricular nucleus of the thalamus & PVT & Thalamus \\
\hline Peripeduncular nucleus & PP & Thalamus \\
\hline Posterior complex of the thalamus & $\mathrm{PO}$ & Thalamus \\
\hline Posterior limiting nucleus of the thalamus & POL & Thalamus \\
\hline Reticular nucleus of the thalamus & RT & Thalamus \\
\hline Submedial nucleus of the thalamus & SMT & Thalamus \\
\hline Subparafascicular nucleus & SPF & Thalamus \\
\hline Thalamus sensory-motor cortex related & DORsm & Thalamus \\
\hline Ventral anterior-lateral complex of the thalamus & VAL & Thalamus \\
\hline Ventral medial nucleus of the thalamus & VM & Thalamus \\
\hline Ventral part of the lateral geniculate complex & LGv & Thalamus \\
\hline Ventral posterior complex of the thalamus & VP & Thalamus \\
\hline Ventral posterolateral nucleus of the thalamus & VPL & Thalamus \\
\hline Anterior hypothalamic nucleus & $\mathrm{AHN}$ & Hypothalamus \\
\hline Anterodorsal preoptic nucleus & ADP & Hypothalamus \\
\hline Anteroventral periventricular nucleus & AVPV & Hypothalamus \\
\hline Anteroventral preoptic nucleus & AVP & Hypothalamus \\
\hline Arcuate hypothalamic nucleus & $\mathrm{ARH}$ & Hypothalamus \\
\hline Dorsal premammillary nucleus & PMd & Hypothalamus \\
\hline Dorsomedial nucleus of the hypothalamus & $\mathrm{DMH}$ & Hypothalamus \\
\hline Lateral hypothalamic area & LHA & Hypothalamus \\
\hline Lateral preoptic area & LPO & Hypothalamus \\
\hline \multirow[t]{2}{*}{ Mammillary body } & $\mathrm{MBO}$ & Hypothalamus \\
\hline & & \\
\hline
\end{tabular}


Table 1: Continued

\begin{tabular}{|c|c|c|}
\hline Brain region & Abbreviation & Allen Group name \\
\hline Medial preoptic area & MPO & Hypothalamus \\
\hline Medial preoptic nucleus & MPN & Hypothalamus \\
\hline Median preoptic nucleus & MEPO & Hypothalamus \\
\hline Parastrial nucleus & PS & Hypothalamus \\
\hline Parasubthalamic nucleus & PSTN & Hypothalamus \\
\hline Paraventricular hypothalamic nucleus & $\mathrm{PVH}$ & Hypothalamus \\
\hline Paraventricular hypothalamic nucleus descending division & PVHd & Hypothalamus \\
\hline Periventricular hypothalamic nucleus posterior part & $P V p$ & Hypothalamus \\
\hline Periventricular hypothalamic nucleus preoptic part & PVpo & Hypothalamus \\
\hline Periventricular zone & PVZ & Hypothalamus \\
\hline Posterior hypothalamic nucleus & $\mathrm{PH}$ & Hypothalamus \\
\hline Preparasubthalamic nucleus & PST & Hypothalamus \\
\hline Retrochiasmatic area & $\mathrm{RCH}$ & Hypothalamus \\
\hline Subparaventricular zone & SBPV & Hypothalamus \\
\hline Subthalamic nucleus & STN & Hypothalamus \\
\hline Suprachiasmatic nucleus & $\mathrm{SCH}$ & Hypothalamus \\
\hline Supramammillary nucleus & SUM & Hypothalamus \\
\hline Supraoptic nucleus & SO & Hypothalamus \\
\hline Tuberal nucleus & TU & Hypothalamus \\
\hline Ventrolateral preoptic nucleus & VLPO & Hypothalamus \\
\hline Ventromedial hypothalamic nucleus & VMH & Hypothalamus \\
\hline Zona incerta & $\mathrm{Zl}$ & Hypothalamus \\
\hline Anterior pretectal nucleus & APN & Midbrain \\
\hline Cuneiform nucleus & CUN & Midbrain \\
\hline Inferior colliculus & IC & Midbrain \\
\hline Interpeduncular nucleus & IPN & Midbrain \\
\hline Medial pretectal area & MPT & Midbrain \\
\hline Midbrain reticular nucleus & MRN & Midbrain \\
\hline Midbrain reticular nucleus retrorubral area & $\mathrm{RR}$ & Midbrain \\
\hline Nucleus of Darkschewitsch & ND & Midbrain \\
\hline Nucleus of the brachium of the inferior colliculus & NB & Midbrain \\
\hline Nucleus of the optic tract & NOT & Midbrain \\
\hline Nucleus of the posterior commissure & NPC & Midbrain \\
\hline Olivary pretectal nucleus & OP & Midbrain \\
\hline Parabigeminal nucleus & PBG & Midbrain \\
\hline Pedunculopontine nucleus & PPN & Midbrain \\
\hline Periaqueductal gray & PAG & Midbrain \\
\hline Posterior pretectal nucleus & PPT & Midbrain \\
\hline Precommissural nucleus & PRC & Midbrain \\
\hline Red nucleus & RN & Midbrain \\
\hline Substantia nigra compact part & SNc & Midbrain \\
\hline Substantia nigra reticular part & $\mathrm{SNr}$ & Midbrain \\
\hline Superior colliculus motor related & $\mathrm{SCm}$ & Midbrain \\
\hline Superior colliculus sensory related & SCs & Midbrain \\
\hline Ventral tegmental area & VTA & Midbrain \\
\hline Pons & $\mathrm{P}$ & Hindbrain \\
\hline Pons motor related & P-mot & Hindbrain \\
\hline Pontine reticular nucleus & PRNr & Hindbrain \\
\hline Vestibular nuclei & VNC & Hindbrain \\
\hline Ansiform lobule & AN & Cerebellum \\
\hline Central lobule & CENT & Cerebellum \\
\hline Culmen & CUL & Cerebellum \\
\hline Paraflocculus & PFL & Cerebellum \\
\hline Simple lobule & SIM & Cerebellum \\
\hline
\end{tabular}

$$
P_{i}=1-\sum_{s=1}^{N_{M}}\left(\frac{k_{i s}}{k_{i}}\right)^{2}
$$

This provides a measure of the extent to which the connections of a region are distributed mostly within its own module (PC approaching 0) or distributed evenly among all modules (PC approaching 1).
A high PC was considered $\geq 0.30$, and a high WMDz was considered $\geq 0.80$. Previous studies have used ranges of $\geq 0.30-0.80$ for high $P C$ and $\geq 1.5-2.5$ for high WMDz (Guimera and Nunes Amaral, 2005; Cohen and D'Esposito, 2016). Because of differences in the sizes/types of networks that were examined and the methods that were used (e.g., Fos vs functional magnetic resonance imaging), we adjusted the range 


\section{A. Experimental Design}

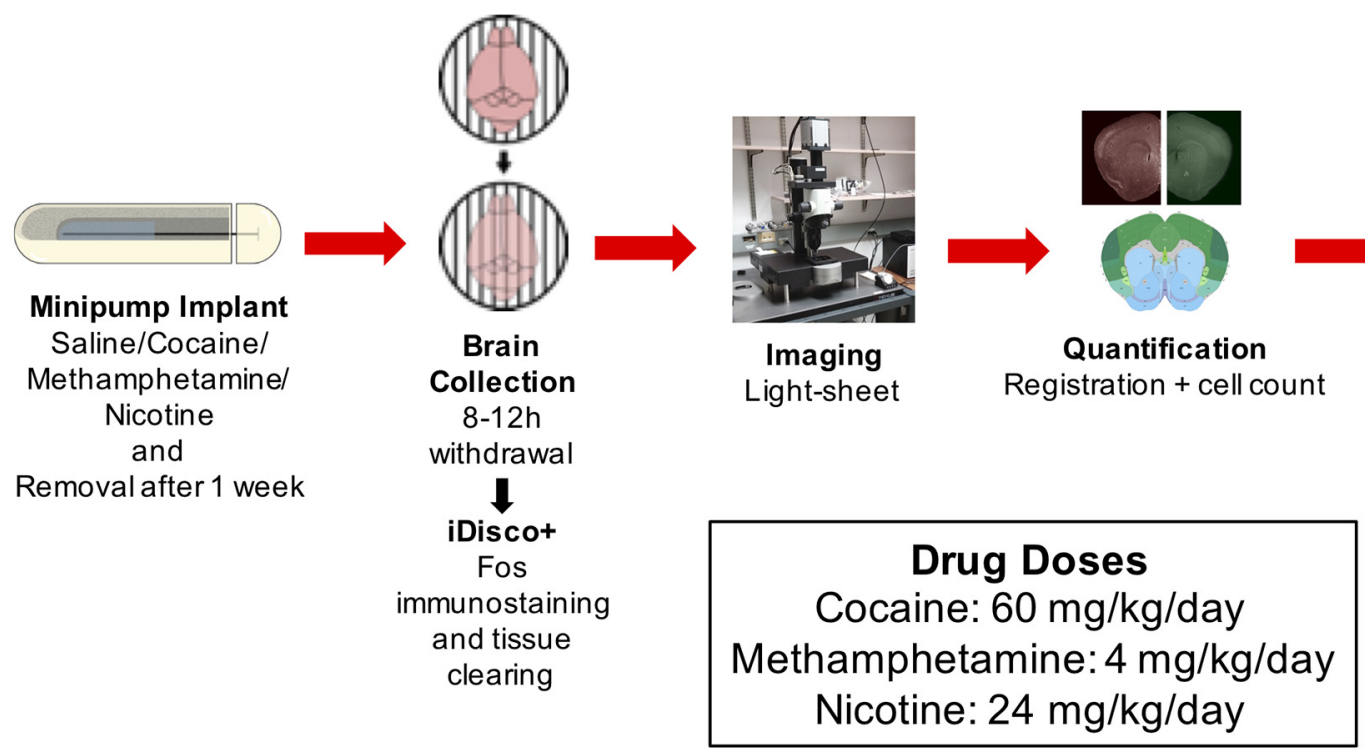

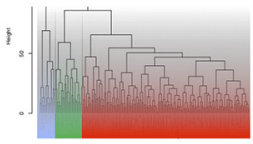

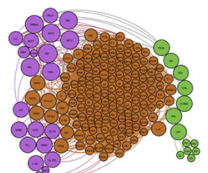

Analysis

Hierarchical Clustering

Graph theory

\section{B. ClearMap Workflow}
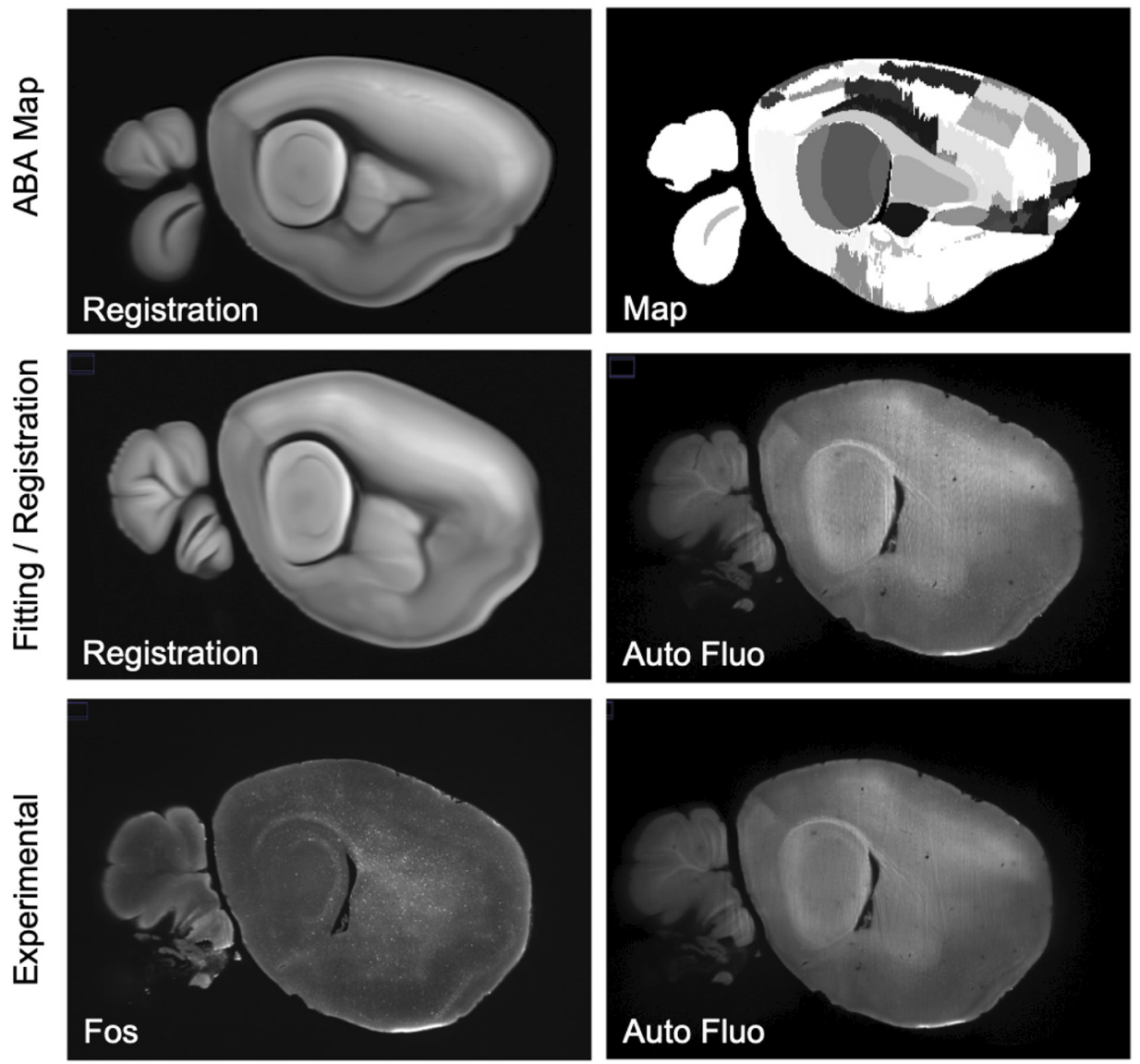

Allen Brain Atlas Map and Registration of auto-fluorescence
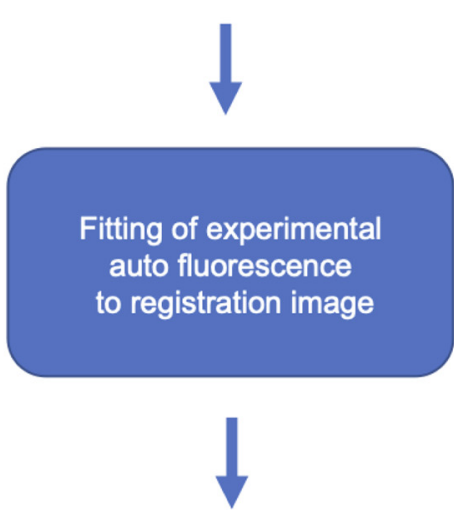

Example of experimental Fos and auto-fluorescence

Figure 1. $\boldsymbol{A}$, Experimental design. Mice were surgically implanted with an osmotic minipump that contained either saline or a psychostimulant $(60 \mathrm{mg} / \mathrm{kg} / \mathrm{d}$ cocaine, $4 \mathrm{mg} / \mathrm{kg} / \mathrm{d}$ methamphetamine, or $24 \mathrm{mg} / \mathrm{kg} / \mathrm{d}$ nicotine). They were then returned to their home cage for one week. After one week, the minipumps were surgically removed, and the mice were returned to their home cage until brain tissue was collected $8 \mathrm{~h}$ later (saline, cocaine, nicotine) or $12 \mathrm{~h}$ later (methamphetamine). Brains were then processed for whole-brain Fos immunohistochemistry and clearing via iDISCO + and then imaged on a light-sheet microscope. Fos values were detected and registered to the 
continued

Allen Brain Atlas using ClearMap Renier et al., 2016. Pearson correlations were then calculated to determine functional coactivation among brain regions. Brain regions were then grouped into modules based on their coactivation patterns through hierarchical clustering. Graph theory analyses was then performed to identify brain regions that are heavily involved in intramodular and intermodular connectivity. $\boldsymbol{B}$, Workflow diagram of registration to the Allen Brain Atlas using ClearMap. Registration is performed by matching a the autofluorescence to a preregistered two-photon image set that has been matched to brain region delineations of the Allen Brain Atlas. The brain region demarcations mapped to the autofluorescence are then used to map onto the Fos values taken from the corresponding frame. Auto Fluo = Autofluorescence.

for consideration as having high PC and WMDz accordingly.

Network visualization was performed using a combination of Gephi 0.9.2 software (Bastian et al., 2009) and Adobe Illustrator software. Nodes were positioned using the Force Atlas 2 algorithm (Jacomy et al., 2014) with a handful of nodes that were repositioned manually for better visual organization.

\section{Results}

\section{Psychostimulant withdrawal induces restructuring of brain functional networks}

We examined the ways in which withdrawal from different psychostimulants alters functional connectivity and modular structuring of the brain. For an overview of the experimental design and analysis pipeline, see Figure 1. Representative examples Fos images collected can be seen in Figure 2. For all of the drugs tested, acute withdrawal produced widespread increases in the functional connectivity of brain regions compared with saline controls (Fig. 3A-D). Importantly, modular structuring of the brain decreased in response to withdrawal from each psychostimulant compared with controls. When using a threshold of $50 \%$ of tree height, saline control mice exhibited a modular structure of the brain that contained seven modules, whereas cocaine mice had four modules, methamphetamine mice had three modules, and nicotine mice had five modules and one isolated brain region that was not grouped with any other region (i.e., interanterodorsal nucleus of the thalamus; Fig. $3 A-E$ ). Notably, the decrease in the number of modules during withdrawal was independent of the clustering thresholds that were used (Fig. 3E). These data indicate that psychostimulant withdrawal decreases modularity of the functional network compared with controls.

\section{Characterization of individual network features}

To further characterize the features of each individual network, we used a graph theory approach to identify potential hub brain regions with the most intramodular and intermodular connectivity, which may drive activity within the network and thus be critical for neuronal function in the withdrawal state. We examined positive connectivity (thresholded to a Pearson correlation coefficient $>0.75$ $[0.75 \mathrm{R}]$ for inclusion as a network connection) for the network for each treatment and used the modular organization that was identified by hierarchical clustering to partition the regions of the networks. The $0.75 \mathrm{R}$ threshold was chosen because all of the brain regions in each network showed connections to other regions at this threshold. Previous animal model studies used various thresholds, ranging from $0.3 \mathrm{R}$ to $0.85 \mathrm{R}$ (Wheeler et al., 2013; Orsini et al., 2018), to examine connectivity. Negative network connectivity was not examined herein because the precise meaning of such connectivity is controversial and thus is not often examined in network-based approaches (Giove et al., 2009; Meunier et al., 2009; Murphy et al., 2009; Chen et al., 2011).

We determined the PC (i.e., a measure of importance for intermodular connectivity) and the WMDz (i.e., a measure of importance for intramodular connectivity; Guimera and Nunes Amaral, 2005) for all brain regions in the networks. A high PC was considered $\geq 0.30$, and a high WMDz was considered $\geq 0.80$. Overall, the control and nicotine networks showed much greater intermodular connectivity (high PC) and a great number of regions with both high intermodular and intramodular connectivity (high PC and WMDz). The cocaine and methamphetamine networks showed higher levels of intramodular connectivity (high WMDz) and a low number of regions with intermodular connectivity (Fig. 4A$C)$. We named each module in each network based on the group of brain regions with the highest WMDz score in the module and considered these regions to be drivers of activity within individual modules (Figs. 58 for names).

\section{The control network is driven by sensory-motor regions}

The saline control network had 3176 total functional connections and consisted of seven modules, many of which were heavily driven by sensory-motor brain regions. Of these seven modules, five contained several sensory or motor brain regions that were ranked in the top five for intramodular connectivity (high WMDz). In most cases, a separate set of thalamic brain regions was responsible for intermodular connectivity (high PC; see Table 2 for a full list of values for the network). Overall, the control network had more brain regions with high WMDz, high PC, or both in individual modules compared with other networks. This indicates a more interconnected network with more hub regions (Figs. 2, 3).

\section{The cocaine withdrawal network is driven by cortico- thalamo-hypothalamic regions}

The cocaine network had 7127 total functional connections and consisted of four modules, one with the majority of all brain regions and three others with a small subset of regions. In the large module (module 1; 144 brain regions), nearly one-third $(32 \%)$ of the total brain regions within the module (i.e., a mixed set of midbrain-cortico-thalamic-hypothalamic-amygdalar brain regions) had high WMDz. 
A.

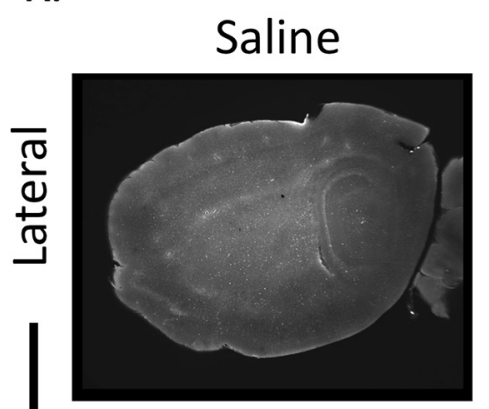

Methamphetamine

Cocaine
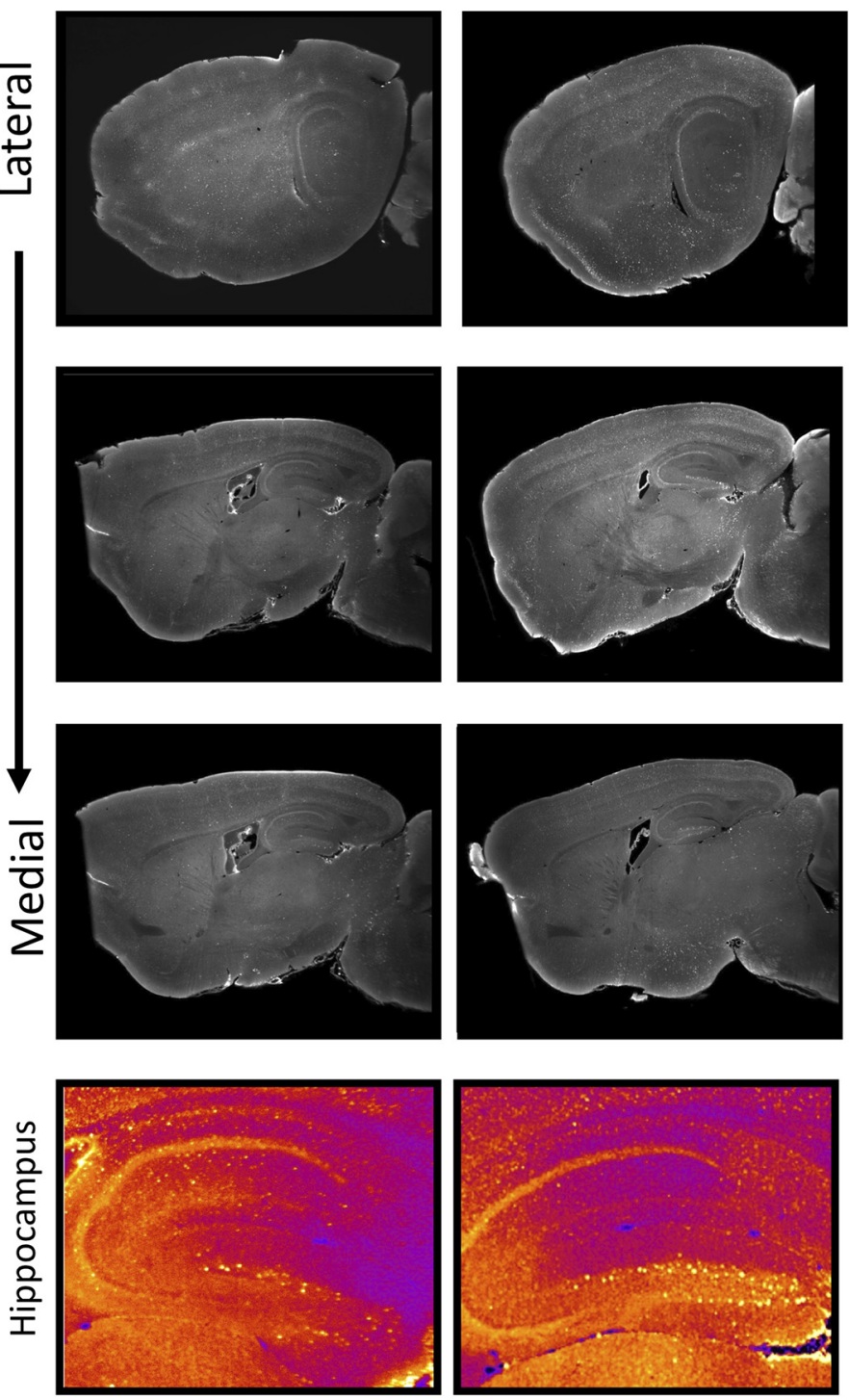

B.
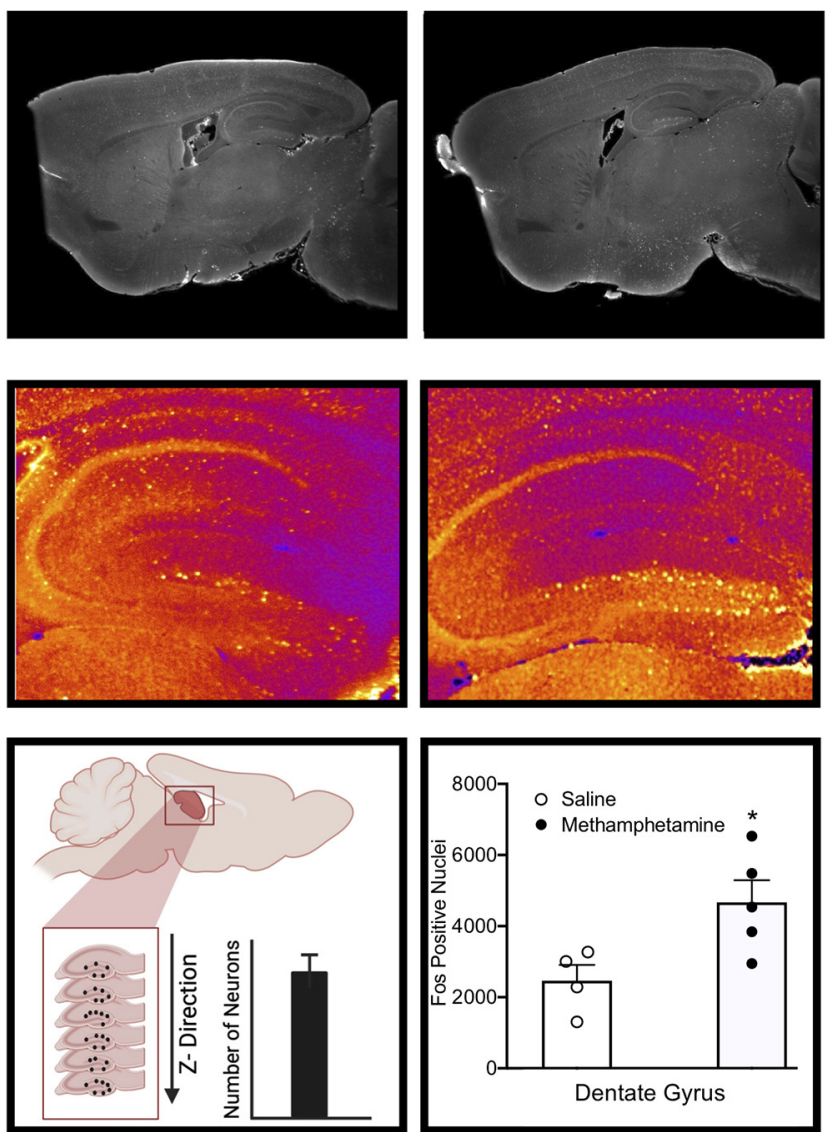
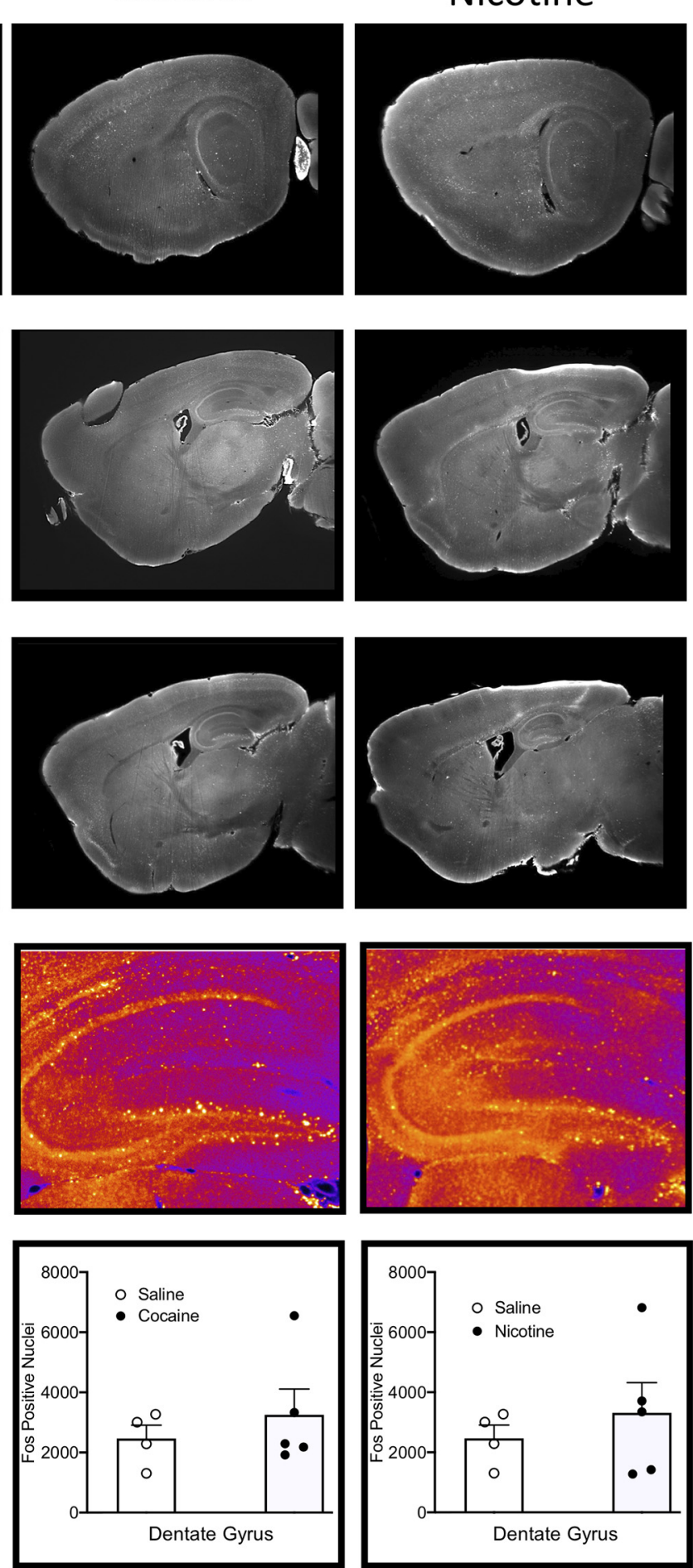

Figure 2. A, Lateral to medial sagittal representative sections of the brain and zoomed in representative hippocampal subsections for each treatment. $\boldsymbol{B}$, Comparisons of Fos values for saline versus each treatment in the dentate gyrus. See Extended Data Figure 2-2 for raw Fos values and Extended Data Figure 2-1 for comparisons of raw Fos for treatments versus saline.

The brain regions that drive intramodular connectivity (high WMDz) in this module did not have any intermodular connectivity (PC). Interestingly, only three brain regions in this module (subparaventricular zone, lateral posterior nucleus of the thalamus, and frontal pole cerebral cortex) reached the criterion $(\mathrm{PC} \geq 0.30)$ for a high level of intermodular connectivity, suggesting sparse communication with other modules. 

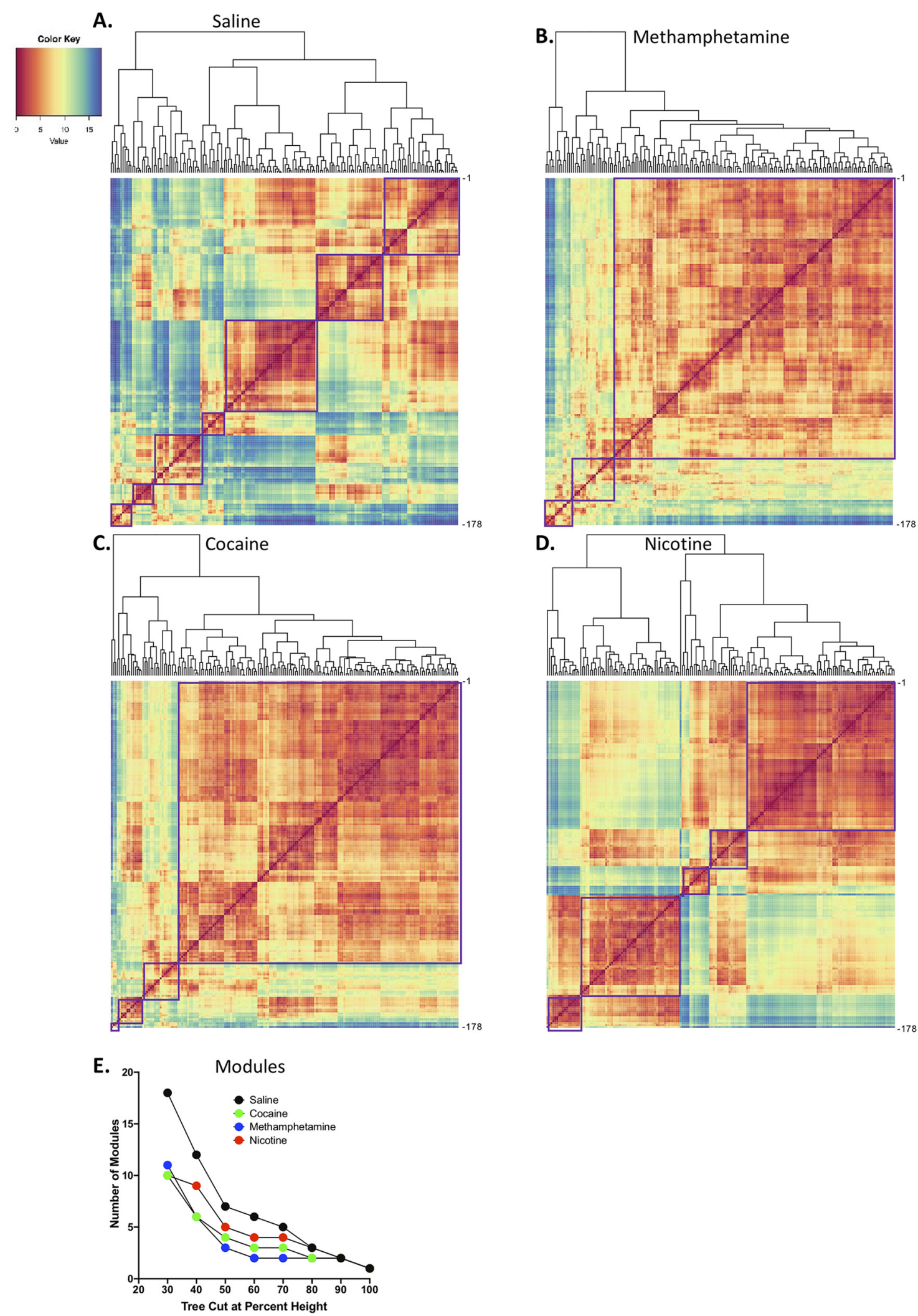

Figure 3. $\boldsymbol{A}-\boldsymbol{D}$, Hierarchical clustering of complete Euclidean distance matrices for each treatment. Modules were determined by cutting each dendrogram at half of the maximal tree height. $\boldsymbol{A}$, Relative distance of each brain region relative to the others that were examined in saline control mice. In control mice, seven distinct modules of coactivation were identified. $\boldsymbol{B}$, Relative distance of each brain region relative to the others that were examined in cocaine mice. In cocaine mice, four distinct modules of coactivation were identified. $\boldsymbol{C}$, Relative distance of each brain region relative to the others that were examined in methamphetamine mice. In 
continued

methamphetamine mice, three distinct modules of coactivation were identified. $\boldsymbol{D}$, Relative distance of each brain region relative to the others that were examined in nicotine mice. In nicotine mice, five distinct modules of coactivation were identified. For all distance matrices, each module is boxed in purple. For the individual brain regions that are listed in panels $\boldsymbol{A}-\boldsymbol{D}$, see Table 6 . $\boldsymbol{E}$, Number of modules in each treatment condition after cutting the hierarchical clustered dendrogram at different percentages of tree height. In all cases (except at extreme cutoff values; e.g., 90-100\%), the psychostimulant networks showed lower modularity compared with the control network. See Extended Data Figure 3-1 for correlation matrices for each treatment.

One of the smaller modules, a septal (triangular nucleus of the septum) and cortical (e.g., secondary motor area and dorsal anterior cingulate area) module (module 3) had a different set of thalamic brain regions that had high PC. The other two smaller modules, a prefrontal-habenular module [module 4; dorsal peduncular area (DP), induseum griseum, and lateral habenula] and a thalamic (parafascicular nucleus, mediodorsal nucleus of the thalamus, and ventral medial nucleus of the thalamus), midbrain (nucleus of the posterior commissure), and striatal (bed nucleus of the accessory olfactory tract) module (module 2) contained regions with both a high WMDz and high PC, suggesting that these regions may be potential hubs within the network. Overall, the cocaine network contained the highest number of functional connections in any network but had minimal interconnection between modules (Figs. 2, 4; see Table 3 for a full list of values for the network).

\section{The methamphetamine withdrawal network is driven by thalamic regions}

The methamphetamine network had 3182 functional connections and consisted of three modules, one with the majority of all brain regions and two others with a small subset of regions. In the large module (module 1), a group of thalamic (e.g., intermediodorsal nucleus of the thalamus, paraventricular nucleus of the thalamus, intergeniculate leaflet of the lateral geniculate complex, and ventral part of the lateral geniculate complex) and amygdalar (intercalated amygdala, central amygdala, and lateral amygdala) regions had high WMDz, but these brain regions did not have any intermodular connectivity (PC), and a separate set of hypothala$\mathrm{mic}$, cortical, and mid/hindbrain regions was responsible for intermodular connectivity.

The second module (module 2) had several hypothalamic (e.g., mammillary body, ventrolateral preoptic nucleus, and tuberal nucleus) and pallidal (globus pallidus and internal segment) brain regions with high WMDz and a separate set of cortical regions (e.g., DP and orbital area, ventral part) and midbrain regions (e.g., posterior pretectal nucleus, nucleus of the posterior commissure, and nucleus of Darkschewitsch) that had high interconnectivity with other modules (high PC).

The third module (module 3), a thalamic module, had several thalamic regions with high WMDz (e.g., ventral medial nucleus of the thalamus, posterior complex of the thalamus, parafascicular nucleus, and lateral dorsal nucleus of the thalamus). Interestingly, within this module, a separate set of thalamic regions (e.g., paracentral nucleus, ventral anterior-lateral complex of the thalamus, ventral posterior complex of the thalamus, and anterodorsal nucleus) had high PC, indicating that this module is internally directed by thalamic regions and also externally communicates through these regions. Overall, the methamphetamine network had a similar number of total connections to the control network, but it had minimal interconnections between modules (Figs. 2, 5; see Table 4 for a full list of values for the network).

\section{The nicotine withdrawal network is driven by cortical and extended amygdalar regions}

The nicotine network had 4957 functional connections, the second most of all conditions, and consisted of five modules and one brain region (interanterodorsal nucleus of the thalamus) that was disconnected from the entire network. Overall, the nicotine network was relatively interconnected between modules and had two large modules and three medium modules.

One of the large modules (module 1) contained midbrain (e.g., pedunculopontine nucleus and periaqueductal gray), hindbrain (e.g., pons and pontine reticular nucleus), cortical (e.g., perirhinal area, posterior auditory area, ventral anterior cingulate temporal association areas, and visceral area), and subcortical (claustrum) brain regions that had high WMDz. A separate set of cortical (e.g., postsubiculum, lateral visual area, and gustatory areas), thalamic (e. g., anteroventral nucleus of the thalamus and peripeduncular nucleus), hypothalamic (e.g., posterior periventricular nucleus, supramammillary nucleus, and periventricular zone), and midbrain (e.g., midbrain reticular nucleus, ventral tegmental area, and medial pretectal area) brain regions and a few others that included the central amygdala and vestibular nuclei had high PC.

In the second large module (module 4), a set of sensory/cortical [e.g., primary somatosensory area, lower limb, ventral agranular insular area (Alv), and primary motor area] and hypothalamic (e.g., parastriatal nucleus, retrochiasmatic area, lateral preoptic area, medial preoptic area, and zona incerta) brain regions had high WMDz. All of the same sensory/cortical and hypothalamic regions had high PC and a number of other thalamic and sensory regions. Additionally, the anterior amygdalar area (AAA) also showed both high WMDz and high PC.

One of the smaller modules (module 2) consisted of hippocampal (dentate gyrus) and sensory/cortical (e.g., posterolateral visual area, anteromedial visual area, and subiculum [SUB]) regions, along with the nucleus of reuniens (RE) with high WMDz. The SUB and RE also had high $\mathrm{PC}$, along with other thalamic, hypothalamic, and midbrain regions.

In another smaller module (module 3), the precommissural nucleus (PRC), medial habenula, and intergeniculate leaflet of the lateral geniculate complex (IGL) had high 
A.

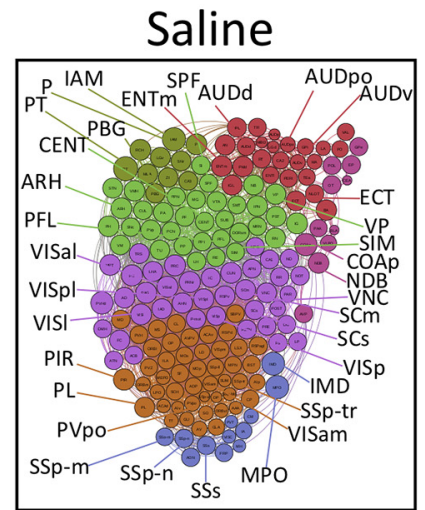

B.

Saline

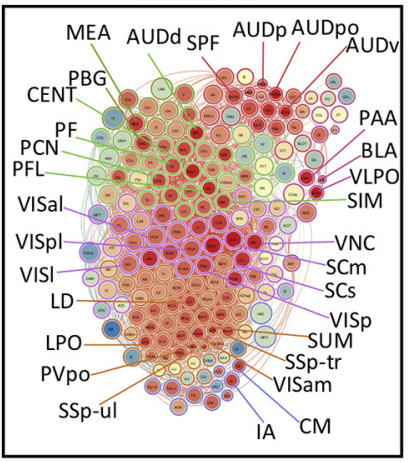

Intermodular connectivity (PC=Size)

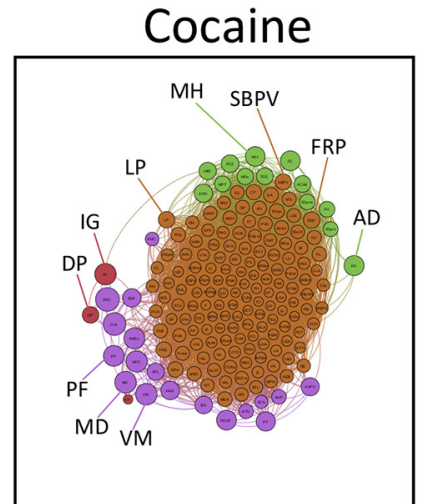

Nicotine

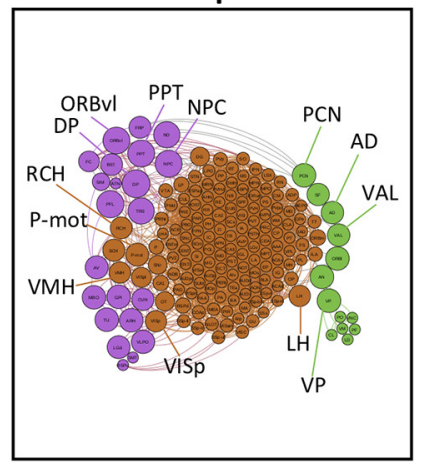

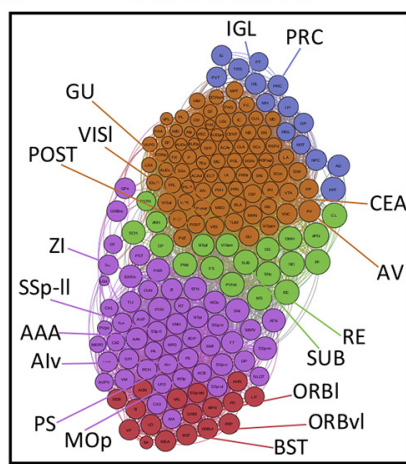

Intramodular connectivity (WMDz=Internal color)
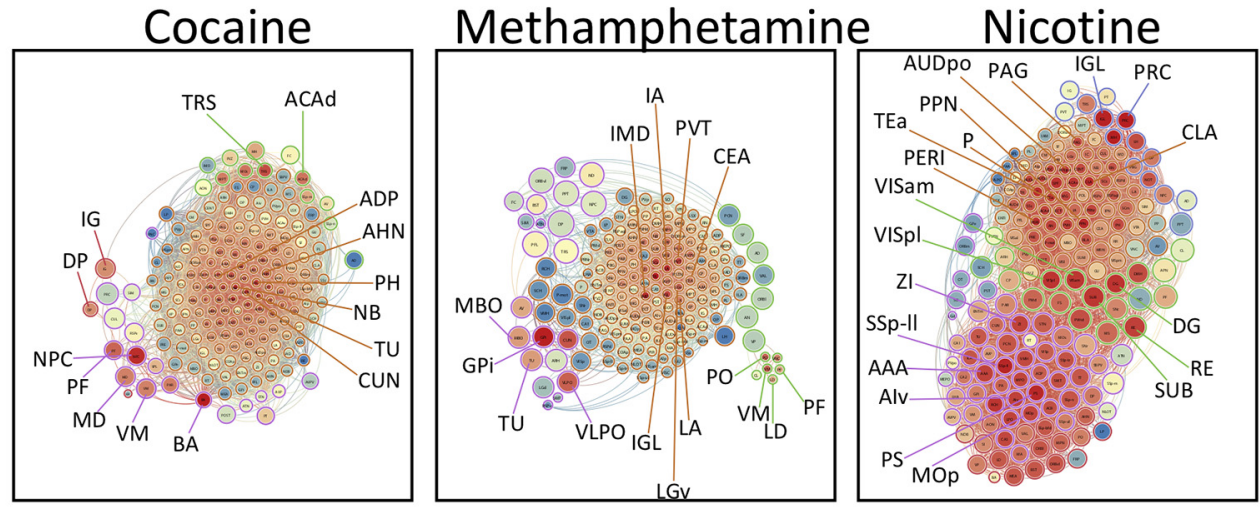

C.

\section{Total Intra and Intermodular connectivity of each network}
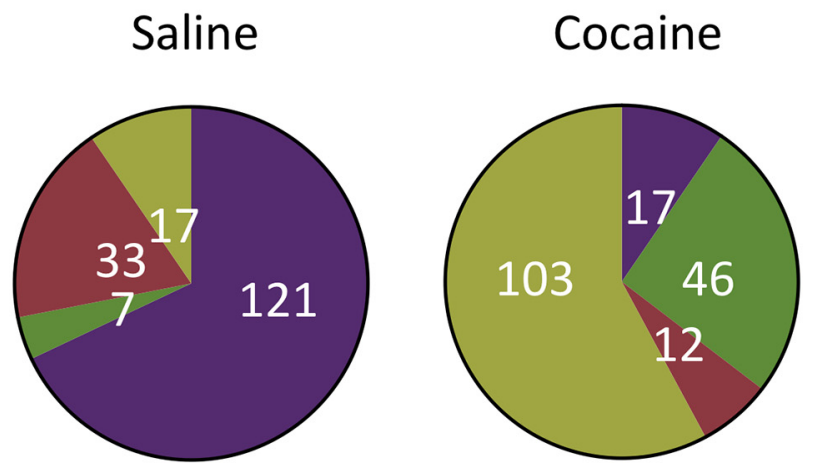
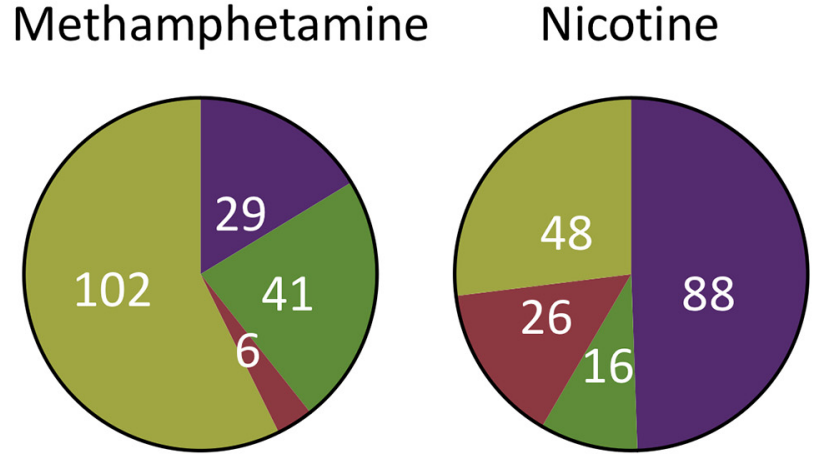

Figure 4. Intramodular (WMDz) and intermodular (PC) network features of each treatment. A high $P C$ was considered $\geq 0.30$, and a high WMDz was considered $\geq 0.80$. A, Highlights of several regions with high PC in each module of each network (see Table 1 for names of abbreviations). $\boldsymbol{B}$, Highlights of several regions with high WMDz (red, higher; blue, lower) in each module of each network. Note that the WMDz color intensity is only relative to the other regions within the same network and not other networks (see Table 1 for names of abbreviations). $\boldsymbol{C}$, Total number of brain regions that accounted for high PC, high WMDz, or both in each network. The control and nicotine networks showed much greater intermodular connectivity and a greater number of regions with both high intermodular and intramodular connectivity. The cocaine and methamphetamine networks showed higher levels of intramodular connectivity and a low number of regions with intermodular connectivity. 


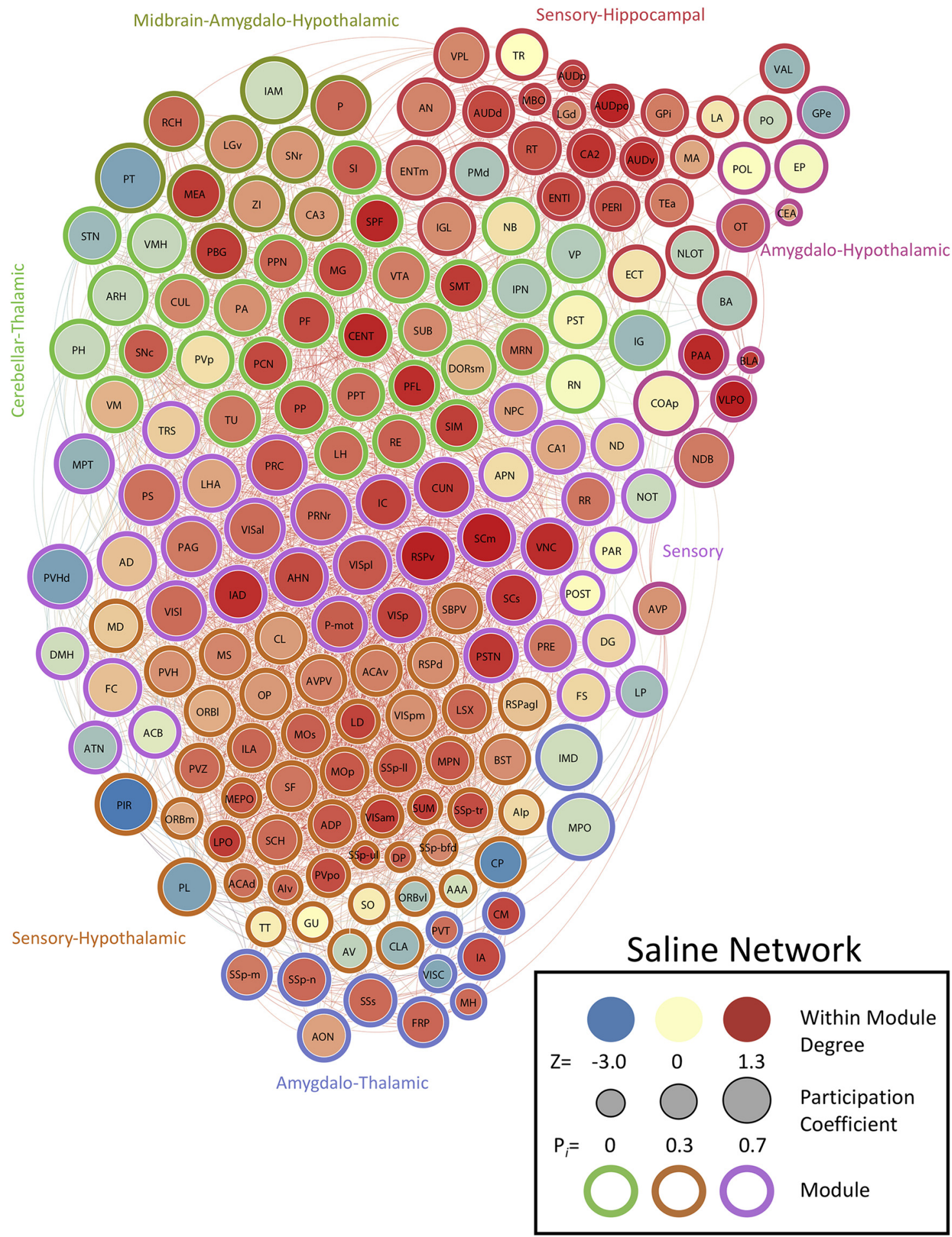

Figure 5. Neural network of control mice thresholded to $0.75 \mathrm{R}$. Nodes/brain regions of the network are represented by circles. The size of the node represents the PC (smaller, lower PC; larger, higher PC). The internal color of each circle represents the WMDz (dark blue, lowest; dark red, highest). The color of the modules that are identified in Figure $1 C$ are represented by different colored edges. See figure key for examples of each representative component of the figure.

WMDz and high PC. Other midbrain and thalamic regions also had high PC.

In the last small module (module 5), no regions reached the criterion for high WMDz, but the orbitofrontal cortex (lateral and ventrolateral orbital area), bed nucleus of the stria terminalis, and medial amygdalar nucleus were all in the top five values $(\mathrm{WMDz}=0.64-0.67)$. However, every region in this module, with the exception of the bed 
Table 2: Saline network values

\begin{tabular}{|c|c|c|c|}
\hline Brain region & Module & $\mathrm{PC}$ & WMDz \\
\hline Agranular insular area posterior part & 3 & 0.35 & -0.48 \\
\hline Agranular insular area ventral part & 3 & 0.15 & 0.56 \\
\hline Anterior cingulate area dorsal part & 3 & 0.22 & 0.49 \\
\hline Anterior cingulate area ventral part & 3 & 0.47 & 0.34 \\
\hline Anterior olfactory nucleus & 4 & 0.50 & 0.02 \\
\hline Anterolateral visual area & 1 & 0.65 & 0.53 \\
\hline Anteromedial visual area & 3 & 0.31 & 0.99 \\
\hline $\begin{array}{l}\text { Cortical amygdalar area posterior } \\
\text { part }\end{array}$ & 7 & 0.72 & -0.69 \\
\hline Dentate gyrus & 1 & 0.49 & -0.46 \\
\hline Dorsal auditory area & 5 & 0.48 & 0.87 \\
\hline Dorsal peduncular area & 3 & 0.08 & 0.66 \\
\hline Ectorhinal area & 5 & 0.58 & -0.57 \\
\hline Entorhinal area lateral part & 5 & 0.40 & 0.89 \\
\hline Entorhinal area medial part & 5 & 0.63 & 0.20 \\
\hline Fasciola cinerea & 1 & 0.60 & -0.26 \\
\hline Field CA1 & 1 & 0.52 & -0.04 \\
\hline Field CA2 & 5 & 0.41 & 1.11 \\
\hline Field CA3 & 6 & 0.52 & 0.08 \\
\hline Frontal pole cerebral cortex & 4 & 0.46 & 0.59 \\
\hline Gustatory areas & 3 & 0.26 & -0.79 \\
\hline Induseum griseum & 2 & 0.64 & -1.94 \\
\hline Infralimbic area & 3 & 0.42 & 0.59 \\
\hline Lateral visual area & 1 & 0.63 & 0.54 \\
\hline Nucleus of the lateral olfactory tract & 5 & 0.50 & -1.57 \\
\hline Orbital area lateral part & 3 & 0.47 & -0.09 \\
\hline Orbital area medial part & 3 & 0.29 & -0.10 \\
\hline Orbital area ventrolateral part & 3 & 0.25 & -1.76 \\
\hline Parasubiculum & 1 & 0.38 & -0.78 \\
\hline Perirhinal area & 5 & 0.44 & 0.75 \\
\hline Piriform area & 3 & 0.66 & -2.98 \\
\hline Piriform-amygdalar area & 7 & 0.44 & 1.21 \\
\hline Posterior auditory area & 5 & 0.32 & 1.25 \\
\hline Posterolateral visual area & 1 & 0.61 & 0.72 \\
\hline Posteromedial visual area & 3 & 0.46 & 0.19 \\
\hline Postpiriform transition area & 5 & 0.47 & -0.83 \\
\hline Postsubiculum & 1 & 0.34 & -0.78 \\
\hline Prelimbic area & 3 & 0.59 & -2.32 \\
\hline Presubiculum & 1 & 0.49 & 0.42 \\
\hline Primary auditory area & 5 & 0.09 & 0.94 \\
\hline Primary motor area & 3 & 0.42 & 0.73 \\
\hline $\begin{array}{l}\text { Primary somatosensory area barrel } \\
\text { field }\end{array}$ & 3 & 0.19 & 0.28 \\
\hline $\begin{array}{l}\text { Primary somatosensory area lower } \\
\text { limb }\end{array}$ & 3 & 0.41 & 0.76 \\
\hline Primary somatosensory area mouth & 4 & 0.45 & 0.40 \\
\hline Primary somatosensory area nose & 4 & 0.50 & 0.57 \\
\hline Primary somatosensory area trunk & 3 & 0.34 & 0.84 \\
\hline $\begin{array}{l}\text { Primary somatosensory area upper } \\
\text { limb }\end{array}$ & 3 & 0.04 & 0.97 \\
\hline Primary visual area & 1 & 0.53 & 0.94 \\
\hline Retrosplenial area dorsal part & 3 & 0.47 & 0.22 \\
\hline $\begin{array}{l}\text { Retrosplenial area lateral agranular } \\
\text { part }\end{array}$ & 3 & 0.49 & -0.27 \\
\hline Retrosplenial area ventral part & 1 & 0.59 & 1.30 \\
\hline Secondary motor area & 3 & 0.42 & 0.65 \\
\hline Subiculum & 2 & 0.50 & 0.25 \\
\hline Supplemental somatosensory area & 4 & 0.50 & 0.56 \\
\hline Taenia tecta & 3 & 0.25 & -0.68 \\
\hline Temporal association areas & 5 & 0.40 & 0.38 \\
\hline Ventral auditory area & 5 & 0.32 & 1.17 \\
\hline (Continued) & 4 & 0.21 & -2.23 \\
\hline
\end{tabular}

Table 2: Continued

\begin{tabular}{|c|c|c|c|}
\hline Brain region & Module & PC & WMDz \\
\hline Basolateral amygdalar nucleus & 7 & 0.00 & 0.99 \\
\hline Claustrum & 3 & 0.39 & -1.94 \\
\hline Endopiriform nucleus & 7 & 0.50 & -0.93 \\
\hline Lateral amygdalar nucleus & 5 & 0.28 & -0.60 \\
\hline Posterior amygdalar nucleus & 2 & 0.57 & 0.18 \\
\hline Anterior amygdalar area & 3 & 0.21 & -1.32 \\
\hline $\begin{array}{l}\text { Bed nucleus of the accessory olfac- } \\
\text { tory tract }\end{array}$ & 5 & 0.62 & -1.74 \\
\hline Caudoputamen & 3 & 0.46 & -2.69 \\
\hline Central amygdalar nucleus & 7 & 0.00 & -0.01 \\
\hline Fundus of striatum & 1 & 0.49 & -0.47 \\
\hline Intercalated amygdalar nucleus & 4 & 0.39 & 0.87 \\
\hline Lateral septal complex & 3 & 0.43 & 0.60 \\
\hline Medial amygdalar nucleus & 6 & 0.58 & 1.02 \\
\hline Nucleus accumbens & 1 & 0.48 & -1.18 \\
\hline Olfactory tubercle & 7 & 0.50 & 0.51 \\
\hline Septofimbrial nucleus & 3 & 0.46 & 0.44 \\
\hline Bed nuclei of the stria terminalis & 3 & 0.46 & 0.21 \\
\hline Diagonal band nucleus & 7 & 0.62 & 0.39 \\
\hline Globus pallidus external segment & 7 & 0.48 & -2.08 \\
\hline Globus pallidus internal segment & 5 & 0.39 & 0.38 \\
\hline Magnocellular nucleus & 5 & 0.31 & -0.02 \\
\hline Medial septal nucleus & 3 & 0.47 & 0.29 \\
\hline Substantia innominata & 2 & 0.50 & 0.69 \\
\hline Triangular nucleus of septum & 1 & 0.58 & -0.37 \\
\hline Anterior group of the dorsal thalamus & 1 & 0.50 & -1.82 \\
\hline Anterodorsal nucleus & 1 & 0.62 & -0.25 \\
\hline Anteroventral nucleus of thalamus & 3 & 0.33 & -1.54 \\
\hline $\begin{array}{l}\text { Central lateral nucleus of the } \\
\text { thalamus }\end{array}$ & 3 & 0.48 & 0.09 \\
\hline $\begin{array}{l}\text { Central medial nucleus of the } \\
\text { thalamus }\end{array}$ & 4 & 0.29 & 0.91 \\
\hline $\begin{array}{l}\text { Dorsal part of the lateral geniculate } \\
\text { complex }\end{array}$ & 5 & 0.13 & 0.17 \\
\hline $\begin{array}{l}\text { Interanterodorsal nucleus of the } \\
\text { thalamus }\end{array}$ & 1 & 0.59 & 1.15 \\
\hline $\begin{array}{l}\text { Interanteromedial nucleus of the } \\
\text { thalamus }\end{array}$ & 6 & 0.77 & -1.38 \\
\hline $\begin{array}{l}\text { Intergeniculate leaflet of the lateral } \\
\text { geniculate complex }\end{array}$ & 5 & 0.60 & 0.22 \\
\hline $\begin{array}{l}\text { Intermediodorsal nucleus of the } \\
\text { thalamus }\end{array}$ & 4 & 0.75 & -1.36 \\
\hline Lateral dorsal nucleus of thalamus & 3 & 0.34 & 0.94 \\
\hline Lateral habenula & 2 & 0.50 & 0.53 \\
\hline $\begin{array}{l}\text { Lateral posterior nucleus of the } \\
\text { thalamus }\end{array}$ & 1 & 0.47 & -1.86 \\
\hline Medial geniculate complex & 2 & 0.50 & 0.88 \\
\hline Medial habenula & 4 & 0.18 & 0.55 \\
\hline Mediodorsal nucleus of thalamus & 3 & 0.51 & -0.33 \\
\hline Nucleus of reuniens & 2 & 0.49 & 0.64 \\
\hline Paracentral nucleus & 2 & 0.49 & 0.88 \\
\hline Parafascicular nucleus & 2 & 0.55 & 0.85 \\
\hline Parataenial nucleus & 6 & 0.82 & -2.30 \\
\hline $\begin{array}{l}\text { Paraventricular nucleus of the } \\
\text { thalamus }\end{array}$ & 4 & 0.18 & 0.49 \\
\hline Peripeduncular nucleus & 2 & 0.50 & 0.83 \\
\hline Posterior complex of the thalamus & 5 & 0.40 & -1.44 \\
\hline $\begin{array}{l}\text { Posterior limiting nucleus of the } \\
\text { thalamus }\end{array}$ & 7 & 0.48 & -0.86 \\
\hline Reticular nucleus of the thalamus & 5 & 0.50 & 0.77 \\
\hline Submedial nucleus of the thalamus & 2 & 0.47 & 1.02 \\
\hline $\begin{array}{l}\text { Subparafascicular nucleus } \\
\qquad \text { (Continued) }\end{array}$ & 2 & 0.48 & 1.22 \\
\hline
\end{tabular}


Table 2: Continued

\begin{tabular}{l} 
Brain region \\
\hline Thalamus sensory-motor cortex \\
related \\
Ventral anterior-lateral complex of \\
the thalamus \\
Ventral medial nucleus of the \\
thalamus \\
Ventral part of the lateral geniculate \\
complex \\
Ventral posterior complex of the \\
thalamus \\
Ventral posterolateral nucleus of the \\
thalamus \\
Anterior hypothalamic nucleus \\
Anterodorsal preoptic nucleus \\
Anteroventral periventricular nucleus \\
Anteroventral preoptic nucleus \\
Arcuate hypothalamic nucleus \\
Dorsal premammillary nucleus \\
Dorsomedial nucleus of the \\
hypothalamus \\
Lateral hypothalamic area \\
Lateral preoptic area \\
Mammillary body \\
Medial preoptic area \\
Medial preoptic nucleus \\
Median preoptic nucleus \\
Parastrial nucleus \\
Parasubthalamic nucleus \\
Paraventricular hypothalamic \\
nucleus
\end{tabular}

Paraventricular hypothalamic nucleus descending division

Periventricular hypothalamic nucleus posterior part

Periventricular hypothalamic nucleus preoptic part

Periventricular zone

Posterior hypothalamic nucleus

Preparasubthalamic nucleus

Retrochiasmatic area

Subparaventricular zone

Subthalamic nucleus

Suprachiasmatic nucleus

Supramammillary nucleus

Supraoptic nucleus

Tuberal nucleus

Ventrolateral preoptic nucleus

Ventromedial hypothalamic nucleus

Zona incerta

Anterior pretectal nucleus

Cuneiform nucleus

Inferior colliculus

Interpeduncular nucleus

Medial pretectal area

Midbrain reticular nucleus

Midbrain reticular nucleus retrorubral area

Nucleus of Darkschewitsch

Nucleus of the brachium of the inferior colliculus

Nucleus of the optic tract

Nucleus of the posterior commissure

(Continued)
Table 2: Continued

\begin{tabular}{lllr}
\hline \multicolumn{1}{c}{ Brain region } & Module & PC & WMDz \\
\hline Olivary pretectal nucleus & 3 & 0.47 & 0.12 \\
Parabigeminal nucleus & 6 & 0.54 & 1.00 \\
Pedunculopontine nucleus & 2 & 0.49 & 0.60 \\
Periaqueductal gray & 1 & 0.64 & 0.39 \\
Posterior pretectal nucleus & 2 & 0.50 & 0.52 \\
Precommissural nucleus & 1 & 0.64 & 0.72 \\
Red nucleus & 2 & 0.60 & -0.92 \\
Substantia nigra compact part & 2 & 0.50 & 0.69 \\
Substantia nigra reticular part & 6 & 0.57 & 0.13 \\
Superior colliculus motor related & 1 & 0.60 & 1.32 \\
Superior colliculus sensory related & 1 & 0.54 & 1.10 \\
Ventral tegmental area & 2 & 0.56 & 0.37 \\
Pons & 6 & 0.63 & 0.57 \\
Pons motor related & 1 & 0.55 & 0.67 \\
Pontine reticular nucleus & 1 & 0.65 & 0.52 \\
Vestibular nuclei & 1 & 0.58 & 1.16 \\
Ansiform lobule & 5 & 0.60 & 0.30 \\
Central lobule & 2 & 0.51 & 1.22 \\
Culmen & 2 & 0.51 & 0.28 \\
Paraflocculus & 2 & 0.46 & 1.16 \\
Simple lobule & 2 & 0.47 & 0.98 \\
\hline
\end{tabular}

nucleus of the accessory olfactory tract, reached the criterion for high PC (Figs. 2, 6; see Table 5 for a full list of values for the network).

\section{Discussion}

The present study used unbiased single-cell wholebrain imaging to identify changes in brain functional architecture after withdrawal from chronic exposure to psychostimulants. Withdrawal from psychostimulants resulted in increased functional connectivity that was associated with a decrease in modularity with varying degrees of severity, depending on the drug, compared with control mice. This decreased modularity resulted in the emergence of new network architecture and organization of the brain. Using graph theory, we identified brain regions that are most responsible for intermodular and intramodular communication within each network. Withdrawal from all of the psychostimulants that were tested in the present study resulted in different network organization than the control network. The methamphetamine and cocaine withdrawal networks closely resembled each other in structural organization, primarily through thalamic motifs, whereas the nicotine withdrawal network shared some similarities with the control network. These unbiased whole-brain analyses demonstrate that psychostimulant withdrawal produces the drug-dependent remodeling of functional architecture of the brain and suggest that decreased modularity of the brain functional network may be a central feature of withdrawal.

\section{Changes to modularity and structure of the brain caused by psychostimulant withdrawal}

We found that cocaine, methamphetamine, and nicotine withdrawal produced major increases in functional connectivity throughout the brain compared with control 
Table 3: Cocaine network values

\begin{tabular}{|c|c|c|c|}
\hline Brain region & Module & $\mathrm{PC}$ & WMDz \\
\hline Agranular insular area posterior part & 1 & 0.07 & -0.69 \\
\hline Agranular insular area ventral part & 1 & 0.22 & -0.76 \\
\hline Anterior cingulate area dorsal part & 3 & 0.34 & 0.93 \\
\hline Anterior cingulate area ventral part & 1 & 0.21 & -0.30 \\
\hline Anterior olfactory nucleus & 3 & 0.41 & -0.32 \\
\hline Anterolateral visual area & 1 & 0.09 & 0.74 \\
\hline Anteromedial visual area & 1 & 0.05 & 0.80 \\
\hline $\begin{array}{l}\text { Cortical amygdalar area posterior } \\
\text { part }\end{array}$ & 1 & 0.16 & -0.72 \\
\hline Dentate gyrus & 1 & 0.02 & 0.36 \\
\hline Dorsal auditory area & 1 & 0.05 & 0.35 \\
\hline Dorsal peduncular area & 4 & 0.32 & 0.71 \\
\hline Ectorhinal area & 1 & 0.01 & 1.37 \\
\hline Entorhinal area lateral part & 1 & 0.04 & 1.05 \\
\hline Entorhinal area medial part & 1 & 0.17 & -0.58 \\
\hline Fasciola cinerea & 3 & 0.47 & -0.19 \\
\hline Field CA1 & 1 & 0.02 & 0.71 \\
\hline Field CA2 & 1 & 0.02 & -0.11 \\
\hline Field CA3 & 1 & 0.05 & 0.89 \\
\hline Frontal pole cerebral cortex & 1 & 0.32 & -1.86 \\
\hline Gustatory areas & 1 & 0.21 & -0.85 \\
\hline Induseum griseum & 4 & 0.55 & 0.71 \\
\hline Infralimbic area & 1 & 0.25 & -1.28 \\
\hline Lateral visual area & 1 & 0.00 & 1.11 \\
\hline Nucleus of the lateral olfactory tract & 1 & 0.18 & -0.41 \\
\hline Orbital area lateral part & 1 & 0.10 & 0.66 \\
\hline Orbital area medial part & 1 & 0.07 & 0.39 \\
\hline Orbital area ventrolateral part & 1 & 0.04 & 1.10 \\
\hline Parasubiculum & 2 & 0.53 & -0.16 \\
\hline Perirhinal area & 1 & 0.05 & 0.61 \\
\hline Piriform area & 1 & 0.00 & 0.47 \\
\hline Piriform-amygdalar area & 1 & 0.17 & -0.63 \\
\hline Posterior auditory area & 1 & 0.07 & 0.11 \\
\hline Posterolateral visual area & 1 & 0.00 & 1.58 \\
\hline Posteromedial visual area & 1 & 0.13 & -1.88 \\
\hline Postpiriform transition area & 1 & 0.10 & 0.52 \\
\hline Postsubiculum & 2 & 0.60 & -0.47 \\
\hline Prelimbic area & 1 & 0.23 & -1.08 \\
\hline Presubiculum & 1 & 0.28 & -1.55 \\
\hline Primary auditory area & 1 & 0.00 & 1.19 \\
\hline Primary motor area & 1 & 0.12 & 0.37 \\
\hline $\begin{array}{l}\text { Primary somatosensory area barrel } \\
\text { field }\end{array}$ & 1 & 0.07 & 0.31 \\
\hline $\begin{array}{l}\text { Primary somatosensory area lower } \\
\text { limb }\end{array}$ & 1 & 0.19 & -0.44 \\
\hline Primary somatosensory area mouth & 3 & 0.29 & 0.47 \\
\hline Primary somatosensory area nose & 3 & 0.25 & -0.72 \\
\hline Primary somatosensory area trunk & 1 & 0.02 & 1.01 \\
\hline $\begin{array}{l}\text { Primary somatosensory area upper } \\
\text { limb }\end{array}$ & 1 & 0.16 & 0.07 \\
\hline Primary visual area & 1 & 0.06 & 0.92 \\
\hline Retrosplenial area dorsal part & 1 & 0.02 & 0.80 \\
\hline $\begin{array}{l}\text { Retrosplenial area lateral agranular } \\
\text { part }\end{array}$ & 1 & 0.00 & 1.32 \\
\hline Retrosplenial area ventral part & 2 & 0.17 & -0.53 \\
\hline Secondary motor area & 3 & 0.32 & 0.95 \\
\hline Subiculum & 1 & 0.22 & -0.86 \\
\hline Supplemental somatosensory area & 1 & 0.14 & -1.08 \\
\hline Taenia tecta & 1 & 0.13 & -0.63 \\
\hline Temporal association areas & 1 & 0.01 & 1.19 \\
\hline Ventral auditory area & 1 & 0.02 & 0.81 \\
\hline (Continued) & 1 & 0.12 & -0.03 \\
\hline
\end{tabular}

Table 3: Continued

\begin{tabular}{|c|c|c|c|}
\hline Brain region & Module & $\mathrm{PC}$ & $\overline{W M D z}$ \\
\hline Basolateral amygdalar nucleus & $\overline{1}$ & 0.03 & $\overline{0.83}$ \\
\hline Claustrum & 1 & 0.08 & -0.82 \\
\hline Endopiriform nucleus & 1 & 0.00 & 1.06 \\
\hline Lateral amygdalar nucleus & 1 & 0.07 & -0.35 \\
\hline Posterior amygdalar nucleus & 1 & 0.14 & -0.55 \\
\hline Anterior amygdalar area & 1 & 0.00 & 0.83 \\
\hline $\begin{array}{l}\text { Bed nucleus of the accessory olfac- } \\
\text { tory tract }\end{array}$ & 2 & 0.42 & 0.84 \\
\hline Caudoputamen & 1 & 0.27 & -1.88 \\
\hline Central amygdalar nucleus & 1 & 0.06 & 0.13 \\
\hline Fundus of striatum & 1 & 0.19 & -1.88 \\
\hline Intercalated amygdalar nucleus & 1 & 0.03 & 0.97 \\
\hline Lateral septal complex & 1 & 0.20 & -0.72 \\
\hline Medial amygdalar nucleus & 1 & 0.24 & -1.74 \\
\hline Nucleus accumbens & 1 & 0.15 & 0.13 \\
\hline Olfactory tubercle & 1 & 0.00 & 1.23 \\
\hline Septofimbrial nucleus & 1 & 0.17 & -0.31 \\
\hline Bed nuclei of the stria terminalis & 1 & 0.11 & 0.91 \\
\hline Diagonal band nucleus & 1 & 0.17 & -1.14 \\
\hline Globus pallidus external segment & 1 & 0.28 & -1.46 \\
\hline Globus pallidus internal segment & 1 & 0.18 & -1.30 \\
\hline Magnocellular nucleus & 1 & 0.12 & 0.87 \\
\hline Medial septal nucleus & 1 & 0.21 & -1.35 \\
\hline Substantia innominata & 1 & 0.00 & 0.95 \\
\hline Triangular nucleus of septum & 3 & 0.34 & 1.31 \\
\hline Anterior group of the dorsal thalamus & 2 & 0.38 & 1.78 \\
\hline Anterodorsal nucleus & 3 & 0.48 & -2.30 \\
\hline Anteroventral nucleus of thalamus & 3 & 0.29 & 0.00 \\
\hline $\begin{array}{l}\text { Central lateral nucleus of the } \\
\text { thalamus }\end{array}$ & 1 & 0.13 & -1.96 \\
\hline $\begin{array}{l}\text { Central medial nucleus of the } \\
\text { thalamus }\end{array}$ & 1 & 0.16 & -0.82 \\
\hline $\begin{array}{l}\text { Dorsal part of the lateral geniculate } \\
\text { complex }\end{array}$ & 1 & 0.03 & 1.01 \\
\hline $\begin{array}{l}\text { Interanterodorsal nucleus of the } \\
\text { thalamus }\end{array}$ & 1 & 0.11 & -0.89 \\
\hline $\begin{array}{l}\text { Interanteromedial nucleus of the } \\
\text { thalamus }\end{array}$ & 1 & 0.00 & 0.42 \\
\hline $\begin{array}{l}\text { Intergeniculate leaflet of the lateral } \\
\text { geniculate complex }\end{array}$ & 1 & 0.12 & -0.18 \\
\hline $\begin{array}{l}\text { Intermediodorsal nucleus of the } \\
\text { thalamus }\end{array}$ & 3 & 0.36 & -1.56 \\
\hline Lateral dorsal nucleus of thalamus & 1 & 0.12 & 0.47 \\
\hline Lateral habenula & 4 & 0.00 & -1.41 \\
\hline $\begin{array}{l}\text { Lateral posterior nucleus of the } \\
\text { thalamus }\end{array}$ & 1 & 0.32 & -2.30 \\
\hline Medial geniculate complex & 1 & 0.10 & -0.86 \\
\hline Medial habenula & 3 & 0.47 & 0.46 \\
\hline Mediodorsal nucleus of thalamus & 2 & 0.55 & 0.82 \\
\hline Nucleus of reuniens & 1 & 0.19 & -2.35 \\
\hline Paracentral nucleus & 1 & 0.16 & -1.09 \\
\hline Parafascicular nucleus & 2 & 0.45 & 0.18 \\
\hline Parataenial nucleus & 2 & 0.24 & -0.20 \\
\hline $\begin{array}{l}\text { Paraventricular nucleus of the } \\
\text { thalamus }\end{array}$ & 1 & 0.00 & 1.09 \\
\hline Peripeduncular nucleus & 1 & 0.03 & -0.79 \\
\hline Posterior complex of the thalamus & 1 & 0.03 & 0.85 \\
\hline $\begin{array}{l}\text { Posterior limiting nucleus of the } \\
\text { thalamus }\end{array}$ & 1 & 0.02 & -0.23 \\
\hline Reticular nucleus of the thalamus & 1 & 0.17 & -1.27 \\
\hline Submedial nucleus of the thalamus & 1 & 0.15 & 0.50 \\
\hline $\begin{array}{l}\text { Subparafascicular nucleus } \\
\text { (Continued) }\end{array}$ & 1 & 0.12 & 0.33 \\
\hline
\end{tabular}


Table 3: Continued

\begin{tabular}{|c|c|c|c|}
\hline Brain region & Module & $\mathrm{PC}$ & WMDz \\
\hline $\begin{array}{l}\text { Thalamus sensory-motor cortex } \\
\text { related }\end{array}$ & 1 & 0.07 & $\overline{0.30}$ \\
\hline $\begin{array}{l}\text { Ventral anterior-lateral complex of } \\
\text { the thalamus }\end{array}$ & 1 & 0.13 & -0.70 \\
\hline $\begin{array}{l}\text { Ventral medial nucleus of the } \\
\text { thalamus }\end{array}$ & 2 & 0.66 & -0.94 \\
\hline $\begin{array}{l}\text { Ventral part of the lateral geniculate } \\
\text { complex }\end{array}$ & 1 & 0.11 & -0.02 \\
\hline $\begin{array}{l}\text { Ventral posterior complex of the } \\
\text { thalamus }\end{array}$ & 1 & 0.07 & -0.50 \\
\hline $\begin{array}{l}\text { Ventral posterolateral nucleus of the } \\
\text { thalamus }\end{array}$ & 2 & 0.40 & -1.10 \\
\hline Anterior hypothalamic nucleus & 1 & 0.06 & 1.22 \\
\hline Anterodorsal preoptic nucleus & 1 & 0.00 & 1.28 \\
\hline Anteroventral periventricular nucleus & 2 & 0.54 & 1.62 \\
\hline Anteroventral preoptic nucleus & 2 & 0.52 & 1.08 \\
\hline Arcuate hypothalamic nucleus & 1 & 0.17 & -0.98 \\
\hline Dorsal premammillary nucleus & 1 & 0.06 & 1.26 \\
\hline $\begin{array}{l}\text { Dorsomedial nucleus of the } \\
\text { hypothalamus }\end{array}$ & 1 & 0.21 & -0.49 \\
\hline Lateral hypothalamic area & 1 & 0.07 & 0.67 \\
\hline Lateral preoptic area & 1 & 0.10 & 0.53 \\
\hline Mammillary body & 1 & 0.22 & -1.28 \\
\hline Medial preoptic area & 1 & 0.02 & 0.83 \\
\hline Medial preoptic nucleus & 1 & 0.15 & -1.12 \\
\hline Median preoptic nucleus & 1 & 0.13 & -1.07 \\
\hline Parastrial nucleus & 1 & 0.02 & 0.96 \\
\hline Parasubthalamic nucleus & 1 & 0.10 & 0.97 \\
\hline $\begin{array}{l}\text { Paraventricular hypothalamic } \\
\text { nucleus }\end{array}$ & 1 & 0.22 & -0.40 \\
\hline $\begin{array}{l}\text { Paraventricular hypothalamic nucleus } \\
\text { descending division }\end{array}$ & 1 & 0.13 & 0.22 \\
\hline $\begin{array}{l}\text { Periventricular hypothalamic nucleus } \\
\text { posterior part }\end{array}$ & 1 & 0.24 & -1.54 \\
\hline $\begin{array}{l}\text { Periventricular hypothalamic nucleus } \\
\text { preoptic part }\end{array}$ & 1 & 0.25 & -0.91 \\
\hline Periventricular zone & 3 & 0.38 & 0.12 \\
\hline Posterior hypothalamic nucleus & 1 & 0.04 & 1.47 \\
\hline Preparasubthalamic nucleus & 1 & 0.06 & -0.14 \\
\hline Retrochiasmatic area & 1 & 0.06 & 0.70 \\
\hline Subparaventricular zone & 1 & 0.30 & -1.46 \\
\hline Subthalamic nucleus & 2 & 0.48 & -0.73 \\
\hline Suprachiasmatic nucleus & 1 & 0.12 & -0.77 \\
\hline Supramammillary nucleus & 1 & 0.06 & 0.69 \\
\hline Supraoptic nucleus & 1 & 0.00 & 1.32 \\
\hline Tuberal nucleus & 1 & 0.00 & 1.40 \\
\hline Ventrolateral preoptic nucleus & 1 & 0.07 & -1.56 \\
\hline Ventromedial hypothalamic nucleus & 1 & 0.13 & 0.16 \\
\hline Zona incerta & 1 & 0.11 & -0.75 \\
\hline Anterior pretectal nucleus & 1 & 0.10 & -0.21 \\
\hline Cuneiform nucleus & 1 & 0.00 & 1.54 \\
\hline Inferior colliculus & 1 & 0.03 & 0.94 \\
\hline Interpeduncular nucleus & 1 & 0.06 & -0.20 \\
\hline Medial pretectal area & 3 & 0.30 & 0.84 \\
\hline Midbrain reticular nucleus & 1 & 0.00 & 1.08 \\
\hline $\begin{array}{l}\text { Midbrain reticular nucleus retrorubral } \\
\text { area }\end{array}$ & 1 & 0.09 & 1.03 \\
\hline Nucleus of Darkschewitsch & 1 & 0.05 & -0.40 \\
\hline $\begin{array}{l}\text { Nucleus of the brachium of the infe- } \\
\text { rior colliculus }\end{array}$ & 1 & 0.00 & 1.60 \\
\hline Nucleus of the optic tract & 1 & 0.07 & 0.98 \\
\hline $\begin{array}{l}\text { Nucleus of the posterior commissure } \\
\text { (Continued) }\end{array}$ & 2 & 0.36 & 0.33 \\
\hline
\end{tabular}

Table 3: Continued

\begin{tabular}{lllr}
\hline Brain region & Module & PC & WMDz \\
\hline Olivary pretectal nucleus & 1 & 0.21 & -0.61 \\
Parabigeminal nucleus & 1 & 0.09 & 0.20 \\
Pedunculopontine nucleus & 1 & 0.05 & 0.90 \\
Periaqueductal gray & 1 & 0.12 & 0.70 \\
Posterior pretectal nucleus & 1 & 0.06 & -1.07 \\
Precommissural nucleus & 2 & 0.24 & -0.50 \\
Red nucleus & 1 & 0.01 & 1.32 \\
Substantia nigra compact part & 1 & 0.01 & 1.18 \\
Substantia nigra reticular part & 1 & 0.00 & 1.23 \\
Superior colliculus motor related & 1 & 0.11 & 0.71 \\
Superior colliculus sensory related & 1 & 0.11 & -0.05 \\
Ventral tegmental area & 1 & 0.11 & 0.26 \\
Pons & 1 & 0.01 & 1.03 \\
Pons motor related & 1 & 0.21 & -1.09 \\
Pontine reticular nucleus & 1 & 0.02 & 0.98 \\
Vestibular nuclei & 2 & 0.19 & -2.26 \\
Ansiform lobule & 1 & 0.15 & -1.44 \\
Central lobule & 1 & 0.20 & -0.79 \\
Culmen & 2 & 0.56 & 0.82 \\
Paraflocculus & 1 & 0.17 & -1.50 \\
Simple lobule & 2 & 0.41 & -0.57 \\
\hline
\end{tabular}

mice. We further found that withdrawal resulted in a decrease in modular structuring of the brain compared with control mice (seven modules). The decrease in modularity was most evident for methamphetamine withdrawal (three modules) and cocaine withdrawal (four modules), whereas nicotine withdrawal showed a smaller reduction of modularity (five modules). Using the same approaches (i.e., whole-brain network analysis of Fos) reduced modularity after abstinence from alcohol dependence in mice was similarly found (Kimbrough et al., 2020). Further, humans who suffer from dementia and traumatic brain injury have shown reduced modularity that is associated with cognitive deficits (de Haan et al., 2012; Brier et al., 2014; Arnemann et al., 2015; Gallen et al., 2016; Sporns and Betzel, 2016; Bertolero et al., 2018). Changes in network structure/functional connectivity (Tomasi et al., 2010; Konova et al., 2013, 2015; Ma et al., 2015) and cognitive function (Spronk et al., 2013; Ashare et al., 2014; Sabrini et al., 2019) have been observed after chronic drug use and withdrawal, suggesting that similar mechanisms may be active between these different neural disorders.

\section{Features of psychostimulant networks}

We examined the components of individual modules within each network and found that the control network was heavily driven by sensory and motor brain regions. This result confers validity to our single-cell whole-brain network analysis approach for characterizing network features because it fits with what might be expected from a normal, awake, behaving animal that explores the environment and relies heavily on sensory/motor systems. Furthermore, the control network was more interconnected between modules overall and contained several regions that could be classified as hubs of each module that are critical for network function, based on high 
Table 4: Methamphetamine network values

\begin{tabular}{|c|c|c|c|}
\hline Brain region & Module & $\mathrm{PC}$ & WMDz \\
\hline Agranular insular area posterior part & 1 & 0.00 & -0.90 \\
\hline Agranular insular area ventral part & 1 & 0.00 & 0.64 \\
\hline Anterior cingulate area dorsal part & 1 & 0.00 & -0.08 \\
\hline Anterior cingulate area ventral part & 1 & 0.00 & 0.41 \\
\hline Anterior olfactory nucleus & 1 & 0.00 & -2.01 \\
\hline Anterolateral visual area & 1 & 0.00 & 0.65 \\
\hline Anteromedial visual area & 1 & 0.08 & -1.15 \\
\hline $\begin{array}{l}\text { Cortical amygdalar area posterior } \\
\text { part }\end{array}$ & 1 & 0.09 & -0.41 \\
\hline Dentate gyrus & 1 & 0.32 & -1.31 \\
\hline Dorsal auditory area & 1 & 0.00 & 0.67 \\
\hline Dorsal peduncular area & 2 & 0.67 & -0.41 \\
\hline Ectorhinal area & 1 & 0.00 & 0.81 \\
\hline Entorhinal area lateral part & 1 & 0.00 & 0.70 \\
\hline Entorhinal area medial part & 1 & 0.00 & -0.26 \\
\hline Fasciola cinerea & 2 & 0.38 & -0.46 \\
\hline Field CA1 & 1 & 0.18 & -1.45 \\
\hline Field CA2 & 1 & 0.10 & -1.36 \\
\hline Field CA3 & 1 & 0.00 & -0.84 \\
\hline Frontal pole cerebral cortex & 2 & 0.43 & -1.01 \\
\hline Gustatory areas & 1 & 0.07 & -1.09 \\
\hline Induseum griseum & 1 & 0.00 & 0.05 \\
\hline Infralimbic area & 1 & 0.13 & -1.04 \\
\hline Lateral visual area & 1 & 0.00 & 1.30 \\
\hline Nucleus of the lateral olfactory tract & 1 & 0.07 & -1.03 \\
\hline Orbital area lateral part & 3 & 0.50 & -0.59 \\
\hline Orbital area medial part & 1 & 0.18 & -1.44 \\
\hline Orbital area ventrolateral part & 2 & 0.63 & -0.41 \\
\hline Parasubiculum & 1 & 0.00 & 0.95 \\
\hline Perirhinal area & 1 & 0.00 & 0.61 \\
\hline Piriform area & 1 & 0.00 & -0.10 \\
\hline Piriform-amygdalar area & 1 & 0.00 & 0.11 \\
\hline Posterior auditory area & 1 & 0.05 & -0.25 \\
\hline Posterolateral visual area & 1 & 0.35 & -1.44 \\
\hline Posteromedial visual area & 1 & 0.00 & -0.29 \\
\hline Postpiriform transition area & 1 & 0.00 & 2.19 \\
\hline Postsubiculum & 1 & 0.00 & 0.92 \\
\hline Prelimbic area & 1 & 0.00 & -1.01 \\
\hline Presubiculum & 1 & 0.00 & 0.98 \\
\hline Primary auditory area & 1 & 0.00 & 1.01 \\
\hline Primary motor area & 1 & 0.00 & -0.94 \\
\hline $\begin{array}{l}\text { Primary somatosensory area barrel } \\
\text { field }\end{array}$ & 1 & 0.00 & -0.18 \\
\hline $\begin{array}{l}\text { Primary somatosensory area lower } \\
\text { limb }\end{array}$ & 1 & 0.08 & -1.08 \\
\hline Primary somatosensory area mouth & 1 & 0.00 & -1.12 \\
\hline Primary somatosensory area nose & 1 & 0.00 & -0.26 \\
\hline Primary somatosensory area trunk & 1 & 0.07 & -0.97 \\
\hline $\begin{array}{l}\text { Primary somatosensory area upper } \\
\text { limb }\end{array}$ & 1 & 0.07 & -1.08 \\
\hline Primary visual area & 1 & 0.41 & -1.52 \\
\hline Retrosplenial area dorsal part & 1 & 0.17 & -1.33 \\
\hline $\begin{array}{l}\text { Retrosplenial area lateral agranular } \\
\text { part }\end{array}$ & 1 & 0.04 & 0.18 \\
\hline Retrosplenial area ventral part & 2 & 0.00 & -1.56 \\
\hline Secondary motor area & 1 & 0.00 & -1.40 \\
\hline Subiculum & 1 & 0.00 & 1.00 \\
\hline Supplemental somatosensory area & 1 & 0.00 & -1.37 \\
\hline Taenia tecta & 1 & 0.09 & -1.18 \\
\hline Temporal association areas & 1 & 0.00 & 0.66 \\
\hline Ventral auditory area & 1 & 0.00 & 0.15 \\
\hline (Continued) & 1 & 0.07 & -1.11 \\
\hline
\end{tabular}

Table 4: Continued

\begin{tabular}{|c|c|c|c|}
\hline Brain region & Module & $\mathrm{PC}$ & $\overline{W M D z}$ \\
\hline Basolateral amygdalar nucleus & $\overline{1}$ & 0.00 & $\overline{0.35}$ \\
\hline Claustrum & 1 & 0.00 & 0.54 \\
\hline Endopiriform nucleus & 1 & 0.00 & 0.93 \\
\hline Lateral amygdalar nucleus & 1 & 0.00 & 1.26 \\
\hline Posterior amygdalar nucleus & 1 & 0.00 & 0.01 \\
\hline Anterior amygdalar area & 1 & 0.00 & 1.07 \\
\hline $\begin{array}{l}\text { Bed nucleus of the accessory olfac- } \\
\text { tory tract }\end{array}$ & 1 & 0.00 & 0.51 \\
\hline Caudoputamen & 1 & 0.00 & 0.87 \\
\hline Central amygdalar nucleus & 1 & 0.00 & 1.21 \\
\hline Fundus of striatum & 1 & 0.06 & -0.84 \\
\hline Intercalated amygdalar nucleus & 1 & 0.00 & 2.04 \\
\hline Lateral septal complex & 1 & 0.06 & -0.83 \\
\hline Medial amygdalar nucleus & 1 & 0.06 & -0.61 \\
\hline Nucleus accumbens & 1 & 0.00 & -0.05 \\
\hline Olfactory tubercle & 1 & 0.32 & -1.28 \\
\hline Septofimbrial nucleus & 3 & 0.45 & -0.71 \\
\hline Bed nuclei of the stria terminalis & 2 & 0.43 & 0.28 \\
\hline Diagonal band nucleus & 1 & 0.05 & -0.24 \\
\hline Globus pallidus external segment & 1 & 0.00 & -0.20 \\
\hline Globus pallidus internal segment & 2 & 0.50 & 2.18 \\
\hline Magnocellular nucleus & 1 & 0.00 & -0.13 \\
\hline Medial septal nucleus & 1 & 0.00 & 0.49 \\
\hline Substantia innominata & 1 & 0.00 & 0.66 \\
\hline Triangular nucleus of septum & 2 & 0.61 & 0.15 \\
\hline Anterior group of the dorsal thalamus & 2 & 0.00 & -1.56 \\
\hline Anterodorsal nucleus & 3 & 0.45 & -0.61 \\
\hline Anteroventral nucleus of thalamus & 2 & 0.48 & 0.85 \\
\hline $\begin{array}{l}\text { Central lateral nucleus of the } \\
\text { thalamus }\end{array}$ & 3 & 0.00 & -0.03 \\
\hline $\begin{array}{l}\text { Central medial nucleus of the } \\
\text { thalamus }\end{array}$ & 1 & 0.00 & -0.30 \\
\hline $\begin{array}{l}\text { Dorsal part of the lateral geniculate } \\
\text { complex }\end{array}$ & 2 & 0.47 & -0.90 \\
\hline $\begin{array}{l}\text { Interanterodorsal nucleus of the } \\
\text { thalamus }\end{array}$ & 1 & 0.00 & -0.67 \\
\hline $\begin{array}{l}\text { Interanteromedial nucleus of the } \\
\text { thalamus }\end{array}$ & 1 & 0.00 & -1.28 \\
\hline $\begin{array}{l}\text { Intergeniculate leaflet of the lateral } \\
\text { geniculate complex }\end{array}$ & 1 & 0.00 & 1.80 \\
\hline $\begin{array}{l}\text { Intermediodorsal nucleus of the } \\
\text { thalamus }\end{array}$ & 1 & 0.00 & 2.04 \\
\hline Lateral dorsal nucleus of thalamus & 3 & 0.00 & 0.81 \\
\hline Lateral habenula & 1 & 0.41 & -1.97 \\
\hline $\begin{array}{l}\text { Lateral posterior nucleus of the } \\
\text { thalamus }\end{array}$ & 1 & 0.16 & -1.32 \\
\hline Medial geniculate complex & 1 & 0.00 & 0.87 \\
\hline Medial habenula & 1 & 0.00 & -0.19 \\
\hline Mediodorsal nucleus of thalamus & 1 & 0.00 & 0.08 \\
\hline Nucleus of reuniens & 1 & 0.00 & 1.27 \\
\hline Paracentral nucleus & 3 & 0.50 & -1.38 \\
\hline Parafascicular nucleus & 3 & 0.00 & 0.85 \\
\hline Parataenial nucleus & 1 & 0.00 & 0.74 \\
\hline $\begin{array}{l}\text { Paraventricular nucleus of the } \\
\text { thalamus }\end{array}$ & 1 & 0.00 & 1.82 \\
\hline Peripeduncular nucleus & 1 & 0.00 & 0.33 \\
\hline Posterior complex of the thalamus & 3 & 0.00 & 1.48 \\
\hline $\begin{array}{l}\text { Posterior limiting nucleus of the } \\
\text { thalamus }\end{array}$ & 1 & 0.00 & -0.12 \\
\hline Reticular nucleus of the thalamus & 1 & 0.04 & -0.11 \\
\hline Submedial nucleus of the thalamus & 2 & 0.00 & -0.90 \\
\hline $\begin{array}{l}\text { Subparafascicular nucleus } \\
\text { (Continued) }\end{array}$ & 1 & 0.00 & 1.36 \\
\hline
\end{tabular}


Table 4: Continued

\begin{tabular}{|c|c|c|c|}
\hline Brain region & Module & $\mathrm{PC}$ & WMDz \\
\hline $\begin{array}{l}\text { Thalamus sensory-motor cortex } \\
\text { related }\end{array}$ & 1 & 0.00 & 0.57 \\
\hline $\begin{array}{l}\text { Ventral anterior-lateral complex of } \\
\text { the thalamus }\end{array}$ & 3 & 0.45 & -1.28 \\
\hline $\begin{array}{l}\text { Ventral medial nucleus of the } \\
\text { thalamus }\end{array}$ & 3 & 0.00 & 1.54 \\
\hline $\begin{array}{l}\text { Ventral part of the lateral geniculate } \\
\text { complex }\end{array}$ & 1 & 0.00 & 1.48 \\
\hline $\begin{array}{l}\text { Ventral posterior complex of the } \\
\text { thalamus }\end{array}$ & 3 & 0.50 & -0.68 \\
\hline $\begin{array}{l}\text { Ventral posterolateral nucleus of the } \\
\text { thalamus }\end{array}$ & 1 & 0.00 & 0.54 \\
\hline Anterior hypothalamic nucleus & 1 & 0.00 & 0.69 \\
\hline Anterodorsal preoptic nucleus & 1 & 0.06 & -0.84 \\
\hline Anteroventral periventricular nucleus & 1 & 0.00 & 1.34 \\
\hline Anteroventral preoptic nucleus & 1 & 0.00 & 1.23 \\
\hline Arcuate hypothalamic nucleus & 2 & 0.50 & -0.32 \\
\hline Dorsal premammillary nucleus & 1 & 0.07 & -0.82 \\
\hline $\begin{array}{l}\text { Dorsomedial nucleus of the } \\
\text { hypothalamus }\end{array}$ & 1 & 0.00 & 0.39 \\
\hline Lateral hypothalamic area & 1 & 0.00 & -1.22 \\
\hline Lateral preoptic area & 1 & 0.04 & 0.14 \\
\hline Mammillary body & 2 & 0.50 & 0.98 \\
\hline Medial preoptic area & 1 & 0.00 & 0.53 \\
\hline Medial preoptic nucleus & 1 & 0.00 & 0.75 \\
\hline Median preoptic nucleus & 1 & 0.00 & -0.14 \\
\hline Parastrial nucleus & 1 & 0.00 & 0.86 \\
\hline Parasubthalamic nucleus & 1 & 0.00 & 0.82 \\
\hline $\begin{array}{l}\text { Paraventricular hypothalamic } \\
\text { nucleus }\end{array}$ & 1 & 0.00 & 1.36 \\
\hline $\begin{array}{l}\text { Paraventricular hypothalamic nucleus } \\
\text { descending division }\end{array}$ & 1 & 0.00 & 0.75 \\
\hline $\begin{array}{l}\text { Periventricular hypothalamic nucleus } \\
\text { posterior part }\end{array}$ & 1 & 0.11 & -0.62 \\
\hline $\begin{array}{l}\text { Periventricular hypothalamic nucleus } \\
\text { preoptic part }\end{array}$ & 1 & 0.00 & 0.65 \\
\hline Periventricular zone & 1 & 0.00 & 0.14 \\
\hline Posterior hypothalamic nucleus & 1 & 0.00 & 0.52 \\
\hline Preparasubthalamic nucleus & 1 & 0.00 & -0.08 \\
\hline Retrochiasmatic area & 1 & 0.43 & -1.79 \\
\hline Subparaventricular zone & 1 & 0.00 & 1.26 \\
\hline Subthalamic nucleus & 1 & 0.07 & -0.83 \\
\hline Suprachiasmatic nucleus & 1 & 0.44 & -1.61 \\
\hline Supramammillary nucleus & 1 & 0.00 & -0.11 \\
\hline Supraoptic nucleus & 1 & 0.07 & -0.73 \\
\hline Tuberal nucleus & 2 & 0.50 & 0.97 \\
\hline Ventrolateral preoptic nucleus & 2 & 0.49 & 1.53 \\
\hline Ventromedial hypothalamic nucleus & 1 & 0.41 & -1.83 \\
\hline Zona incerta & 1 & 0.00 & 1.35 \\
\hline Anterior pretectal nucleus & 1 & 0.00 & -0.98 \\
\hline Cuneiform nucleus & 2 & 0.44 & 1.64 \\
\hline Inferior colliculus & 1 & 0.00 & 1.08 \\
\hline Interpeduncular nucleus & 1 & 0.05 & -0.36 \\
\hline Medial pretectal area & 1 & 0.00 & 0.45 \\
\hline Midbrain reticular nucleus & 1 & 0.00 & 0.65 \\
\hline $\begin{array}{l}\text { Midbrain reticular nucleus retrorubral } \\
\text { area }\end{array}$ & 1 & 0.00 & 1.08 \\
\hline Nucleus of Darkschewitsch & 2 & 0.60 & 0.27 \\
\hline $\begin{array}{l}\text { Nucleus of the brachium of the infe- } \\
\text { rior colliculus }\end{array}$ & 1 & 0.00 & 1.09 \\
\hline Nucleus of the optic tract & 1 & 0.00 & 0.27 \\
\hline $\begin{array}{l}\text { Nucleus of the posterior commissure } \\
\text { (Continued) }\end{array}$ & 2 & 0.63 & -0.23 \\
\hline
\end{tabular}

Table 4: Continued

\begin{tabular}{lllr}
\hline Brain region & Module & PC & WMDz \\
\hline Olivary pretectal nucleus & 1 & 0.10 & -1.47 \\
Parabigeminal nucleus & 1 & 0.00 & 0.57 \\
Pedunculopontine nucleus & 1 & 0.00 & 0.86 \\
Periaqueductal gray & 1 & 0.00 & -0.01 \\
Posterior pretectal nucleus & 2 & 0.63 & -0.27 \\
Precommissural nucleus & 1 & 0.00 & 0.85 \\
Red nucleus & 1 & 0.04 & -0.18 \\
Substantia nigra compact part & 1 & 0.00 & 0.80 \\
Substantia nigra reticular part & 1 & 0.30 & -1.69 \\
Superior colliculus motor related & 1 & 0.00 & 1.18 \\
Superior colliculus sensory related & 1 & 0.00 & 1.79 \\
Ventral tegmental area & 1 & 0.11 & -1.43 \\
Pons & 1 & 0.14 & -0.54 \\
Pons motor related & 1 & 0.47 & -1.84 \\
Pontine reticular nucleus & 1 & 0.09 & -0.34 \\
Vestibular nuclei & 3 & 0.00 & 1.21 \\
Ansiform lobule & 3 & 0.50 & -0.60 \\
Central lobule & 1 & 0.00 & 0.14 \\
Culmen & 1 & 0.00 & 0.23 \\
Paraflocculus & 2 & 0.64 & 0.22 \\
Simple lobule & 2 & 0.26 & -1.03 \\
\hline
\end{tabular}

intramodular and intermodular connectivity. This suggests that the control brain may be more resilient to the disruption of function because additional hub regions may compensate more easily in response to such disruptions.

In the networks that were associated with withdrawal from psychostimulants, a shift was observed from sensory/motor regions to more subcortical (e.g., amygdalar, thalamic, hypothalamic, and midbrain) regions that drive the network. A similar effect was seen in nonhuman primates after cocaine abstinence (Murnane et al., 2015), and alterations of functional connectivity of the somatosensory cortex are associated with smokers (Claus and Weywadt, 2020). This may represent a shift from topdown cortical network control (Gilbert and Sigman, 2007) to bottom-up subcortical network control and may reflect the greater influence of internal drives that are associated with negative affect during withdrawal in controlling the whole-brain network (Koob, 2015). This shift may be a major reason why drugs are so addictive because higher cortical functional connectivity in humans may protect against relapse (McHugh et al., 2017).

Given the modular organization of the different networks, both the control network and nicotine network had a much higher incidence of intermodular connectivity, whereas the methamphetamine and cocaine networks had only a small subset of brain regions that were connected between different modules. Similar changes in neural activity, combined with decreases in interconnectivity and network efficiency, have been observed in humans after psychostimulant use (Ahmadlou et al., 2013; Wang et al., 2015; Liang et al., 2015). The nicotine network was different from the methamphetamine and cocaine networks and somewhat resembled a slightly altered control network. Similarities and differences in network properties of the three different drugs are likely to be caused by differences in receptor mechanisms and 


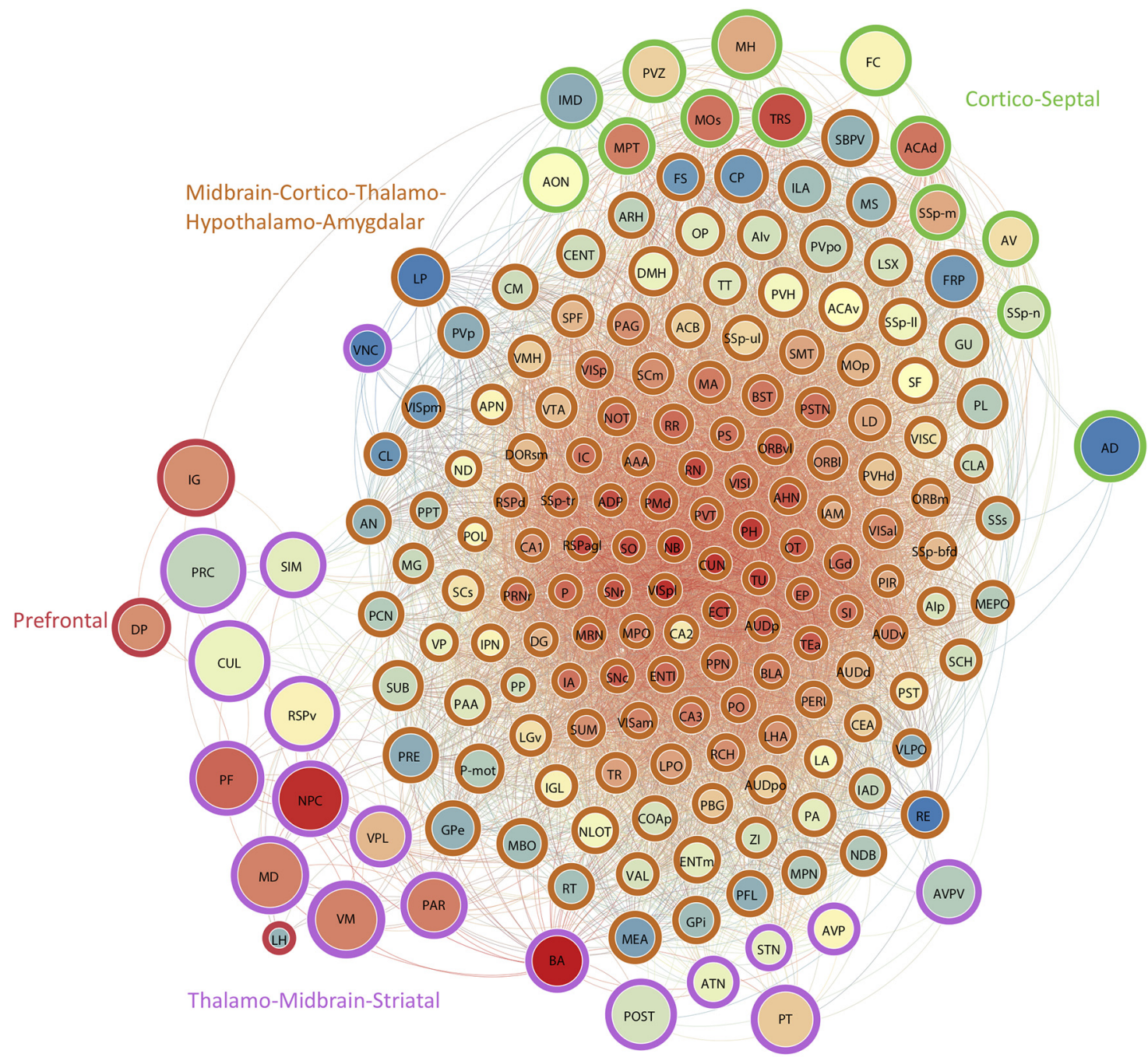

Cocaine Network

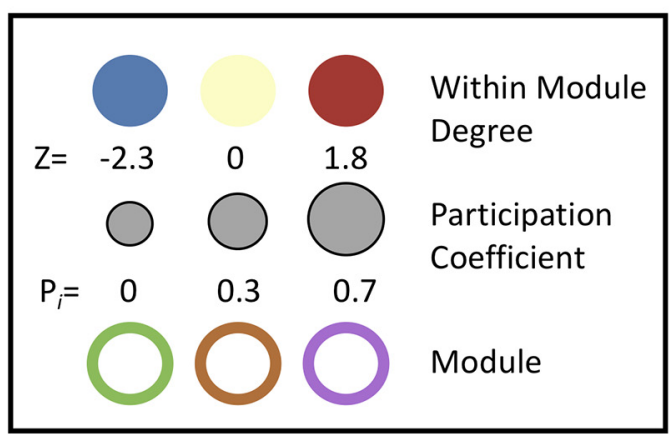

Figure 6. Neural network of cocaine mice during withdrawal thresholded to $0.75 \mathrm{R}$. Nodes/brain regions of the network are represented by circles. The size of the node represents the PC (smaller, lower PC; larger, higher PC). The internal color of each circle represents the WMDz (dark blue, lowest; dark red, highest). The color of the modules that are identified in Figure $1 D$ are represented by different colored edges. See figure key for examples of each representative component of the figure.

locations where each drug acts throughout the brain. Indeed, both cocaine and methamphetamine target the same dopamine transporter, whereas nicotine acts on nicotinic receptors (Rothman and Baumann, 2003; Nestler, 2005; Sulzer et al., 2005; D'Souza and Markou, 2011).
The interanterodorsal nucleus of the thalamus was disconnected from the nicotine network, suggesting that it may not be involved in controlling the withdrawal network, although we cannot exclude the possibility that its disconnection may instead be a critical feature of nicotine 
Table 5: Nicotine network values

\begin{tabular}{|c|c|c|c|}
\hline Region & Module & PC & WMDz \\
\hline Agranular insular area posterior part & 1 & 0.03 & 0.12 \\
\hline Agranular insular area ventral part & 4 & 0.43 & 0.85 \\
\hline Anterior cingulate area dorsal part & 1 & 0.17 & 0.87 \\
\hline Anterior cingulate area ventral part & 1 & 0.22 & 0.94 \\
\hline Anterior olfactory nucleus & 5 & 0.42 & 0.27 \\
\hline Anterolateral visual area & 1 & 0.38 & -0.12 \\
\hline Anteromedial visual area & 2 & 0.57 & 0.97 \\
\hline $\begin{array}{l}\text { Cortical amygdalar area posterior } \\
\text { part }\end{array}$ & 1 & 0.12 & -0.46 \\
\hline Dentate gyrus & 2 & 0.58 & 0.99 \\
\hline Dorsal auditory area & 1 & 0.20 & 0.52 \\
\hline Dorsal peduncular area & 4 & 0.49 & 0.33 \\
\hline Ectorhinal area & 1 & 0.13 & 0.78 \\
\hline Entorhinal area lateral part & 1 & 0.28 & -1.50 \\
\hline Entorhinal area medial part & 4 & 0.57 & -0.12 \\
\hline Fasciola cinerea & 1 & 0.25 & -0.35 \\
\hline Field CA1 & 4 & 0.34 & -0.11 \\
\hline Field CA2 & 4 & 0.36 & 0.33 \\
\hline Field CA3 & 4 & 0.44 & 0.80 \\
\hline Frontal pole cerebral cortex & 5 & 0.49 & -2.12 \\
\hline Gustatory areas & 1 & 0.44 & -0.40 \\
\hline Induseum griseum & 3 & 0.47 & -1.01 \\
\hline Infralimbic area & 4 & 0.42 & 0.66 \\
\hline Lateral visual area & 1 & 0.38 & 0.27 \\
\hline Nucleus of the lateral olfactory tract & 4 & 0.41 & -1.16 \\
\hline Orbital area lateral part & 5 & 0.44 & 0.67 \\
\hline Orbital area medial part & 4 & 0.48 & -2.31 \\
\hline Orbital area ventrolateral part & 5 & 0.46 & 0.66 \\
\hline Parasubiculum & 4 & 0.59 & 0.18 \\
\hline Perirhinal area & 1 & 0.13 & 1.02 \\
\hline Piriform area & 1 & 0.00 & 0.11 \\
\hline Piriform-amygdalar area & 1 & 0.11 & -2.62 \\
\hline Posterior auditory area & 1 & 0.12 & 0.95 \\
\hline Posterolateral visual area & 2 & 0.55 & 0.98 \\
\hline Posteromedial visual area & 1 & 0.38 & -0.12 \\
\hline Postpiriform transition area & 1 & 0.10 & 0.58 \\
\hline Postsubiculum & 1 & 0.34 & 0.58 \\
\hline Prelimbic area & 1 & 0.16 & -1.81 \\
\hline Presubiculum & 1 & 0.27 & 0.69 \\
\hline Primary auditory area & 1 & 0.07 & 0.85 \\
\hline Primary motor area & 4 & 0.43 & 0.82 \\
\hline $\begin{array}{l}\text { Primary somatosensory area barrel } \\
\text { field }\end{array}$ & 5 & 0.43 & 0.58 \\
\hline $\begin{array}{l}\text { Primary somatosensory area lower } \\
\text { limb }\end{array}$ & 4 & 0.44 & 1.12 \\
\hline Primary somatosensory area mouth & 4 & 0.61 & -0.75 \\
\hline Primary somatosensory area nose & 4 & 0.54 & 0.67 \\
\hline Primary somatosensory area trunk & 4 & 0.48 & 0.70 \\
\hline $\begin{array}{l}\text { Primary somatosensory area upper } \\
\text { limb }\end{array}$ & 4 & 0.44 & 0.26 \\
\hline Primary visual area & 4 & 0.50 & 0.56 \\
\hline Retrosplenial area dorsal part & 1 & 0.26 & 0.30 \\
\hline $\begin{array}{l}\text { Retrosplenial area lateral agranular } \\
\text { part }\end{array}$ & 1 & 0.21 & 0.67 \\
\hline Retrosplenial area ventral part & 1 & 0.20 & 0.41 \\
\hline Secondary motor area & 4 & 0.55 & 0.27 \\
\hline Subiculum & 2 & 0.66 & 0.97 \\
\hline Supplemental somatosensory area & 1 & 0.22 & 0.73 \\
\hline Taenia tecta & 4 & 0.53 & 0.65 \\
\hline Temporal association areas & 1 & 0.14 & 0.93 \\
\hline Ventral auditory area & 1 & 0.09 & 0.85 \\
\hline Visceral area & 1 & 0.09 & 0.90 \\
\hline
\end{tabular}

Table 5: Continued

\begin{tabular}{|c|c|c|c|}
\hline Region & Module & $\mathrm{PC}$ & $\overline{W M D z}$ \\
\hline Basolateral amygdalar nucleus & $\overline{1}$ & 0.25 & $\overline{0.71}$ \\
\hline Claustrum & 1 & 0.18 & 1.06 \\
\hline Endopiriform nucleus & 1 & 0.10 & -0.96 \\
\hline Lateral amygdalar nucleus & 1 & 0.24 & 0.36 \\
\hline Posterior amygdalar nucleus & 4 & 0.35 & 0.54 \\
\hline Anterior amygdalar area & 4 & 0.52 & 0.86 \\
\hline $\begin{array}{l}\text { Bed nucleus of the accessory olfac- } \\
\text { tory tract }\end{array}$ & 5 & 0.13 & -0.68 \\
\hline Caudoputamen & 2 & 0.61 & -0.17 \\
\hline Central amygdalar nucleus & 1 & 0.36 & -0.01 \\
\hline Fundus of striatum & 2 & 0.59 & 0.47 \\
\hline Intercalated amygdalar nucleus & 1 & 0.29 & 0.46 \\
\hline Lateral septal complex & 1 & 0.22 & -1.88 \\
\hline Medial amygdalar nucleus & 5 & 0.49 & 0.64 \\
\hline Nucleus accumbens & 4 & 0.39 & 0.70 \\
\hline Olfactory tubercle & 4 & 0.39 & -2.16 \\
\hline Septofimbrial nucleus & 1 & 0.16 & -0.31 \\
\hline Bed nuclei of the stria terminalis & 5 & 0.49 & 0.65 \\
\hline Diagonal band nucleus & 5 & 0.44 & -0.33 \\
\hline Globus pallidus external segment & 4 & 0.49 & -2.31 \\
\hline Globus pallidus internal segment & 4 & 0.45 & 0.27 \\
\hline Magnocellular nucleus & 4 & 0.41 & 0.43 \\
\hline Medial septal nucleus & 2 & 0.66 & 0.48 \\
\hline Substantia innominata & 5 & 0.46 & 0.14 \\
\hline Triangular nucleus of septum & 3 & 0.49 & 0.28 \\
\hline Anterior group of the dorsal thalamus & 4 & 0.60 & -1.42 \\
\hline Anterodorsal nucleus & 3 & 0.53 & -1.16 \\
\hline Anteroventral nucleus of thalamus & 1 & 0.53 & -2.45 \\
\hline $\begin{array}{l}\text { Central lateral nucleus of the } \\
\text { thalamus }\end{array}$ & 2 & 0.67 & -1.12 \\
\hline $\begin{array}{l}\text { Central medial nucleus of the } \\
\text { thalamus }\end{array}$ & 1 & 0.17 & 0.09 \\
\hline $\begin{array}{l}\text { Dorsal part of the lateral geniculate } \\
\text { complex }\end{array}$ & 4 & 0.00 & -2.07 \\
\hline $\begin{array}{l}\text { Interanteromedial nucleus of the } \\
\text { thalamus }\end{array}$ & 1 & 0.27 & -2.07 \\
\hline $\begin{array}{l}\text { Intergeniculate leaflet of the lateral } \\
\text { geniculate complex }\end{array}$ & 3 & 0.50 & 1.16 \\
\hline $\begin{array}{l}\text { Intermediodorsal nucleus of the } \\
\text { thalamus }\end{array}$ & 1 & 0.12 & -0.71 \\
\hline Lateral dorsal nucleus of thalamus & 5 & 0.47 & 0.64 \\
\hline Lateral habenula & 3 & 0.47 & 0.75 \\
\hline $\begin{array}{l}\text { Lateral posterior nucleus of the } \\
\text { thalamus }\end{array}$ & 5 & 0.44 & -2.94 \\
\hline Medial geniculate complex & 1 & 0.22 & 0.81 \\
\hline Medial habenula & 3 & 0.38 & 1.19 \\
\hline Mediodorsal nucleus of thalamus & 1 & 0.23 & 0.03 \\
\hline Nucleus of reuniens & 2 & 0.67 & 0.86 \\
\hline Paracentral nucleus & 4 & 0.58 & 0.66 \\
\hline Parafascicular nucleus & 2 & 0.68 & -0.14 \\
\hline Parataenial nucleus & 3 & 0.40 & -0.61 \\
\hline $\begin{array}{l}\text { Paraventricular nucleus of the } \\
\text { thalamus }\end{array}$ & 3 & 0.46 & -1.06 \\
\hline Peripeduncular nucleus & 1 & 0.41 & -1.81 \\
\hline Posterior complex of the thalamus & 5 & 0.45 & 0.26 \\
\hline $\begin{array}{l}\text { Posterior limiting nucleus of the } \\
\text { thalamus }\end{array}$ & 1 & 0.21 & -0.13 \\
\hline Reticular nucleus of the thalamus & 4 & 0.25 & -0.76 \\
\hline Submedial nucleus of the thalamus & 4 & 0.45 & 0.72 \\
\hline Subparafascicular nucleus & 1 & 0.25 & 0.99 \\
\hline Thalamus sensory-motor cortex & 1 & 0.20 & -0.83 \\
\hline
\end{tabular}
related

(Continued) 
Table 5: Continued

\begin{tabular}{|c|c|c|c|}
\hline Region & Module & $\mathrm{PC}$ & WMDz \\
\hline $\begin{array}{l}\text { Ventral anterior-lateral complex of } \\
\text { the thalamus }\end{array}$ & 5 & 0.46 & 0.27 \\
\hline $\begin{array}{l}\text { Ventral medial nucleus of the } \\
\text { thalamus }\end{array}$ & 4 & 0.45 & 0.06 \\
\hline $\begin{array}{l}\text { Ventral part of the lateral geniculate } \\
\text { complex }\end{array}$ & 1 & 0.21 & 0.44 \\
\hline $\begin{array}{l}\text { Ventral posterior complex of the } \\
\text { thalamus }\end{array}$ & 5 & 0.48 & 0.26 \\
\hline $\begin{array}{l}\text { Ventral posterolateral nucleus of the } \\
\text { thalamus }\end{array}$ & 1 & 0.12 & -2.84 \\
\hline Anterior hypothalamic nucleus & 5 & 0.44 & 0.51 \\
\hline Anterodorsal preoptic nucleus & 4 & 0.40 & 0.58 \\
\hline Anteroventral periventricular nucleus & 4 & 0.38 & -0.22 \\
\hline Anteroventral preoptic nucleus & 4 & 0.30 & 0.05 \\
\hline Arcuate hypothalamic nucleus & 2 & 0.49 & -0.42 \\
\hline Dorsal premammillary nucleus & 2 & 0.64 & 0.50 \\
\hline $\begin{array}{l}\text { Dorsomedial nucleus of the } \\
\text { hypothalamus }\end{array}$ & 2 & 0.61 & 0.75 \\
\hline Lateral hypothalamic area & 4 & 0.44 & -0.06 \\
\hline Lateral preoptic area & 4 & 0.40 & 0.85 \\
\hline Mammillary body & 1 & 0.39 & -0.30 \\
\hline Medial preoptic area & 4 & 0.40 & 0.81 \\
\hline Medial preoptic nucleus & 5 & 0.45 & 0.50 \\
\hline Median preoptic nucleus & 4 & 0.29 & -1.51 \\
\hline Parastrial nucleus & 4 & 0.45 & 1.11 \\
\hline Parasubthalamic nucleus & 2 & 0.42 & -0.99 \\
\hline $\begin{array}{l}\text { Paraventricular hypothalamic } \\
\text { nucleus }\end{array}$ & 1 & 0.22 & 0.88 \\
\hline $\begin{array}{l}\text { Paraventricular hypothalamic nucleus } \\
\text { descending division }\end{array}$ & 2 & 0.65 & 0.72 \\
\hline $\begin{array}{l}\text { Periventricular hypothalamic nucleus } \\
\text { posterior part }\end{array}$ & 1 & 0.34 & 0.21 \\
\hline $\begin{array}{l}\text { Periventricular hypothalamic nucleus } \\
\text { preoptic part }\end{array}$ & 4 & 0.21 & -0.74 \\
\hline Periventricular zone & 1 & 0.35 & -0.50 \\
\hline Posterior hypothalamic nucleus & 1 & 0.28 & 0.76 \\
\hline Preparasubthalamic nucleus & 4 & 0.45 & -2.20 \\
\hline Retrochiasmatic area & 4 & 0.45 & 0.98 \\
\hline Subparaventricular zone & 4 & 0.48 & 0.07 \\
\hline Subthalamic nucleus & 4 & 0.59 & 0.58 \\
\hline Suprachiasmatic nucleus & 2 & 0.61 & -2.32 \\
\hline Supramammillary nucleus & 1 & 0.37 & 0.05 \\
\hline Supraoptic nucleus & 4 & 0.45 & -2.10 \\
\hline Tuberal nucleus & 4 & 0.49 & 0.64 \\
\hline Ventrolateral preoptic nucleus & 1 & 0.22 & -2.82 \\
\hline Ventromedial hypothalamic nucleus & 4 & 0.49 & 0.77 \\
\hline Zona incerta & 4 & 0.50 & 0.85 \\
\hline Anterior pretectal nucleus & 2 & 0.68 & -0.63 \\
\hline Cuneiform nucleus & 4 & 0.40 & 0.44 \\
\hline Inferior colliculus & 1 & 0.19 & 0.38 \\
\hline Interpeduncular nucleus & 1 & 0.26 & 0.06 \\
\hline Medial pretectal area & 1 & 0.33 & -1.59 \\
\hline Midbrain reticular nucleus & 1 & 0.37 & 0.26 \\
\hline $\begin{array}{l}\text { Midbrain reticular nucleus retrorubral } \\
\text { area }\end{array}$ & 1 & 0.26 & -0.19 \\
\hline Nucleus of Darkschewitsch & 2 & 0.69 & -2.09 \\
\hline $\begin{array}{l}\text { Nucleus of the brachium of the infe- } \\
\text { rior colliculus }\end{array}$ & 1 & 0.22 & 0.26 \\
\hline Nucleus of the optic tract & 3 & 0.40 & 0.67 \\
\hline Nucleus of the posterior commissure & 3 & 0.49 & 0.20 \\
\hline Olivary pretectal nucleus & 3 & 0.44 & 0.33 \\
\hline \multicolumn{4}{|c|}{ (Continued) } \\
\hline
\end{tabular}

Table 5: Continued

\begin{tabular}{lllr}
\hline Region & Module & PC & WMDz \\
\hline Pedunculopontine nucleus & 1 & 0.21 & 1.08 \\
Periaqueductal gray & 1 & 0.15 & 0.78 \\
Posterior pretectal nucleus & 3 & 0.66 & -2.16 \\
Precommissural nucleus & 3 & 0.46 & 1.21 \\
Red nucleus & 1 & 0.17 & 0.68 \\
Substantia nigra compact part & 2 & 0.64 & 0.19 \\
Substantia nigra reticular part & 4 & 0.62 & -0.15 \\
Superior colliculus motor related & 1 & 0.36 & 0.45 \\
Superior colliculus sensory related & 1 & 0.25 & 0.64 \\
Ventral tegmental area & 1 & 0.37 & -0.33 \\
Pons & 1 & 0.18 & 1.06 \\
Pons motor related & 1 & 0.26 & 0.75 \\
Pontine reticular nucleus & 1 & 0.23 & 0.82 \\
Vestibular nuclei & 1 & 0.47 & -1.51 \\
Ansiform lobule & 1 & 0.25 & 0.84 \\
Central lobule & 1 & 0.20 & 0.76 \\
Culmen & 1 & 0.19 & 0.40 \\
Paraflocculus & 1 & 0.27 & -0.03 \\
Simple lobule & 1 & 0.36 & -0.48 \\
\hline
\end{tabular}

withdrawal. One of the larger modules in the nicotine network was driven by several brain regions, two of which included the AAA and Alv, which have been suggested to be associated with nicotine withdrawal in humans (Naqvi et al., 2007; Sutherland et al., 2013). The methamphetamine and cocaine networks, although having distinctly different features, shared an overall motif of lower modularity and being heavily driven by thalamic brain regions. This suggests that, in a destabilized and less structured neural network, the thalamus becomes more critical to controlling the whole-brain network. The thalamus is thought to play a major role in relaying information, and the reliance of these networks on this group of regions suggests that the thalamus is not simply a relay station but has greater importance in cognitive and emotional function (Sherman, 2007; Ahissar and Oram, 2015). Substantial evidence corroborates the importance of the thalamus in psychostimulant addiction and withdrawal. In a rat model of cocaine self-administration, the thalamus was found to be heavily involved in network function during acute abstinence, but changes in the network disappeared after two weeks (Orsini et al., 2018). Interestingly, the thalamus in humans has been shown to be hypoactive in cocaine abusers (Tomasi et al., 2007), and thalamic connectivity is predictive of cocaine dependence (Zhang et al., 2016) and altered in infants who are exposed to cocaine (Salzwedel et al., 2016). Although network changes that are induced by acute withdrawal are reversed over time (Orsini et al., 2018), prolonged use may lead to more permanent restructuring of the brain, and major differences between the nicotine and methamphetamine/cocaine networks may account for differences in the severity of each drug after long-term use (Nestler, 2005; Grant et al., 2012; Spronk et al., 2013).

In conclusion, in the past 40 years, the substance use disorder field has made tremendous progress by identifying numerous brain regions that are dysregulated after psychostimulant exposure and contribute to withdrawal behaviors (Kalivas and McFarland, 2003; Robinson and 
Table 6: Top to bottom order of brain regions in Figure 1

\begin{tabular}{|c|c|c|}
\hline Number & Saline hierarchical order & Cocaine hierarchical order \\
\hline$\overline{1}$ & Retrosplenial area ventral part & Inferior colliculus \\
\hline 2 & Interanterodorsal nucleus of the thalamus & Primary visual area \\
\hline 3 & Anterior hypothalamic nucleus & Nucleus of the optic tract \\
\hline 4 & Posterolateral visual area & Thalamus sensory-motor cortex related \\
\hline 5 & Precommissural nucleus & Retrosplenial area dorsal part \\
\hline 6 & Superior colliculus motor related & Field CA1 \\
\hline 7 & Cuneiform nucleus & Retrosplenial area lateral agranular part \\
\hline 8 & Primary visual area & Anterior amygdalar area \\
\hline 9 & Superior colliculus sensory related & Anterodorsal preoptic nucleus \\
\hline 10 & Parasubthalamic nucleus & Primary somatosensory area trunk \\
\hline 11 & Vestibular nuclei & Interanteromedial nucleus of the thalamus \\
\hline 12 & Pons motor related & Subparafascicular nucleus \\
\hline 13 & Lateral visual area & Superior colliculus motor related \\
\hline 14 & Anterolateral visual area & Periaqueductal gray \\
\hline 15 & Pontine reticular nucleus & Magnocellular nucleus \\
\hline 16 & Periaqueductal gray & Bed nuclei of the stria terminalis \\
\hline 17 & Parastrial nucleus & Midbrain reticular nucleus retrorubral area \\
\hline 18 & Fasciola cinerea & Ventromedial hypothalamic nucleus \\
\hline 19 & Anterodorsal nucleus & Ventral tegmental area \\
\hline 20 & Triangular nucleus of septum & Anterior pretectal nucleus \\
\hline 21 & Lateral hypothalamic area & Endopiriform nucleus \\
\hline 22 & Dorsomedial nucleus of the hypothalamus & Olfactory tubercle \\
\hline 23 & Nucleus accumbens & Tuberal nucleus \\
\hline 24 & Anterior group of the dorsal thalamus & Piriform area \\
\hline 25 & Paraventricular hypothalamic nucleus descending division & Substantia innominata \\
\hline 26 & Medial pretectal area & Ventral auditory area \\
\hline 27 & Postsubiculum & Dorsal part of the lateral geniculate complex \\
\hline 28 & Parasubiculum & Posterolateral visual area \\
\hline 29 & Nucleus of the optic tract & Nucleus of the brachium of the inferior colliculus \\
\hline 30 & Midbrain reticular nucleus retrorubral area & Supraoptic nucleus \\
\hline 31 & Inferior colliculus & Cuneiform nucleus \\
\hline 32 & Anterior pretectal nucleus & Paraventricular nucleus of the thalamus \\
\hline 33 & Nucleus of Darkschewitsch & Lateral visual area \\
\hline 34 & Field CA1 & Orbital area ventrolateral part \\
\hline 35 & Nucleus of the posterior commissure & Red nucleus \\
\hline 36 & Fundus of striatum & Parastrial nucleus \\
\hline 37 & Dentate gyrus & Parasubthalamic nucleus \\
\hline 38 & Presubiculum & Anterior hypothalamic nucleus \\
\hline 39 & Lateral posterior nucleus of the thalamus & Posterior hypothalamic nucleus \\
\hline 40 & Parafascicular nucleus & Dorsal premammillary nucleus \\
\hline 41 & Peripeduncular nucleus & Lateral hypothalamic area \\
\hline 42 & Central lobule & Retrochiasmatic area \\
\hline 43 & Posterior pretectal nucleus & Perirhinal area \\
\hline 44 & Lateral habenula & Field CA3 \\
\hline 45 & Nucleus of reuniens & Posterior complex of the thalamus \\
\hline 46 & Ventral medial nucleus of the thalamus & Entorhinal area lateral part \\
\hline 47 & Tuberal nucleus & Intercalated amygdalar nucleus \\
\hline 48 & Periventricular hypothalamic nucleus posterior part & Substantia nigra compact part \\
\hline 49 & Posterior amygdalar nucleus & Basolateral amygdalar nucleus \\
\hline 50 & Ventromedial hypothalamic nucleus & Pedunculopontine nucleus \\
\hline 51 & Posterior hypothalamic nucleus & Medial preoptic area \\
\hline 52 & Arcuate hypothalamic nucleus & Ectorhinal area \\
\hline 53 & Subthalamic nucleus & Primary auditory area \\
\hline 54 & Paracentral nucleus & Temporal association areas \\
\hline 55 & Substantia nigra compact part & Pontine reticular nucleus \\
\hline 56 & Culmen & Substantia nigra reticular part \\
\hline 57 & Pedunculopontine nucleus & Pons \\
\hline 58 & Interpeduncular nucleus & Midbrain reticular nucleus \\
\hline 59 & Ventral posterior complex of the thalamus & Field CA2 \\
\hline 60 & Induseum griseum & Supramammillary nucleus \\
\hline 61 & Preparasubthalamic nucleus & Anteromedial visual area \\
\hline \multirow[t]{2}{*}{62} & Nucleus of the brachium of the inferior colliculus & Posterior auditory area \\
\hline & (Continued) & \\
\hline
\end{tabular}


Table 6: Continued

\begin{tabular}{|c|c|c|}
\hline Number & Saline hierarchical order & Cocaine hierarchical order \\
\hline$\overline{63}$ & Red nucleus & Visceral area \\
\hline 64 & Ventral tegmental area & Primary motor area \\
\hline 65 & Substantia innominata & Paraventricular hypothalamic nucleus descending division \\
\hline 66 & Medial geniculate complex & Lateral dorsal nucleus of thalamus \\
\hline 67 & Subiculum & Primary somatosensory area barrel field \\
\hline 68 & Midbrain reticular nucleus & Orbital area medial part \\
\hline 69 & Thalamus sensory-motor cortex related & Orbital area lateral part \\
\hline 70 & Simple lobule & Anterolateral visual area \\
\hline 71 & Paraflocculus & Median preoptic nucleus \\
\hline 72 & Submedial nucleus of the thalamus & Suprachiasmatic nucleus \\
\hline 73 & Subparafascicular nucleus & Supplemental somatosensory area \\
\hline 74 & Olivary pretectal nucleus & Agranular insular area posterior part \\
\hline 75 & Central lateral nucleus of the thalamus & Primary somatosensory area lower limb \\
\hline 76 & Medial septal nucleus & Septofimbrial nucleus \\
\hline 77 & Subparaventricular zone & Anterior cingulate area ventral part \\
\hline 78 & Anterior cingulate area ventral part & Paraventricular hypothalamic nucleus \\
\hline 79 & Secondary motor area & Primary somatosensory area upper limb \\
\hline 80 & Suprachiasmatic nucleus & Submedial nucleus of the thalamus \\
\hline 81 & Periventricular zone & Nucleus accumbens \\
\hline 82 & Septofimbrial nucleus & Claustrum \\
\hline 83 & Paraventricular hypothalamic nucleus & Agranular insular area ventral part \\
\hline 84 & Orbital area lateral part & Lateral septal complex \\
\hline 85 & Mediodorsal nucleus of thalamus & Taenia tecta \\
\hline 86 & Posteromedial visual area & Arcuate hypothalamic nucleus \\
\hline 87 & Retrosplenial area dorsal part & Olivary pretectal nucleus \\
\hline 88 & Anteroventral periventricular nucleus & Dorsomedial nucleus of the hypothalamus \\
\hline 89 & Bed nuclei of the stria terminalis & Prelimbic area \\
\hline 90 & Retrosplenial area lateral agranular part & Periventricular hypothalamic nucleus preoptic part \\
\hline 91 & Medial preoptic nucleus & Gustatory areas \\
\hline 92 & Anterodorsal preoptic nucleus & Frontal pole cerebral cortex \\
\hline 93 & Primary motor area & Subparaventricular zone \\
\hline 94 & Lateral septal complex & Caudoputamen \\
\hline 95 & Primary somatosensory area lower limb & Fundus of striatum \\
\hline 96 & Lateral dorsal nucleus of thalamus & Infralimbic area \\
\hline 97 & Primary somatosensory area trunk & Medial septal nucleus \\
\hline 98 & Anteromedial visual area & Central lateral nucleus of the thalamus \\
\hline 99 & Lateral preoptic area & Posteromedial visual area \\
\hline 100 & Periventricular hypothalamic nucleus preoptic part & Lateral posterior nucleus of the thalamus \\
\hline 101 & Median preoptic nucleus & Central lobule \\
\hline 102 & Infralimbic area & Central medial nucleus of the thalamus \\
\hline 103 & Primary somatosensory area upper limb & Periventricular hypothalamic nucleus posterior part \\
\hline 104 & Supramammillary nucleus & Cortical amygdalar area posterior part \\
\hline 105 & Gustatory areas & Nucleus of the lateral olfactory tract \\
\hline 106 & Taenia tecta & Entorhinal area medial part \\
\hline 107 & Supraoptic nucleus & Zona incerta \\
\hline 108 & Claustrum & Ventral anterior-lateral complex of the thalamus \\
\hline 109 & Anteroventral nucleus of thalamus & Posterior amygdalar nucleus \\
\hline 110 & Prelimbic area & Postpiriform transition area \\
\hline 111 & Piriform area & Lateral preoptic area \\
\hline 112 & Agranular insular area ventral part & Parabigeminal nucleus \\
\hline 113 & Dorsal peduncular area & Intergeniculate leaflet of the lateral geniculate complex \\
\hline 114 & Anterior cingulate area dorsal part & Ventral part of the lateral geniculate complex \\
\hline 115 & Orbital area medial part & Interanterodorsal nucleus of the thalamus \\
\hline 116 & Orbital area ventrolateral part & Lateral amygdalar nucleus \\
\hline 117 & Anterior amygdalar area & Ventrolateral preoptic nucleus \\
\hline 118 & Caudoputamen & Central amygdalar nucleus \\
\hline 119 & Primary somatosensory area barrel field & Dorsal auditory area \\
\hline 120 & Agranular insular area posterior part & Preparasubthalamic nucleus \\
\hline 121 & Paraventricular nucleus of the thalamus & Ventral posterior complex of the thalamus \\
\hline 122 & Medial habenula & Interpeduncular nucleus \\
\hline 123 & Frontal pole cerebral cortex & Peripeduncular nucleus \\
\hline 124 & Anterior olfactory nucleus & Dentate gyrus \\
\hline \multicolumn{3}{|c|}{ (Continued) } \\
\hline
\end{tabular}


Table 6: Continued

\begin{tabular}{|c|c|c|}
\hline Number & Saline hierarchical order & Cocaine hierarchical order \\
\hline 125 & Central medial nucleus of the thalamus & Superior colliculus sensory related \\
\hline 127 & Medial preoptic area & Medial geniculate complex \\
\hline 129 & Supplemental somatosensory area & Nucleus of Darkschewitsch \\
\hline 130 & Primary somatosensory area nose & Posterior limiting nucleus of the thalamus \\
\hline 131 & Primary somatosensory area mouth & Paracentral nucleus \\
\hline 134 & Entorhinal area lateral part & Diagonal band nucleus \\
\hline 135 & Field CA2 & Medial preoptic nucleus \\
\hline 136 & Mammillary body & Paraflocculus \\
\hline 137 & Posterior auditory area & Medial amygdalar nucleus \\
\hline 138 & Ventral auditory area & Globus pallidus internal segment \\
\hline 139 & Temporal association areas & Nucleus of reuniens \\
\hline 144 & Perirhinal area & Pons motor related \\
\hline 145 & Reticular nucleus of the thalamus & Mediodorsal nucleus of thalamus \\
\hline 146 & Ectorhinal area & Ventral medial nucleus of the thalamus \\
\hline 147 & Posterior complex of the thalamus & Retrosplenial area ventral part \\
\hline 148 & Ventral anterior-lateral complex of the thalamus & Nucleus of the posterior commissure \\
\hline 149 & Dorsal part of the lateral geniculate complex & Parafascicular nucleus \\
\hline 150 & Primary auditory area & Culmen \\
\hline 151 & Postpiriform transition area & Simple lobule \\
\hline 152 & Magnocellular nucleus & Precommissural nucleus \\
\hline 153 & Globus pallidus internal segment & Vestibular nuclei \\
\hline 154 & Lateral amygdalar nucleus & Parasubiculum \\
\hline 155 & Nucleus of the lateral olfactory tract & Ventral posterolateral nucleus of the thalamus \\
\hline 156 & Bed nucleus of the accessory olfactory tract & Bed nucleus of the accessory olfactory tract \\
\hline 165 & Medial amygdalar nucleus & Triangular nucleus of septum \\
\hline 166 & Parataenial nucleus & Primary somatosensory area mouth \\
\hline 167 & Interanteromedial nucleus of the thalamus & Medial pretectal area \\
\hline 168 & Piriform-amygdalar area & Anterior olfactory nucleus \\
\hline 169 & Diagonal band nucleus & Primary somatosensory area nose \\
\hline 170 & Ventrolateral preoptic nucleus & Anteroventral nucleus of thalamus \\
\hline 171 & Anteroventral preoptic nucleus & Periventricular zone \\
\hline 172 & Cortical amygdalar area posterior part & Intermediodorsal nucleus of the thalamus \\
\hline 173 & Globus pallidus external segment & Medial habenula \\
\hline 174 & Posterior limiting nucleus of the thalamus & Anterodorsal nucleus \\
\hline 175 & Endopiriform nucleus & Fasciola cinerea \\
\hline 176 & Olfactory tubercle & Dorsal peduncular area \\
\hline 177 & Central amygdalar nucleus & Induseum griseum \\
\hline 178 & Basolateral amygdalar nucleus & Lateral habenula \\
\hline Number & Methamphetamine hierarchical order & Nicotine hierarchical order \\
\hline 1 & Caudoputamen & Ventral tegmental area \\
\hline 2 & Anterior amygdalar area & Midbrain reticular nucleus retrorubral area \\
\hline 3 & Parataenial nucleus & Superior colliculus motor related \\
\hline 4 & Periventricular hypothalamic nucleus preoptic part & Midbrain reticular nucleus \\
\hline 5 & Claustrum & Simple lobule \\
\hline 6 & Medial habenula & Posterior hypothalamic nucleus \\
\hline \multirow[t]{2}{*}{7} & Medial pretectal area & Basolateral amygdalar nucleus \\
\hline & (Continued) & \\
\hline
\end{tabular}


Table 6: Continued

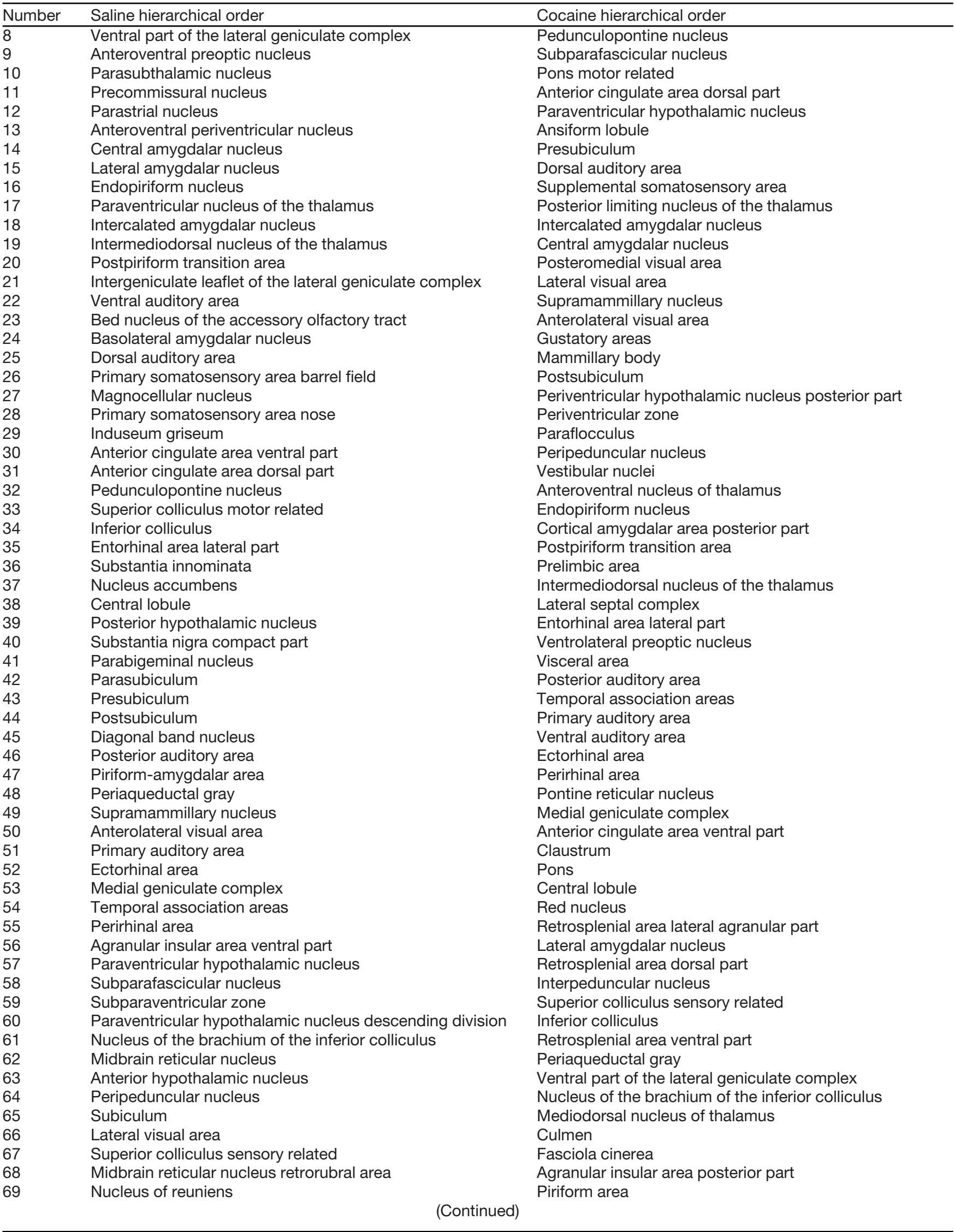


Table 6: Continued

\begin{tabular}{|c|c|c|}
\hline Number & Saline hierarchical order & Cocaine hierarchical order \\
\hline$\overline{70}$ & Zona incerta & Central medial nucleus of the thalamus \\
\hline 71 & Culmen & Interanteromedial nucleus of the thalamus \\
\hline 72 & Retrosplenial area lateral agranular part & Medial pretectal area \\
\hline 73 & Lateral preoptic area & Thalamus sensory-motor cortex related \\
\hline 74 & Anterior pretectal nucleus & Septofimbrial nucleus \\
\hline 75 & Posterior limiting nucleus of the thalamus & Ventral posterolateral nucleus of the thalamus \\
\hline 76 & Preparasubthalamic nucleus & Piriform-amygdalar area \\
\hline 77 & Nucleus of the optic tract & Dorsomedial nucleus of the hypothalamus \\
\hline 78 & Medial preoptic area & Dentate gyrus \\
\hline 79 & Thalamus sensory-motor cortex related & Anteromedial visual area \\
\hline 80 & Medial preoptic nucleus & Posterolateral visual area \\
\hline 81 & Dorsomedial nucleus of the hypothalamus & Fundus of striatum \\
\hline 82 & Red nucleus & Caudoputamen \\
\hline 83 & Lateral septal complex & Arcuate hypothalamic nucleus \\
\hline 84 & Central medial nucleus of the thalamus & Parasubthalamic nucleus \\
\hline 85 & Interpeduncular nucleus & Suprachiasmatic nucleus \\
\hline 86 & Reticular nucleus of the thalamus & Subiculum \\
\hline 87 & Medial septal nucleus & Medial septal nucleus \\
\hline 88 & Supraoptic nucleus & Nucleus of reuniens \\
\hline 89 & Periventricular hypothalamic nucleus posterior part & Substantia nigra compact part \\
\hline 90 & Interanteromedial nucleus of the thalamus & Dorsal premammillary nucleus \\
\hline 91 & Secondary motor area & Paraventricular hypothalamic nucleus descending division \\
\hline 92 & Field CA2 & Central lateral nucleus of the thalamus \\
\hline 93 & Field CA3 & Nucleus of Darkschewitsch \\
\hline 94 & Posteromedial visual area & Anterior pretectal nucleus \\
\hline 95 & Primary motor area & Parafascicular nucleus \\
\hline 96 & Anteromedial visual area & Intergeniculate leaflet of the lateral geniculate complex \\
\hline 97 & Medial amygdalar nucleus & Precommissural nucleus \\
\hline 98 & Piriform area & Lateral habenula \\
\hline 99 & Posterior amygdalar nucleus & Medial habenula \\
\hline 100 & Primary somatosensory area trunk & Parabigeminal nucleus \\
\hline 101 & Nucleus of the lateral olfactory tract & Nucleus of the optic tract \\
\hline 102 & Primary somatosensory area upper limb & Nucleus of the posterior commissure \\
\hline 103 & Primary somatosensory area lower limb & Olivary pretectal nucleus \\
\hline 104 & Cortical amygdalar area posterior part & Anterodorsal nucleus \\
\hline 105 & Visceral area & Posterior pretectal nucleus \\
\hline 106 & Agranular insular area posterior part & Parataenial nucleus \\
\hline 107 & Gustatory areas & Induseum griseum \\
\hline 108 & Supplemental somatosensory area & Triangular nucleus of septum \\
\hline 109 & Primary somatosensory area mouth & Paraventricular nucleus of the thalamus \\
\hline 110 & Anterior olfactory nucleus & Interanterodorsal nucleus of the thalamus \\
\hline 111 & Interanterodorsal nucleus of the thalamus & Medial preoptic area \\
\hline 112 & Globus pallidus external segment & Lateral preoptic area \\
\hline 113 & Anterodorsal preoptic nucleus & Nucleus accumbens \\
\hline 114 & Mediodorsal nucleus of thalamus & Ventral medial nucleus of the thalamus \\
\hline 115 & Ventral posterolateral nucleus of the thalamus & Globus pallidus internal segment \\
\hline 116 & Median preoptic nucleus & Lateral hypothalamic area \\
\hline 117 & Orbital area medial part & Anteroventral periventricular nucleus \\
\hline 118 & Infralimbic area & Magnocellular nucleus \\
\hline 119 & Prelimbic area & Dorsal peduncular area \\
\hline 120 & Taenia tecta & Primary motor area \\
\hline 121 & Fundus of striatum & Primary somatosensory area upper limb \\
\hline 122 & Lateral habenula & Nucleus of the lateral olfactory tract \\
\hline 123 & Olivary pretectal nucleus & Median preoptic nucleus \\
\hline 124 & Entorhinal area medial part & Anterodorsal preoptic nucleus \\
\hline 125 & Periventricular zone & Primary somatosensory area lower limb \\
\hline 126 & Pons & Zona incerta \\
\hline 127 & Dorsal premammillary nucleus & Agranular insular area ventral part \\
\hline 128 & Pontine reticular nucleus & Field CA3 \\
\hline 129 & Substantia nigra reticular part & Ventromedial hypothalamic nucleus \\
\hline 130 & Lateral hypothalamic area & Parastrial nucleus \\
\hline \multirow[t]{2}{*}{131} & Ventral tegmental area & Primary visual area \\
\hline & & \\
\hline
\end{tabular}


Table 6: Continued

\begin{tabular}{|c|c|c|}
\hline Number & Saline hierarchical order & Cocaine hierarchical order \\
\hline$\overline{132}$ & Dentate gyrus & Taenia tecta \\
\hline 134 & Subthalamic nucleus & Field CA2 \\
\hline 136 & Posterolateral visual area & Retrochiasmatic area \\
\hline 137 & Pons motor related & Infralimbic area \\
\hline 138 & Ventromedial hypothalamic nucleus & Anterior amygdalar area \\
\hline 141 & Olfactory tubercle & Primary somatosensory area mouth \\
\hline 142 & Retrosplenial area dorsal part & Secondary motor area \\
\hline 143 & Field CA1 & Subparaventricular zone \\
\hline 144 & Mammillary body & Primary somatosensory area trunk \\
\hline 145 & Globus pallidus internal segment & Reticular nucleus of the thalamus \\
\hline 146 & Arcuate hypothalamic nucleus & Periventricular hypothalamic nucleus preoptic part \\
\hline 151 & Dorsal part of the lateral geniculate complex & Paracentral nucleus \\
\hline 152 & Retrosplenial area ventral part & Cuneiform nucleus \\
\hline 153 & Paraflocculus & Subthalamic nucleus \\
\hline 154 & Bed nuclei of the stria terminalis & Substantia nigra reticular part \\
\hline 155 & Anteroventral nucleus of thalamus & Entorhinal area medial part \\
\hline 156 & Simple lobule & Parasubiculum \\
\hline 157 & Fasciola cinerea & Orbital area medial part \\
\hline 158 & Dorsal peduncular area & Globus pallidus external segment \\
\hline 159 & Triangular nucleus of septum & Olfactory tubercle \\
\hline 160 & Orbital area ventrolateral part & Supraoptic nucleus \\
\hline 161 & Posterior pretectal nucleus & Dorsal part of the lateral geniculate complex \\
\hline 162 & Nucleus of the posterior commissure & Medial preoptic nucleus \\
\hline 163 & Nucleus of Darkschewitsch & Posterior complex of the thalamus \\
\hline 172 & Septofimbrial nucleus & Anterior hypothalamic nucleus \\
\hline 173 & Paracentral nucleus & Medial amygdalar nucleus \\
\hline 174 & Posterior complex of the thalamus & Bed nuclei of the stria terminalis \\
\hline 175 & Ventral medial nucleus of the thalamus & Ventral posterior complex of the thalamus \\
\hline 176 & Central lateral nucleus of the thalamus & Frontal pole cerebral cortex \\
\hline 177 & Lateral dorsal nucleus of thalamus & Lateral posterior nucleus of the thalamus \\
\hline 178 & Parafascicular nucleus & Bed nucleus of the accessory olfactory tract \\
\hline
\end{tabular}

Kolb, 2004; Kalivas, 2007; Everitt et al., 2008; Jedynak et al., 2012; Koob and Volkow, 2016; Bobadilla et al., 2017). The present results confirm that a substantial number of brain regions are affected by psychostimulant exposure and suggest that a common pathway that is associated with withdrawal may not reside at the level of brain regions or even single neural circuits. Instead, these results suggest that the main common phenomenon that is observed among all three of these psychostimulants is decreased modularity of whole-brain functional architecture, suggesting that a common feature may reside at the whole-network level. This interpretation is consistent with the literature on the modularity of complex systems, including the brain and mind, showing that lower modularity reduces the capacity of the system to adapt to its environment (Kashtan and Alon, 2005). It is however worth noting that further studies will be necessary to determine whether lower modularity is simply a feature of increased functional connectivity regardless of whether it is because of withdrawal or other mechanisms. One limitation of the present study is that it did not assess withdrawal behaviors after minipump removal for comparison to network changes. This was done to avoid confounds as to the source of Fos production (e.g., withdrawal or behavioral testing). Another limitation of the present study is the lack of direct comparisons between neural activation 

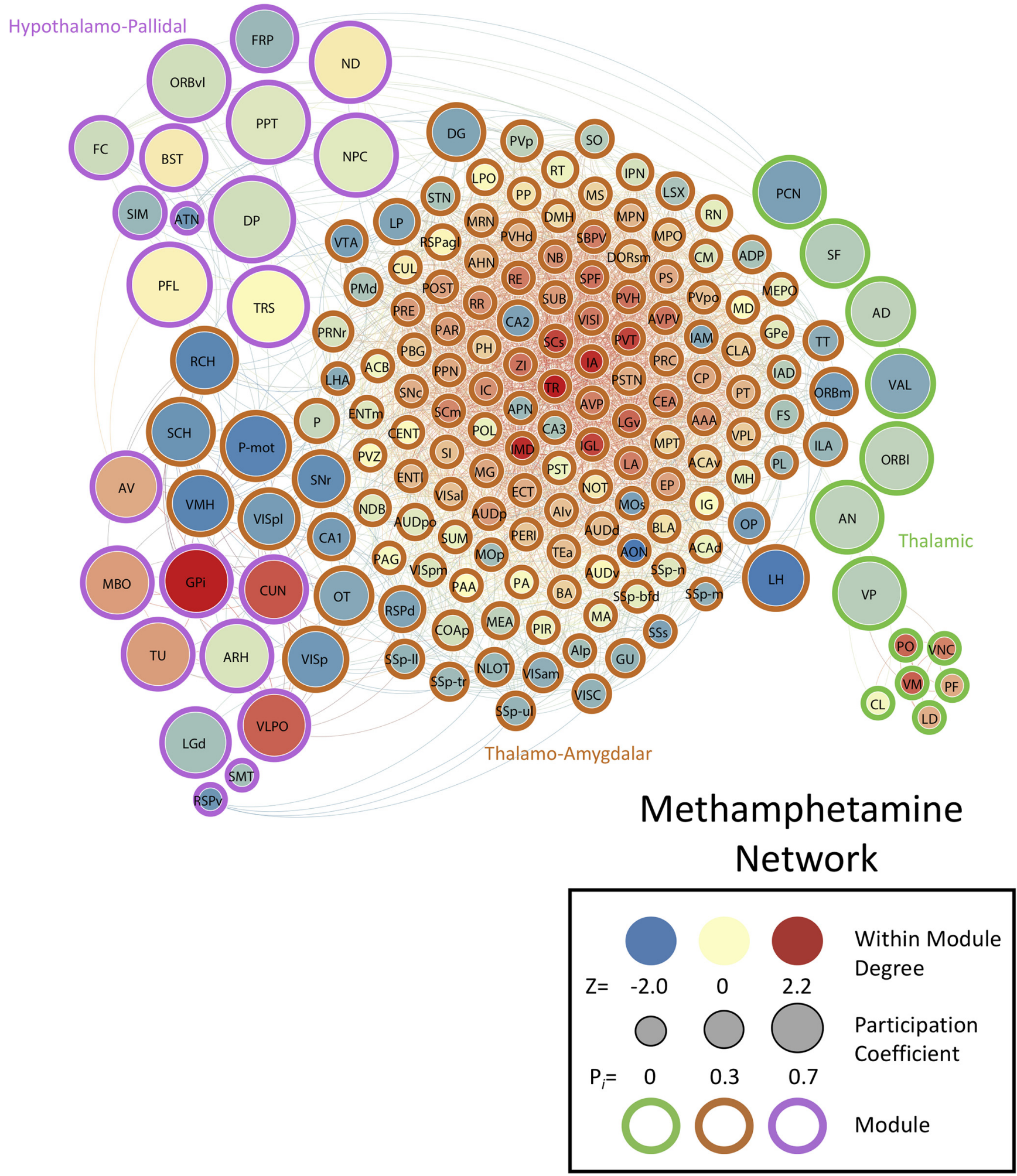

Figure 7. Neural network of methamphetamine mice during withdrawal thresholded to $0.75 \mathrm{R}$. Nodes/brain regions of the network are represented by circles. The size of the node represents the PC (smaller, lower PC; larger, higher PC). The internal color of each circle represents the WMDz (dark blue, lowest; dark red, highest). The color of the modules that are identified in Figure $1 E$ are represented by different colored edges. See figure key for examples of each representative component of the figure. 


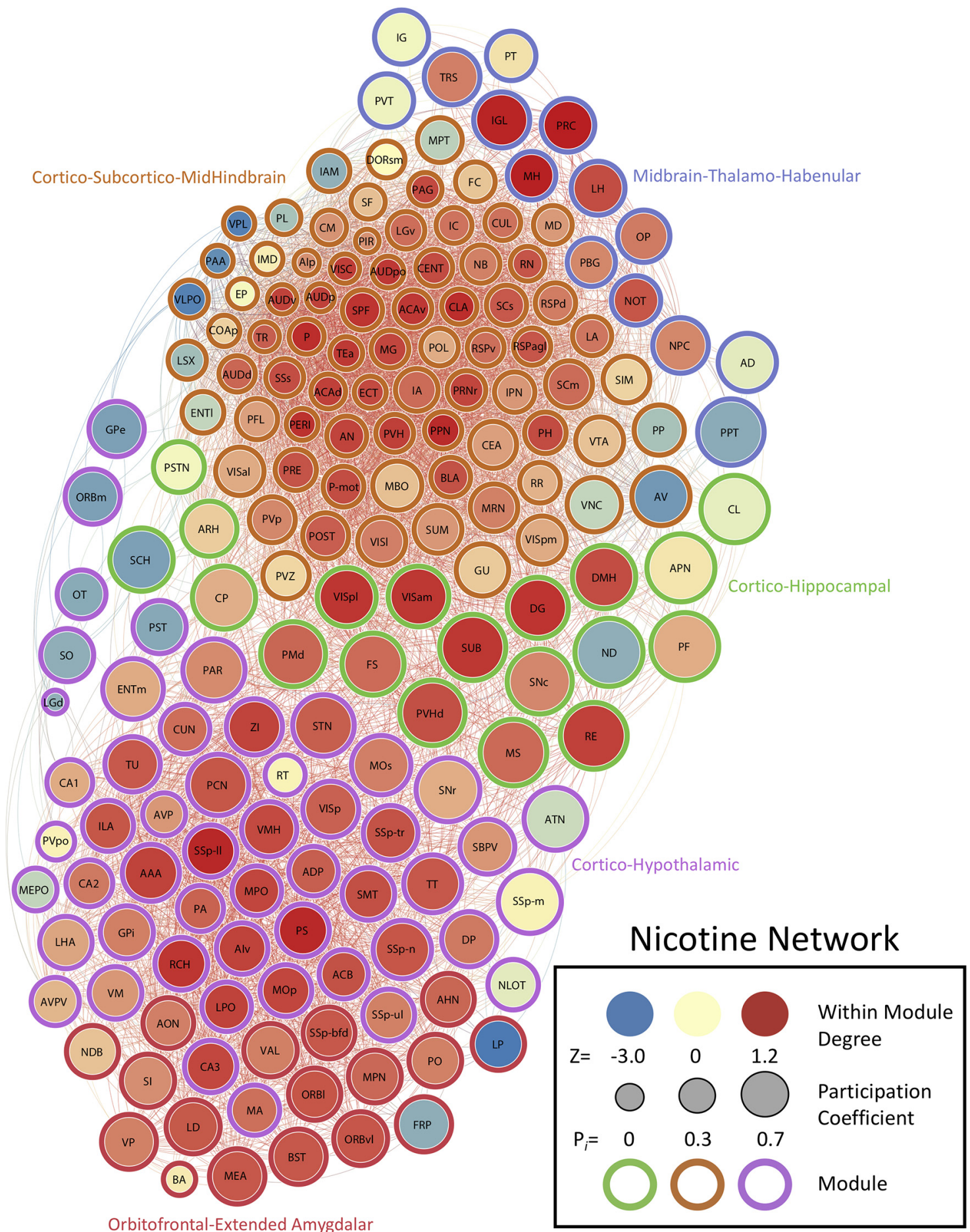

Figure 8. Neural network of nicotine mice during withdrawal thresholded to $0.75 \mathrm{R}$. Nodes/brain regions of the network are represented by circles. The size of the node represents the PC (smaller, lower PC; larger, higher PC). The internal color of each circle represents the WMDz (dark blue, lowest; dark red, highest). The color of the modules that are identified in Figure $1 F$ are represented by different colored edges. See figure key for examples of each representative component of the figure.

of each treatment. The approaches used within this study can be leveraged to study and better understand numerous cognitive states (Smith and Kimbrough, 2020; Simpson et al., 2021). However, in the future assessing neural and network differences in more quantitative ways will be necessary.
In summary, the present study showed that withdrawal from psychostimulants results in changes in neural network structure, including increases in functional connectivity among brain regions and decreases in modularity. Psychostimulant withdrawal resulted in a shift from a sensory/motor-driven network to a network that is highly 
driven by subcortical regions. We also found that different psychostimulants do not produce the same neural networks, although methamphetamine and cocaine shared similar properties. These findings shed light on alterations of brain function that are caused by drug exposure and identify potential brain regions that warrant future study. The present study demonstrates that psychostimulant withdrawal produces drug-dependent remodeling of the functional architecture of the brain and suggests that decreased modularity of the brain functional networks may be a common feature of withdrawal. These findings may prove critical to designing future treatment approaches for withdrawal symptoms.

\section{References}

Ahissar E, Oram T (2015) Thalamic relay or cortico-thalamic processing? Old question, new answers. Cereb Cortex 25:845-848.

Ahmadlou M, Ahmadi K, Rezazade M, Azad-Marzabadi E (2013) Global organization of functional brain connectivity in methamphetamine abusers. Clin Neurophysiol 124:1122-1131.

Allen Institute for Brain Science (2004) Allen mouse brain atlas. Allen Institute for Brain Science. Available at http://mouse.brain-map. org/.

Arnemann KL, Chen AJ, Novakovic-Agopian T, Gratton C, Nomura EM, D'Esposito M (2015) Functional brain network modularity predicts response to cognitive training after brain injury. Neurology 84:1568-1574.

Ashare RL, Falcone M, Lerman C (2014) Cognitive function during nicotine withdrawal: implications for nicotine dependence treatment. Neuropharmacology 76 [Pt B]:581-591.

Babu M, Vlasblom J, Pu S, Guo X, Graham C, Bean BDM, Burston HE, Vizeacoumar FJ, Snider J, Phanse S, Fong V, Tam YYC, Davey M, Hnatshak O, Bajaj N, Chandran S, Punna T, Christopolous C, Wong V, Yu A, et al. (2012) Interaction landscape of membrane-protein complexes in Saccharomyces cerevisiae. Nature 489:585-589.

Balfour DJK (2008) The psychobiology of nicotine dependence. Eur Respir Rev 17:172-181.

Barabasi AL (2009) Scale-free networks: a decade and beyond. Science 325:412-413.

Bargmann $\mathrm{Cl}$, Marder E (2013) From the connectome to brain function. Nat Methods 10:483-490.

Bastian M, Heymann S, Jacomy M (2009) Gephi: an open source software for exploring and manipulating networks. International AAAI Conference on Weblogs and Social Media.

Benuck M, Lajtha A, Reith ME (1987) Pharmacokinetics of systemically administered cocaine and locomotor stimulation in mice. $J$ Pharmacol Exp Ther 243:144-149.

Bertolero MA, Yeo BTT, Bassett DS, D’Esposito M (2018) A mechanistic model of connector hubs, modularity and cognition. Nat Hum Behav 2:765-777.

Bobadilla AC, Heinsbroek JA, Gipson CD, Griffin WC, Fowler CD, Kenny PJ, Kalivas PW (2017) Corticostriatal plasticity, neuronal ensembles, and regulation of drug-seeking behavior. Prog Brain Res 235:93-112.

Brier MR, Thomas JB, Fagan AM, Hassenstab J, Holtzman DM, Benzinger TL, Morris JC, Ances BM (2014) Functional connectivity and graph theory in preclinical Alzheimer's disease. Neurobiol Aging 35:757-768.

Chen G, Chen G, Xie C, Li SJ (2011) Negative functional connectivity and its dependence on the shortest path length of positive network in the resting-state human brain. Brain Connect 1:195-206.

Chiang AS, Lin CY, Chuang CC, Chang HM, Hsieh CH, Yeh CW, Shih CT, Wu JJ, Wang GT, Chen YC, Wu CC, Chen GY, Ching YT, Lee PC, Lin CY, Lin HH, Wu CC, Hsu HW, Huang YA, Chen JY, et al. (2011) Three-dimensional reconstruction of brain-wide wiring networks in Drosophila at single-cell resolution. Curr Biol 21:1-11.

Cho AK, Melega WP, Kuczenski R, Segal DS (2001) Relevance of pharmacokinetic parameters in animal models of methamphetamine abuse. Synapse 39:161-166.

Claus ED, Weywadt CR (2020) Resting-state connectivity in former, current and never smokers. Nicotine Tob Res 22:180-187.

Cohen JR, D'Esposito M (2016) The segregation and integration of distinct brain networks and their relationship to cognition. J Neurosci 36:12083-12094.

de Haan W, Van Der Flier WM, Koene T, Smits LL, Scheltens P, Stam CJ (2012) Disrupted modular brain dynamics reflect cognitive dysfunction in Alzheimer's disease. Neuroimage 59:3085-3093.

D'Souza MS, Markou A (2011) Neuronal mechanisms underlying development of nicotine dependence: implications for novel smoking-cessation treatments. Addict Sci Clin Pract 6:4-16.

Eisener-Dorman AF, Grabowski-Boase L, Tarantino LM (2011) Cocaine locomotor activation, sensitization and place preference in six inbred strains of mice. Behav Brain Funct 7:29.

Everitt BJ, Belin D, Economidou D, Pelloux Y, Dalley JW, Robbins TW (2008) Review. Neural mechanisms underlying the vulnerability to develop compulsive drug-seeking habits and addiction. Philos Trans R Soc Lond B Biol Sci 363:3125-3135.

Fish EW, Riday TT, Mcguigan MM, Faccidomo S, Hodge CW, Malanga CJ (2010) Alcohol, cocaine, and brain stimulation-reward in C57BI6/J and DBA2/J mice. Alcohol Clin Exp Res 34:81-89.

Gallen CL, Baniqued PL, Chapman SB, Aslan S, Keebler M, Didehbani N, D'Esposito M (2016) Modular brain network organization predicts response to cognitive training in older adults. PLoS One 11:e0169015.

Gilbert CD, Sigman M (2007) Brain states: top-down influences in sensory processing. Neuron 54:677-696.

Giove F, Gili T, lacovella V, Macaluso E, Maraviglia B (2009) Imagesbased suppression of unwanted global signals in resting-state functional connectivity studies. Magn Reson Imaging 27:10581064.

Grant KM, Levan TD, Wells SM, Li M, Stoltenberg SF, Gendelman HE, Carlo G, Bevins RA (2012) Methamphetamine-associated psychosis. J Neuroimmune Pharmacol 7:113-139.

Guimera R, Nunes Amaral LA (2005) Functional cartography of complex metabolic networks. Nature 433:895-900.

Jacomy M, Venturini T, Heymann S, Bastian M (2014) ForceAtlas2, a continuous graph layout algorithm for handy network visualization designed for the Gephi software. PLoS One 9:e98679.

Jarrell TA, Wang Y, Bloniarz AE, Brittin CA, Xu M, Thomson JN, Albertson DG, Hall DH, Emmons SW (2012) The connectome of a decision-making neural network. Science 337:437-444.

Jedynak JP, Cameron CM, Robinson TE (2012) Repeated methamphetamine administration differentially alters fos expression in caudate-putamen patch and matrix compartments and nucleus accumbens. PLoS One 7:e34227.

Jeong H, Mason SP, Barabasi AL, Oltvai ZN (2001) Lethality and centrality in protein networks. Nature 411:41-42.

Johnson PM, Hollander JA, Kenny PJ (2008) Decreased brain reward function during nicotine withdrawal in C57BL6 mice: evidence from intracranial self-stimulation (ICSS) studies. Pharmacol Biochem Behav 90:409-415.

Kalivas PW (2007) Cocaine and amphetamine-like psychostimulants: neurocircuitry and glutamate neuroplasticity. Dialogues Clin Neurosci 9:389-397.

Kalivas PW, Mcfarland K (2003) Brain circuitry and the reinstatement of cocaine-seeking behavior. Psychopharmacology (Berl) 168:4456 .

Kashtan N, Alon U (2005) Spontaneous evolution of modularity and network motifs. Proc Natl Acad Sci USA 102:13773-13778.

Kimbrough A, Lurie DJ, Collazo A, Kreifeldt M, Sidhu H, Macedo GC, D'Esposito M, Contet C, George O (2020) Brain-wide functional architecture remodeling by alcohol dependence and abstinence. Proc Natl Acad Sci USA 117:2149-2159. 
Kirst C, Skriabine S, Vieites-Prado A, Topilko T, Bertin P, Gerschenfeld G, Verny F, Topilko P, Michalski N, Tessier-Lavigne M, Renier N (2020) Mapping the fine-scale organization and plasticity of the brain vasculature. Cell 180:780-795.e25.

Konova AB, Moeller SJ, Tomasi D, Volkow ND, Goldstein RZ (2013) Effects of methylphenidate on resting-state functional connectivity of the mesocorticolimbic dopamine pathways in cocaine addiction. JAMA Psychiatry 70:857-868.

Konova AB, Moeller SJ, Tomasi D, Goldstein RZ (2015) Effects of chronic and acute stimulants on brain functional connectivity hubs. Brain Res 1628:147-156.

Koob GF (2015) The dark side of emotion: the addiction perspective. Eur J Pharmacol 753:73-87.

Koob GF, Volkow ND (2016) Neurobiology of addiction: a neurocircuitry analysis. Lancet Psychiatry 3:760-773.

Liang X, He Y, Salmeron BJ, Gu H, Stein EA, Yang Y (2015) Interactions between the salience and default-mode networks are disrupted in cocaine addiction. J Neurosci 35:8081-8090.

Liebmann T, Renier N, Bettayeb K, Greengard P, Tessier-Lavigne M, Flajolet M (2016) Three-dimensional study of Alzheimer's disease hallmarks using the iDISCO clearing method. Cell Rep 16:11381152.

Ma L, Steinberg JL, Moeller FG, Johns SE, Narayana PA (2015) Effect of cocaine dependence on brain connections: clinical implications. Expert Rev Neurother 15:1307-1319.

Markov NT, Ercsey-Ravasz MM, Ribeiro Gomes AR, Lamy C, Magrou L, Vezoli J, Misery P, Falchier A, Quilodran R, Gariel MA, Sallet J, Gamanut R, Huissoud C, Clavagnier S, Giroud P, SappeyMarinier D, Barone P, Dehay C, Toroczkai Z, Knoblauch K, et al. (2014) A weighted and directed interareal connectivity matrix for macaque cerebral cortex. Cereb Cortex 24:17-36. [Database]

Mchugh MJ, Gu H, Yang Y, Adinoff B, Stein EA (2017) Executive control network connectivity strength protects against relapse to cocaine use. Addict Biol 22:1790-1801.

Meunier D, Achard S, Morcom A, Bullmore E (2009) Age-related changes in modular organization of human brain functional networks. Neuroimage 44:715-723.

Murnane KS, Gopinath KS, Maltbie E, Daunais JB, Telesford QK, Howell LL (2015) Functional connectivity in frontal-striatal brain networks and cocaine self-administration in female rhesus monkeys. Psychopharmacology (Berl) 232:745-754.

Murphy K, Birn RM, Handwerker DA, Jones TB, Bandettini PA (2009) The impact of global signal regression on resting state correlations: are anti-correlated networks introduced? Neuroimage 44:893-905.

Naqvi NH, Rudrauf D, Damasio H, Bechara A (2007) Damage to the insula disrupts addiction to cigarette smoking. Science 315:531534.

Nestler EJ (2005) The neurobiology of cocaine addiction. Sci Pract Perspect 3:4-10

Norman AB, Tabet MR, Norman MK, Buesing WR, Pesce AJ, Ball WJ (2007) A chimeric human/murine anticocaine monoclonal antibody inhibits the distribution of cocaine to the brain in mice. $J$ Pharmacol Exp Ther 320:145-153.

Oh SW, Harris JA, Ng L, Winslow B, Cain N, Mihalas S, Wang Q, Lau C, Kuan L, Henry AM, Mortrud MT, Ouellette B, Nguyen Tn, Sorensen SA, Slaughterbeck CR, Wakeman W, Li Y, Feng D, Ho A, Nicholas E, et al. (2014) A mesoscale connectome of the mouse brain. Nature 508:207-214.

Orsini CA, Colon-Perez LM, Heshmati SC, Setlow B, Febo M (2018) Functional connectivity of chronic cocaine use reveals progressive neuroadaptations in neocortical, striatal, and limbic networks. eNeuro 5:ENEURO.0081-18.2018.

Phillips KA, Epstein DH, Preston KL (2014) Psychostimulant addiction treatment. Neuropharmacology 87:150-160.

Power JD, Schlaggar BL, Lessov-Schlaggar CN, Petersen SE (2013) Evidence for hubs in human functional brain networks. Neuron 79:798-813
Qian K, Liu J, Cao Y, Yang J, Qu S (2021) Intraperitoneal injection of lithium chloride induces lateralized activation of the insular cortex in adult mice. Mol Brain 14:71.

Renier N, Wu Z, Simon Dj, Yang J, Ariel P, Tessier-Lavigne M (2014) iDISCO: a simple, rapid method to immunolabel large tissue samples for volume imaging. Cell 159:896-910.

Renier N, Adams EL, Kirst C, Wu Z, Azevedo R, Kohl J, Autry AE, Kadiri L, Umadevi Venkataraju K, Zhou Y, Wang VX, Tang CY, Olsen O, Dulac C, Osten P, Tessier-Lavigne M (2016) Mapping of brain activity by automated volume analysis of immediate early genes. Cell 165:1789-1802.

Robinson Te, Kolb B (2004) Structural plasticity associated with exposure to drugs of abuse. Neuropharmacology 47 [Suppl 1]:3346.

Rothman Rb, Baumann MH (2003) Monoamine transporters and psychostimulant drugs. Eur J Pharmacol 479:23-40.

Rubinov M, Sporns O (2010) Complex network measures of brain connectivity: uses and interpretations. Neuroimage 52:1059-1069.

Sabrini S, Wang GY, Lin JC, lan JK, Curley LE (2019) Methamphetamine use and cognitive function: a systematic review of neuroimaging research. Drug Alcohol Depend 194:75-87.

Salzwedel AP, Grewen KM, Goldman BD, Gao W (2016) Thalamocortical functional connectivity and behavioral disruptions in neonates with prenatal cocaine exposure. Neurotoxicol Teratol 56:16-25.

Shabani S, Mckinnon CS, Cunningham CL, Phillips TJ (2012) Profound reduction in sensitivity to the aversive effects of methamphetamine in mice bred for high methamphetamine intake. Neuropharmacology 62:1134-1141.

Sherman SM (2007) The thalamus is more than just a relay. Curr Opin Neurobiol 17:417-422.

Simpson S, Chen Y, Wellmeyer E, Smith LC, Montes BA, George O, Kimbrough A (2021) The hidden brain: uncovering previously overlooked brain regions by employing novel preclinical unbiased network approaches. Front Syst Neuroscil 15:595507.

Siu EC, Tyndale RF (2007) Characterization and comparison of nicotine and cotinine metabolism in vitro and in vivo in $\mathrm{DBA} / 2$ and C57BL/6 mice. Mol Pharmacol 71:826-834.

Smith LC, Kimbrough A (2020) Leveraging neural networks in preclinical alcohol research. Brain Sci 10:578.

Sporns O, Betzel RF (2016) Modular brain networks. Annu Rev Psychol 67:613-640.

Sporns O, Honey CJ, Kotter R (2007) Identification and classification of hubs in brain networks. PLoS One 2:e1049.

Spronk DB, Van Wel JH, Ramaekers JQ, Verkes RJ (2013) Characterizing the cognitive effects of cocaine: a comprehensive review. Neurosci Biobehav Rev 37:1838-1859.

Stoker AK, Markou A (2011) Withdrawal from chronic cocaine administration induces deficits in brain reward function in C57BL/6J mice. Behav Brain Res 223:176-181.

Stoker AK, Olivier B, Markou A (2012) Involvement of metabotropic glutamate receptor 5 in brain reward deficits associated with cocaine and nicotine withdrawal and somatic signs of nicotine withdrawal. Psychopharmacology (Berl) 221:317-327.

Sulzer D, Sonders MS, Poulsen NW, Galli A (2005) Mechanisms of neurotransmitter release by amphetamines: a review. Prog Neurobiol 75:406-433.

Sutherland MT, Carroll AJ, Salmeron BJ, Ross TJ, Hong LE, Stein EA (2013) Down-regulation of amygdala and insula functional circuits by varenicline and nicotine in abstinent cigarette smokers. Biol Psychiatry 74:538-546.

Tomasi D, Goldstein RZ, Telang F, Maloney T, Alia-Klein N, Caparelli EC, Volkow ND (2007) Thalamo-cortical dysfunction in cocaine abusers: implications in attention and perception. Psychiatry Res 155:189-201.

Tomasi D, Volkow ND, Wang R, Carrillo JH, Maloney T, Alia-Klein N, Woicik PA, Telang F, Goldstein RZ (2010) Disrupted functional connectivity with dopaminergic midbrain in cocaine abusers. PLoS One 5:e10815.

Tracy ME, Banks ML, Shelton KL (2016) Negative allosteric modulation of GABAA receptors inhibits facilitation of brain stimulation 
reward by drugs of abuse in C57BL6/J mice. Psychopharmacology (Berl) 233:715-725.

Varshney LR, Chen BL, Paniagua E, Hall DH, Chklovskii DB (2011) Structural properties of the Caenorhabditis elegans neuronal network. PLoS Comput Biol 7:e1001066.

Vetere G, Kenney JW, Tran LM, Xia F, Steadman PE, Parkinson J, Josselyn SA, Frankland PW (2017) Chemogenetic Interrogation of a brain-wide fear memory network in mice. Neuron 94:363-374.e4.

Wang Z, Suh J, Li Z, Li Y, Franklin T, O’Brien C, Childress AR (2015) A hyper-connected but less efficient small-world network in the substance-dependent brain. Drug Alcohol Depend 152:102-108.
Wheeler AL, Teixeira CM, Wang AH, Xiong X, Kovacevic N, Lerch JP, Mcintosh AR, Parkinson J, Frankland PW (2013) Identification of a functional connectome for long-term fear memory in mice. PLoS Comput Biol 9:e1002853.

Zhang S, Hu S, Sinha R, Potenza MN, Malison RT, Li CS (2016) Cocaine dependence and thalamic functional connectivity: a multivariate pattern analysis. Neuroimage Clin 12:348-358.

Zhu J, Zhao N, Chen Y, Zhu L, Zhong Q, Liu J, Chen T (2017) Sodium butyrate modulates a methamphetamine-induced conditioned place preference. J Neurosci Res 95:1044-1052. 